\title{
Erosion and Sediment Controls on Reclaimed Mine Refuse Impoundments
}

\author{
Sara Dalen \\ sddalen@mix.wvu.edu
}

Follow this and additional works at: https://researchrepository.wvu.edu/etd

Part of the Environmental Engineering Commons, and the Geotechnical Engineering Commons

\section{Recommended Citation}

Dalen, Sara, "Erosion and Sediment Controls on Reclaimed Mine Refuse Impoundments" (2021). Graduate Theses, Dissertations, and Problem Reports. 8066.

https://researchrepository.wvu.edu/etd/8066

This Thesis is protected by copyright and/or related rights. It has been brought to you by the The Research Repository @ WVU with permission from the rights-holder(s). You are free to use this Thesis in any way that is permitted by the copyright and related rights legislation that applies to your use. For other uses you must obtain permission from the rights-holder(s) directly, unless additional rights are indicated by a Creative Commons license in the record and/ or on the work itself. This Thesis has been accepted for inclusion in WVU Graduate Theses, Dissertations, and Problem Reports collection by an authorized administrator of The Research Repository @ WVU. For more information, please contact researchrepository@mail.wvu.edu. 


\title{
Erosion and Sediment Controls on Reclaimed Mine Refuse Impoundments
}

\author{
Sara Dalen
}

Thesis submitted to the

Benjamin M. Statler College of Engineering and Mineral Resources

at West Virginia University

in partial fulfillment of the requirements of the degree of

Master of Science in

Civil and Environmental Engineering

Leslie Hopkinson, Ph.D., Chair

Seung Ho Hong, Ph.D.

John Quaranta, Ph.D.

Wadsworth Department of Civil and Environmental Engineering

Morgantown, West Virginia

2021

Keywords: Acid Mine Drainage (AMD), geotextiles, coal refuse impoundment, runoff and sediment loss, Water Erosion Prediction Project (WEPP)

Copyright 2021 Sara Dalen 


\begin{abstract}
Erosion and Sediment Controls on Reclaimed Mine Refuse Impoundments
\end{abstract}

Sara Dalen

To ensure the sustainable use of one of West Virginia's precious resources, conscientious long-term management of residual waste is of immense importance. This thesis examined two main topics: i) the dewatering process of acid mine drainage (AMD) sludge, and ii) an investigation of soil loss predictions of a reclaimed coal refuse impoundment.

The first aspect of this thesis addresses clarification and remediation of AMD prior to disposal is a prominent component to preventing runoff and seepage of environmentally detrimental byproducts. To examine the effects of flocculation and dewatering more closely by means of geotextiles, an AMD sludge was analyzed. The raw AMD was sourced from the underground mine, treated by precipitation at an approximate $\mathrm{pH}$ of 3.2, and clarified to a $\mathrm{pH}$ of 6.7 using calcium hydroxide (lime). The supernatant is settled through a series of ponds. Then the sludge produced during the clarification process was dredged, flocculated with polymers concentrated at $20 \mathrm{ppm}$ to create filterable flock, and dewatered through a series of geotextile tubes. Following the dewatering process, geotechnical property testing was performed in accordance with ASTM International Standards to determine the predominately lean, elastic silt soil characteristics of the sludge.

The second component utilizes the USDA's Water Erosion Prediction Project (WEPP), a process-based computer modeling program created to anticipate soil displacement, loss, and deposition during singular or continuous storm events, was utilized to evaluate the runoff and sediment loss of a reclaimed coal refuse impoundment. To identify the unique characteristics of the impoundment, field measurements of infiltration, ground cover, and soil samples were completed and analyzed. Using TR-55 single storm predictions, the annual soil loss was predicted to be 0.397 tons for a two-year return period, 0.661 tons for a five-year return period, 0.879 tons for a 10-year return period, 1.245 tons during a 25 -year return period, 1.588 tons from a 50-year event, 1.922 tons during a 100-year event, and finally a total of 2.525 tons of soil lost during a 500-year return event from the impoundment. Due to the minimal slope (i.e., 2.4\%) it can be predicted that the impoundment will not experience substantial amounts of soil loss for the foreseeable future as long as vegetation is maintained. 


\section{Acknowledgements}

The project described in this publication was supported by Grant/Cooperative Agreement Number G16AP00091 from the United States Geological Survey. Its contents are solely the responsibility of the authors and do not necessarily represent the official views of the USGS. The authors would like to thank the West Virginia Department of Environmental Protection Office of Special Reclamation.

I would firstly like to extend my sincerest thanks to Dr. Leslie Hopkinson, my academic advisor and committee chairperson, for her guidance, help, and council. Without her motivation and knowledge, this project would not have been possible to complete.

Additionally, I would like to thank my committee members, Dr. Seung Ho Hong and Dr. John Quaranta. A special thanks to Dr. John Quaranta for convincing me this was a good idea and his continuous support. Also, a huge thank you to Iuri Santos for his help and knowledge in the geotechnical laboratory.

In addition to my academic mentors, I thank my family. Their endless support, love, and encouragement enable me to achieve my goals and more.

I owe my deepest gratitude to my partner, Jacob Nead. His constant encouragement and unwavering love bless me infinitely. I cannot thank him enough.

Lastly, I would like to thank the Lord for enabling me with the ability and perseverance to run this educational race. 


\section{Table of Contents}

Acknowledgements .....................................................................................................

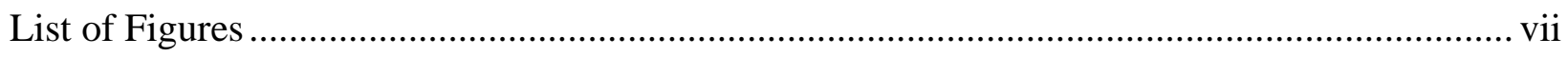

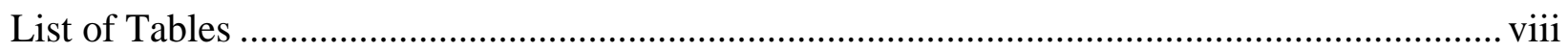

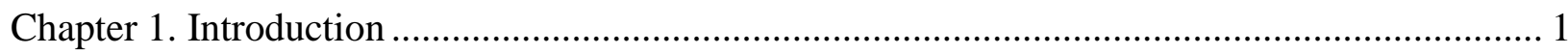

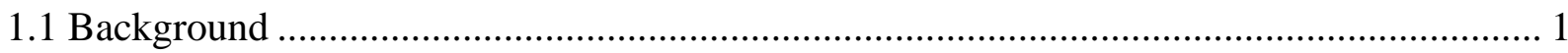

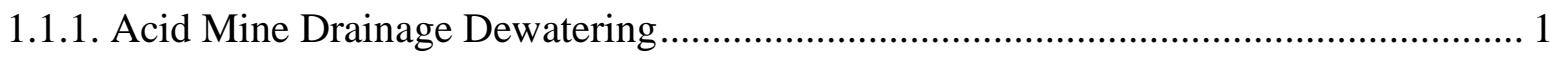

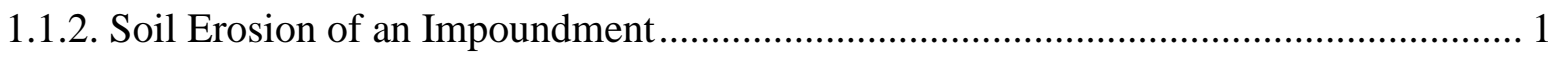

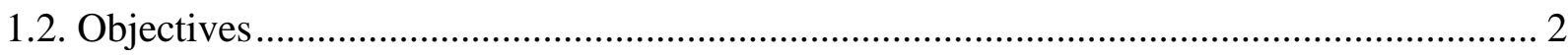

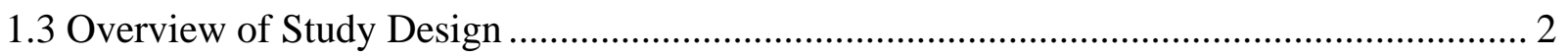

1.3.1. Acid Mine Drainage Dewatering Study Design ...................................................... 2

1.3.2. Soil Erosion of Impoundment Study Design ........................................................... 2

Chapter 2. Literature Review Study: Acid Mine Drainage and Dewatering ................................. 3

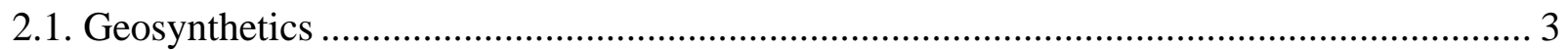

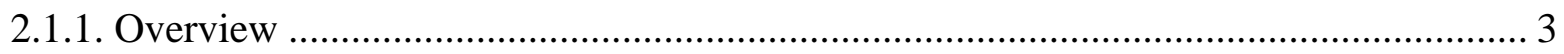

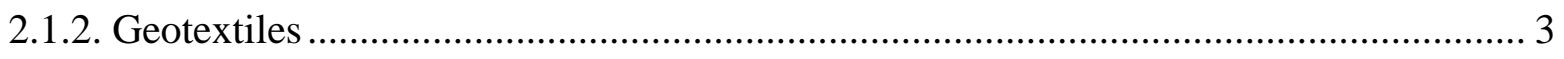

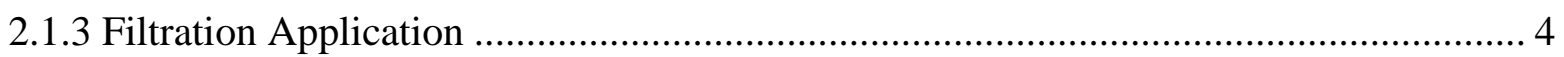

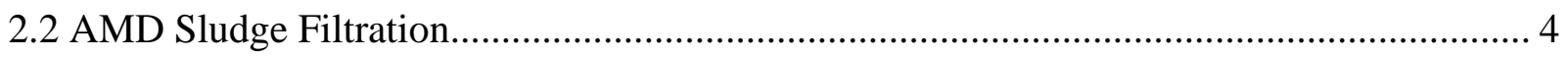

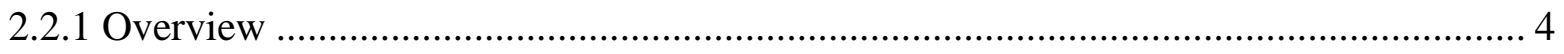

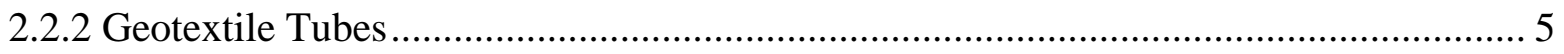

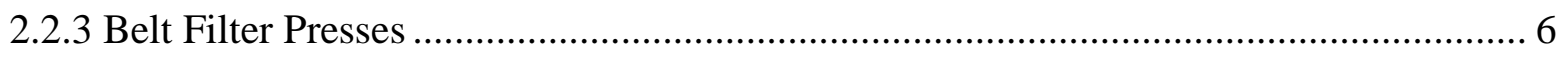

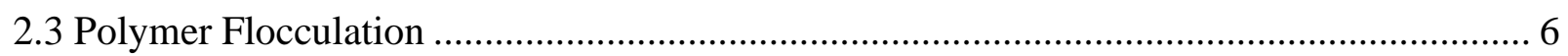

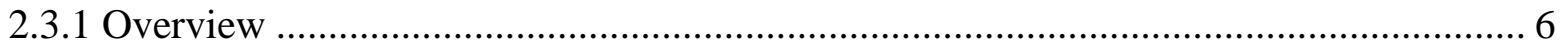

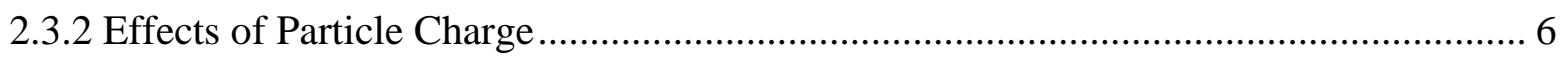

2.3.3 Effects of Molecular Weight ................................................................................ 7

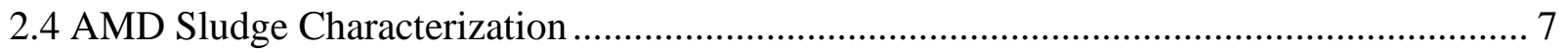

2.4.1 Geotechnical Index Properties of Different Sludges .................................................... 7

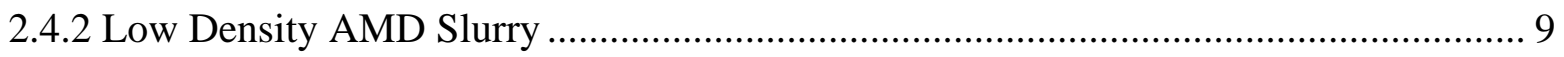

2.4.3 AMD Sludge

2.4.4 Hard Rock Tailings.......................................................................................... 10

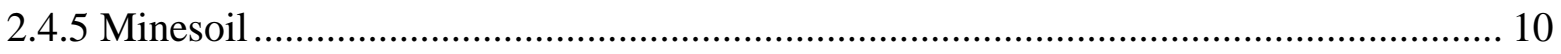

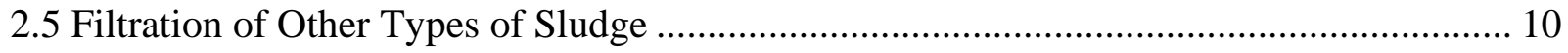

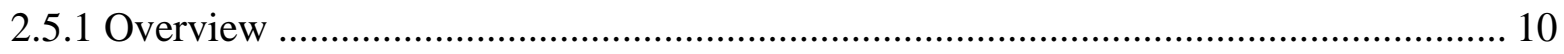

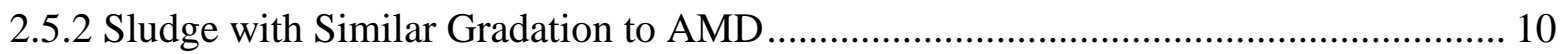


2.6 Particle Size Analysis Procedures for Highly Saturated Sludges ....................................... 12

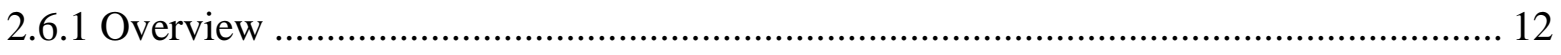

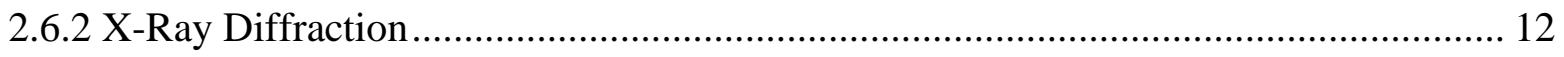

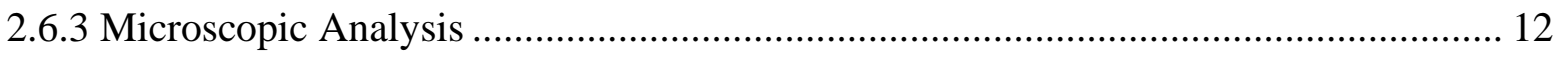

2.7 Omega Sludge Characteristics ............................................................................. 13

2.7.1 Introduction of Omega AMD Sludge ……......................................................... 13

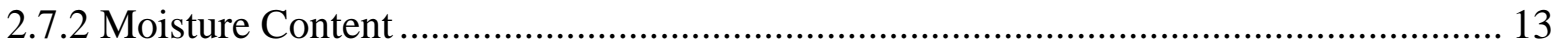

2.7.3 Particle-Size Analysis ......................................................................................... 14

2.7.4 Specific Gravity of Soil Solids by Water Pycnometer .................................................. 16

2.7.5 Atterberg Limits .................................................................................................... 17

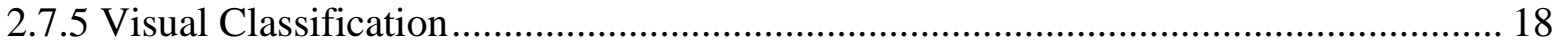

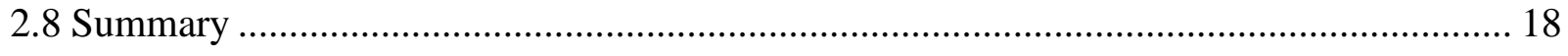

Chapter 3: Sediment Management for Sludge Impoundments ……………................................. 19

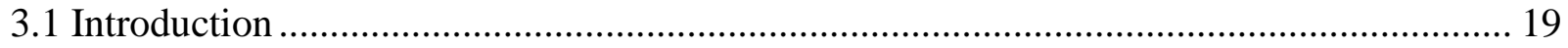

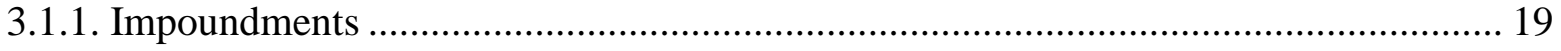

3.1.2. Water Erosion Prediction Project (WEPP) ……..................................................... 20

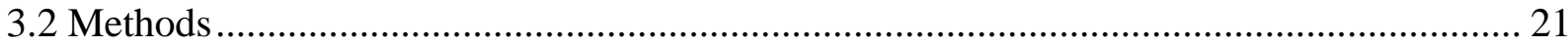

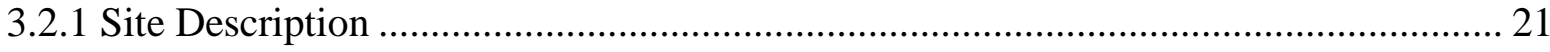

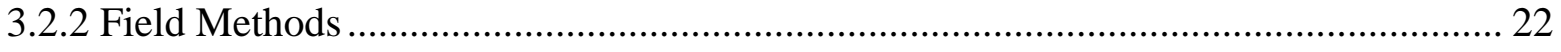

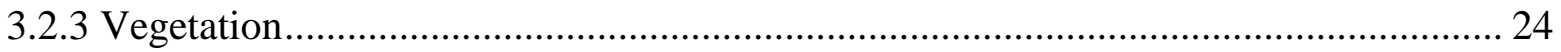

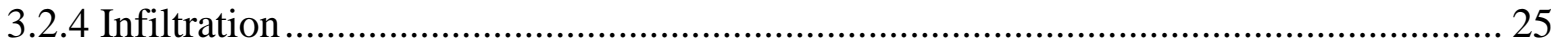

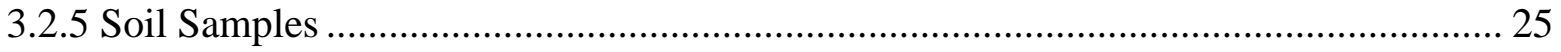

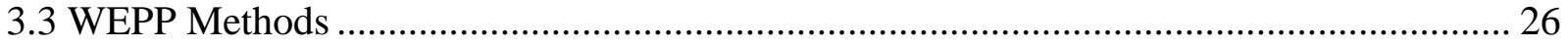

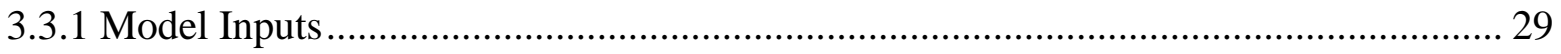

3.3.2 Model Scenarios ………………………………................................................. 31

Chapter 4. Results and Discussion ....................................................................................... 33

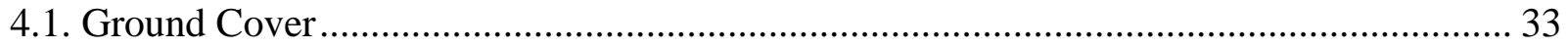

4.2. Soil Characteristics........................................................................................... 34

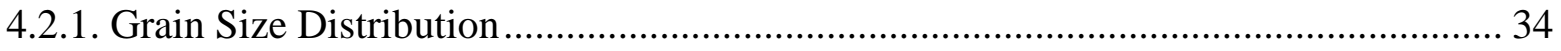

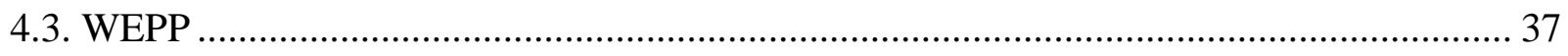

4.3.1. Modeling Layout ………………....................................................................... 37

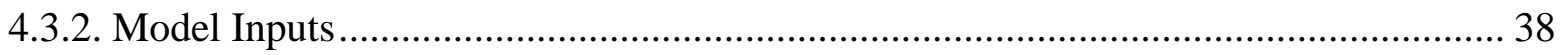

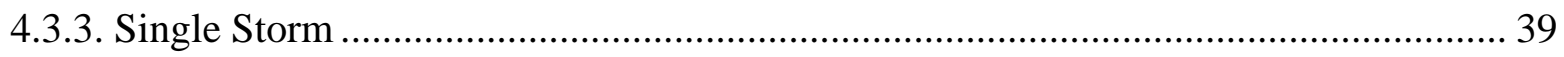

4.3.4. Long-term Modeling............................................................................................. 39 


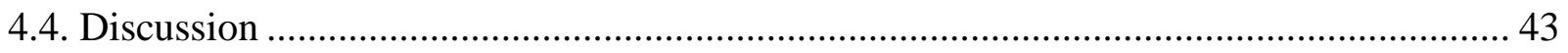

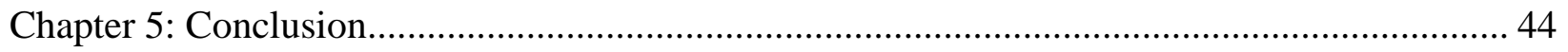

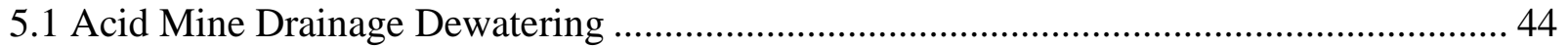

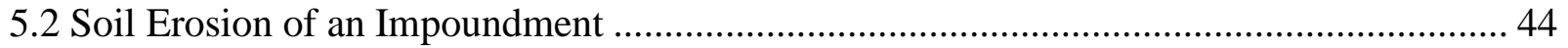

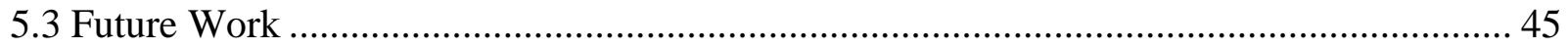

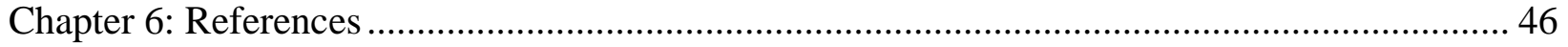

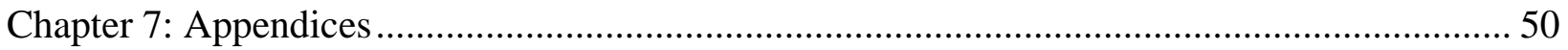

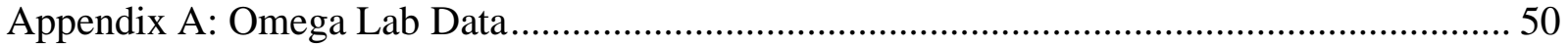

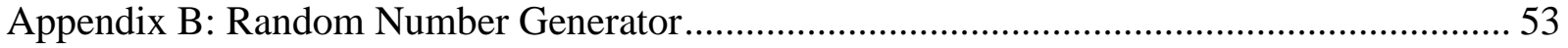

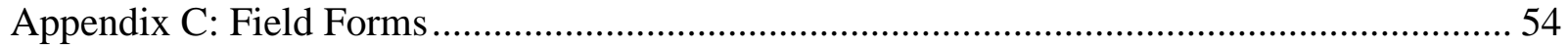

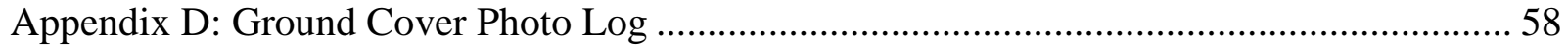




\section{List of Figures}

Figure 1. Filled geotextile tube secreting water. Source: L.C. Hopkinson. ........................................... 5

Figure 2. Grain size distribution curves from dry sieve................................................................. 15

Figure 3. Grain size distribution determined by wet sieve analysis..................................................... 16

Figure 4. Century coal refuse impoundment prior to reclamation. Earth dam located at the top of the photo with ponded water collected at the bottom of the photo (north end) . ....................................... 19

Figure 5. Location of the Refuse Impoundment within West Virginia..................................................22

Figure 6. Sampling locations from November 2020, distance measured in meters

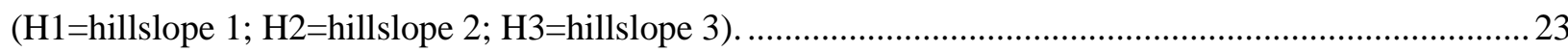

Figure 7. Portable Point Frame used for Ground Cover calculations. ...................................................2 24

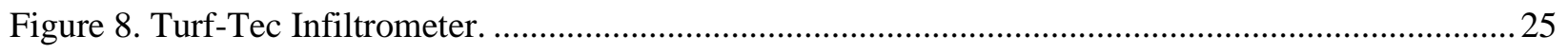

Figure 9. Division of the impoundment into three hillslopes............................................................ 27

Figure 10. Rectangular areas of the individual hillslopes for WEPP modeling.....................................28

Figure 11. Collective grass, straw, and bare ground percentages from each sample point of the three

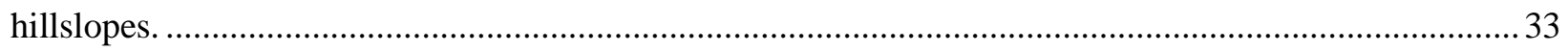

Figure 12. Averaged percentages of grass, straw, and bare coverages for the three hillslopes. ................. 34

Figure 13. Grain size distributions of the three hillslopes with respective coefficients of uniformity $(\mathrm{Cu})$,

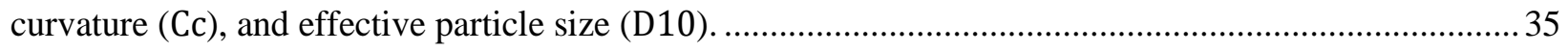

Figure 14. Double hydrometer test of the impoundment soils to discern dispersive qualities....................36

Figure 15. Example of the WEPP modeling window of Hillslope 2 (Model not to scale)........................ 37

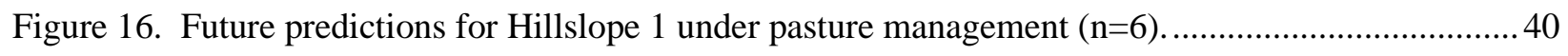

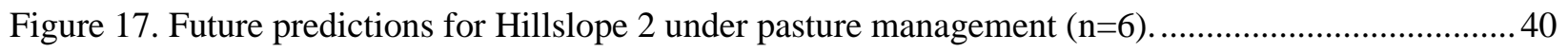

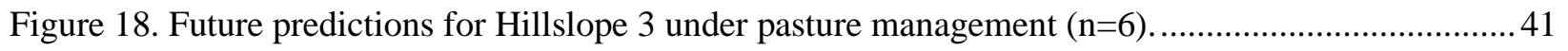

Figure 19. Forested impoundment future predictions of Hillslope 1.................................................. 41

Figure 20. Forested impoundment future predictions of Hillslope 2 ....................................................42

Figure 21. Forested impoundment future predictions of Hillslope 3 .................................................... 42

Figure 22. Field work form - hillslope location ..........................................................................5

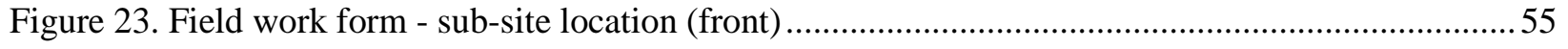

Figure 24. Field work form - sub-site location (back) ….................................................................56

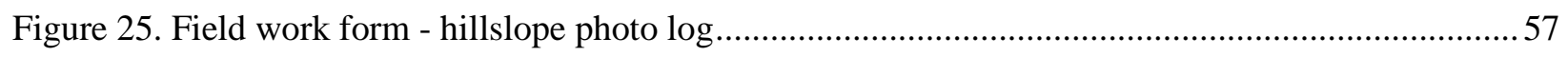

Figure 26. Hillslope 1 Portable Point Frames at the five sampling locations (a, b, c, d, and e)...............58

Figure 27. Hillslope 2 Portable Point Frames at the five sampling locations (a, b, c, d, and e)...............59

Figure 28. Hillslope 2 Portable Point Frames at the five sampling locations (f, g, h, i, and j).................59

Figure 29. Hillslope 3 Portable Point Frames at the five sampling locations (a, b, c, d, and e)...............59

Figure 30. Hillslope 3 Portable Point Frames at the five sampling locations (f, g, h, i, and j).................59 


\section{List of Tables}

Table 1. Geotechnical properties of a variety of mining generated waste materials. ................................. 8

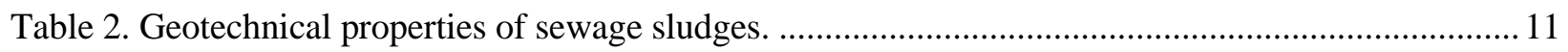

Table 3. Geotechnical property tests undertaken on the AMD sludge.................................................. 13

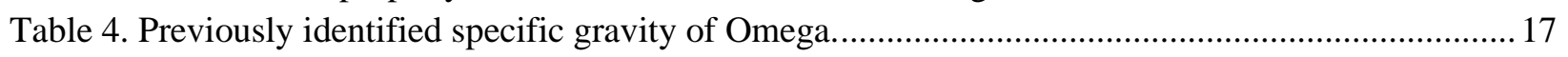

Table 5. Recorded data and calculated specific gravity of Omega. ...................................................... 17

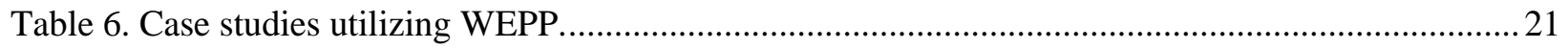

Table 7. WEPP inputs for the three separate hillslopes of the impoundment.........................................29

Table 8. Soil characteristic inputs for WEPP hillslope modeling. .......................................................... 31

Table 9. Specific inputs of the impoundment used in the WEPP modeling. ........................................... 38

Table 10. TR-55 Single storm predictions for the individual hillslopes. .............................................. 39

Table 11. Total runoff volume the impoundment (inches). ................................................................... 43

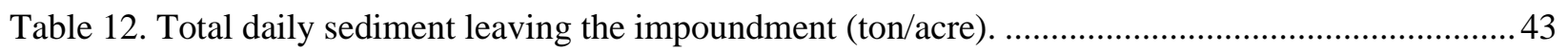

Table 13. Initial sieve analysis results for material passing No. $20(0.85 \mathrm{~mm})$ Sieve. ...........................50

Table 14. Secondary sieve analysis of sludge passing No. $20(0.85 \mathrm{~mm})$ Sieve ...................................50

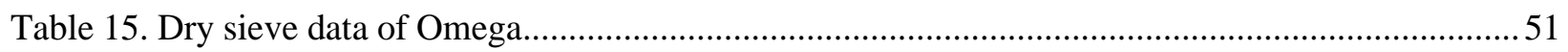

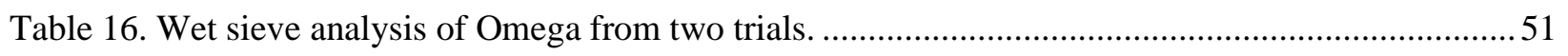

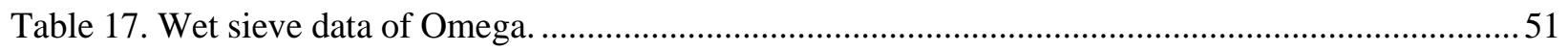

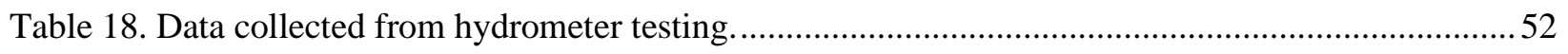

Table 19. Additional information needed for hydrometer corrections and calculations...........................52

Table 20. Random number generator used for sampling locations.......................................................53 


\section{Chapter 1. Introduction}

\subsection{Background}

Coal mining has been a distinct component of West Virginia's history and economy for generations. Proper management of waste and refuse after mining is a capital component of responsible use of this natural resource. While there are innumerable subjects that could be addressed within this area, the following thesis can distinctly be broken down into two subjects: i) the dewatering process of acid mine drainage (AMD) sludge and ii) an investigation of soil loss predictions of a decommission coal refuse impoundment.

\subsubsection{Acid Mine Drainage Dewatering}

The residual mine waste that is created after the extraction of coal during mining operations and following preparation for market sale contains high levels of water saturation. Prior to long-term storage, this waste must be dewatered, the act of extracting water from a saturated substance (Franks et al. 2011). Possible ways to dewater these materials is to passively allow the material to naturally consolidate, give time for the water to evaporate from the surface of the collection center, and then properly dispose of the remaining collection of dewatered material. The major downfall of this process is the amount of time and space required for it to work efficiently (Newman et al. 2003, Liao and Bhatia 2003). Geotextile incorporated into tubes and filter presses are a sound alternative to aid the dewatering process.

\subsubsection{Soil Erosion of an Impoundment}

Impoundments are storage facilities contained by earthen embankments. They serve to withhold produced coal refuse slurry, sediments, and water (D'Appolonia Engineering, Inc. 2009). The particulate composition of coal refuse has extremely low cohesive capabilities, therefore when precipitation runoff travels through the coal refuse, it has a remarkably high tendency to breakdown and erode (Liu et al. 2015).

This exposure to water and oxygen can produce AMD into the surrounding environment. To prevent this appropriate reclamation must be undertaken. The closure of an impoundment involves the deconstruction and drainage of the earthen dam, and the compiled coal refuse is mixed with topsoil, reestablished to the land contour, and revegetated to ensure nondestructive water runoff occurring during precipitation events (Skousen 2019). 


\subsection{Objectives}

To cultivate a greater understanding of the processes that proceed the mining of coal, the following objectives were identified: i) investigate AMD dewatering techniques and a case study was conducted to characterize a specific AMD slurry, and ii) assess total runoff and sediment loads of an abandoned coal refuse impoundment.

\subsection{Overview of Study Design}

\subsubsection{Acid Mine Drainage Dewatering Study Design}

To begin the study of dewatering AMD sludges, an initial look into different aspects of geotextiles was undertaken to curate a fundamental understanding of the physical parameters of the mechanics of dewatering. Then the application geotextiles to the dewatering process and the prominent constituents of AMD waste were investigated. In closing, the physical components of a specific AMD sludge were analyzed and identified.

\subsubsection{Soil Erosion of Impoundment Study Design}

A coal impoundment in central West Virginia has undergone reclamation by the West Virginia Department of Environmental Protection. To ensure sustainability and preservation of this area, the potential soil loss due to water erosion was predicted and analyzed through a series of soil, slope, and climate modeling. This was conducted through the Water Erosion Prediction Project (WEPP), a computer modeling program created by the United States Department of Agriculture's Agricultural Research Services (USDA ARS) (Flanagan et al. 2012). To understand the variable soil characteristics of the impoundment, field samples were collected, evaluated, and applied to the WEPP modeling. 


\section{Chapter 2. Literature Review Study: Acid Mine Drainage and Dewatering}

\subsection{Geosynthetics}

\subsubsection{Overview}

The name geosynthetics encompasses a vast number of different mediums including geotextiles, geogrids, geonets, geomembranes, geosynthetic clay liners, geopipe, geofoam, and geocomposities. These materials have extensive function in civil, environmental, transportation, hydraulic, and construction design (Koerner 2005). According to Koerner (2005), the most notable functions of geosynthetics can be broken down into five categories: separation, reinforcement, filtration, drainage, and liquid/gas containment.

Compositionally, geosynthetics are crafted from polymers. Polymers are made up of multifaceted layers of monomers. These monomers are held together by hydrogen bonds, permanent dipoles, or Van der Waals forces. Geosynthetics consist of, roughly, $92 \%$ polypropylene, $5 \%$ polyester, $2 \%$ polyethylene, and $1 \%$ polyamide. Small segments of polymers are bonded together and incorporated into long, fibrous strands.

\subsubsection{Geotextiles}

There are five categories these strands can be classified in which include monofilament, multifilament, staple fiber, slit film monofilament, and slit-film multifilament. Staple fibers can be twisted together to form staple yarn (Koerner 2005). With these different types of fibers and yarns, geotextiles are created. The four major applications of geotextiles include filtration, separation, reinforcement, and drainage. Water movement is by in-plane flow drainage, cross-plane flow filtration, reinforcement of weak materials, and separation between different substances. Geotextiles can be broken down into three categories according to their composition; woven, nonwoven, and knit. While knit is an option for geotextile creation, it is rarely used in general comparison to the other two options (Koerner 2005).

Woven geotextiles are made on textile weaving machinery in manufactured sheets. The fibers are interlaced generally at right angles in multiple yarn sets much like how a loom weaves together yarn in an over-under repeating fashion. Nonwoven geotextiles are composed of randomly orientated fibers that are then bonded in place by either mechanical, thermal, or chemical means (Müller and Saathoff 2015). Mechanical bonding uses a machine with hundreds of $75 \mathrm{~mm}$ lengthened needles attached to a plate. The geotextile sheet is sent through the machine, and the plate is compressed onto the sheet causing the needles to perforate it with many microscopic holes (Koerner 2005). The holes that are created in the 
nonwoven geotextiles are classified by their apparent opening size (AOS), a measurement based on the largest particle that can pass through the geotextile (Liao and Bhatia 2003).

\subsubsection{Filtration Application}

One prominent function of filtration geotextiles have is dewatering: the displacement of water contents from a saturated material. In many industries, such as mining, agriculture and paper mills, copious amounts of waste are created during the process of creating/extracting the desired material. The waste substances generally have high water concentrations and compressibility but decreased shear strength (Liao and Bhatia 2003). Possible ways to dewater these materials is to passively allow the material to naturally consolidate, give time for the water to evaporate from the surface of the collection center, and then properly dispose of the remaining collection of dewatered material. The major downfall of this process is the amount of time and space required for it to work efficiently (Newman et al. 2003, Liao and Bhatia 2003). Geotextiles incorporated into tubes and mechanical active filtration filter presses are a sound alternative to aid the dewatering process in these different fields of industry.

\subsection{AMD Sludge Filtration}

\subsubsection{Overview}

After coal is extracted from underground and surface mines, the product must be cleaned of any ruminate soil, rock or other non-combustible. The waste material, commonly referred to as tailings, is accumulated in stockpiles for storage (Franks et al. 2011). These sites of tailing collection are producers of acid mine drainage, also known as AMD. Another source can also be abandoned mines. When rainwater or excess water flows through the deposits in the aerobic layers, acid genesis occurs to produce high levels of acid and metals from coal containing pyrite (Johnson 1995).

To avoid the negative consequences AMD can have on the environment, proper treatment must be undertaken. Treatment can take many different forms but following is a very general layout for a more active form of mitigation. Mine feed should be pooled in a collection pond with impermeable lining to avoid any further ground contamination. If the AMD waste contains high levels of acid, neutralization by means of addition of lime $\left(\mathrm{Ca}(\mathrm{OH})_{2}\right)$ should be undertaken (Stewart et al. 2016). To aid in separation and consolidation of the suspended particulates in the waste sludge, a flocculation agent is added and mixed into the collection pond. With time and the addition of flocculant, the sludge separates as the heavier, bonded particles are weighted and sink to the bottom, and the water molecules are displaced to the upper layers. After these processes, the sludge is prepared for further dewatering. 


\subsubsection{Geotextile Tubes}

Geotextile tubes were first used back in the 1970's to alleviate coastal erosion (Newman et al. 2003). Sand can be dredged from water channels and pumped into geotextile tubes. The water is filtered off and a massive, dewatered sandbag remains that can then serve to reinforce eroding shorelines. Generally, nonwoven geotextiles have suitable friction properties and increased flexibility making them more suited for the ever-changing conditions of coastal areas (Müller and Saathoff 2015). Geotextile tubes are tubular containers composed of sheets of geotextile fabric sewed together to create high strength, water permeable filters.

After AMD is treated, the sludge is pumped into the geotextile tubes (Figure 1). Within the filled tubes, the flocculated particles are unable to pass through the textiles' pores. So, while the particulates are retained, the water escapes and dense filter cakes are created internally in the tubes (Liao and Bhatia 2003). On occasion, the flocculated particles can have the same diameter as the pore openings. In these instances, the particles will clog the openings in the geosynthetics inhibiting water to escape and causing build-up of excess material on the interior of the geotextile tube. Due to this possible situation, details of the flocculant and pore diameters must be understood prior to use to avoid clogging.

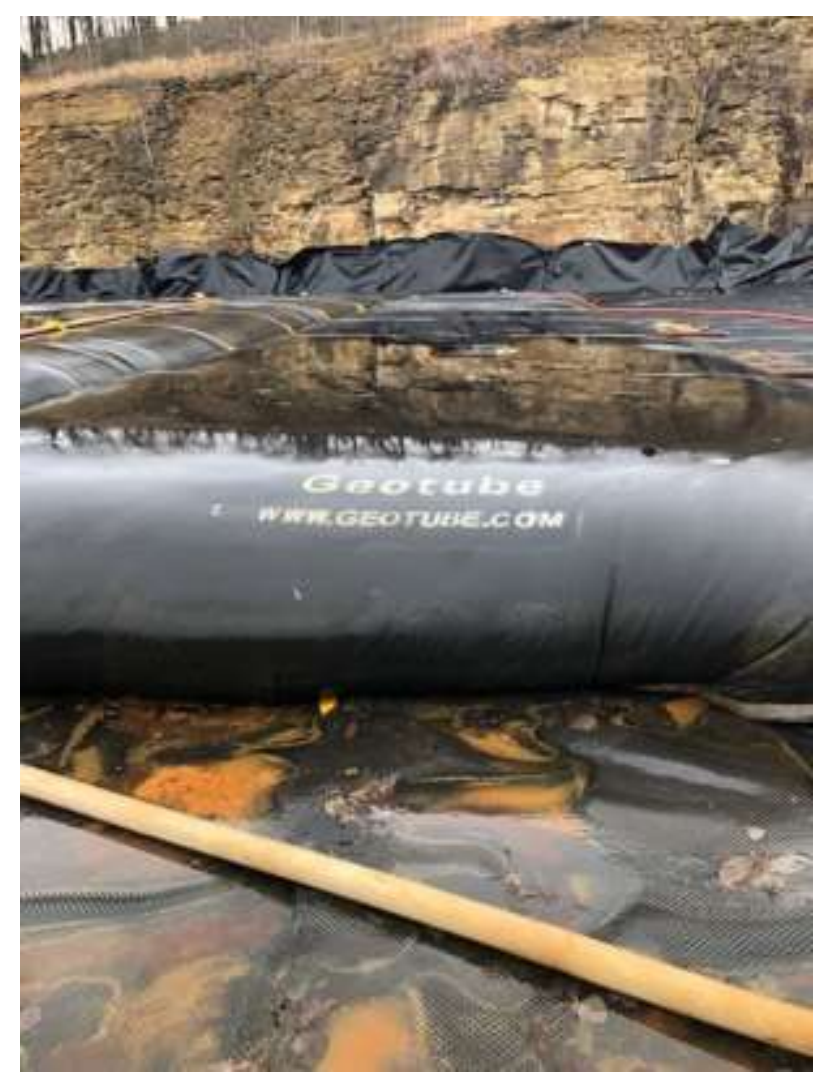

Figure 1. Filled geotextile tube secreting water. Source: L.C. Hopkinson. 


\subsubsection{Belt Filter Presses}

Another system of dewatering applies mechanical pressure to squeeze out excess water from saturated wastewater. The machine used in this system is called a belt filter press. After the addition of a polymer flocculation agent to the wastewater in the conditioning zone, identical to the initial step in preparing a collected waste for dewatering with geotextile tubes, the material is feed into the belt filter press along a conveyor belt where it goes through a gravity induced draining zone and then a variety of different intensities of zones of applied pressure. The final product is a cake reduced of liquid that is ready for proper disposal (Levi et al. 2000).

\subsection{Polymer Flocculation}

\subsubsection{Overview}

Before the dewatering process of a waste slurry can begin, the addition of a flocculation agent to sludge slurries can aid in the retention of specific particles. Flocculation agents consist of carbon-based, macromolecule polymers and can be either synthetic or naturally occurring (Gaffney et al. 2011). Synthetic flocculation agents are easier to manipulate to specific purposes but work best in small doses and have weak shear strength whereas natural polymers work best in large doses, are more stable to shear forces and degrade naturally (Allaedini and Zhang 2019).

\subsubsection{Effects of Particle Charge}

According to Allaedini and Zhang (2019) aggregate particles in sludges generally have negative surface charges which create repulsive forces amongst the molecules. To negate this repulsion, the charge must be neutralized so the particles can coagulate. After this is done, the flocculate forms these coagulated micro molecules into the larger macromolecules. Flocculants can be broken down into three categories according to their charge: anionic, cationic, and non-ionic. Cationic flocculants work best with organic slurries such as sewage sludge, and anionic polymers work most ideally with negatively charged sludge, as well as inorganic, clay, and mineral slurries (Gaffney et al. 2011, Allaedini and Zhang 2019).

In relation to flocculation efficiency, agents with either positive or negative charges attract particles and enhance flocculant accumulation opposed to neutrally charged agents. Allaedini and Zhang (2019) hypothesize this could be related to repulsive or attractive forces of the protons and electrons present on cations and anions. 


\subsubsection{Effects of Molecular Weight}

Molecular weight of flocculant agents varies drastically in relation to maximum efficiency of precipitation formulation. Through experimentation conducted by Allaedini and Zhang (2019) it was determined for neutral ionically charged flocculate agents, a medium range molecular weight retains the greatest number of targeted particles. For cations as the molecular weight increases, the flocculation rate

decreases due to charge reversal that causes dispersion. At times higher molecular weight of flocculant agents creates a higher viscosity that proportionally decreases efficiency.

On the other end of the spectrum, anions create higher amounts of flocculation as the molecular weight of the agent increases. As the molecular weight increases in the case of anions, the number of molecular attachment points increases as the number of electrons increases (Gaffney et al. 2011). It should also be noted that while increased flocculation proportionally relates to the particulate setting rate, it also increases the viscosity of the solution. The viscosity is also increased as the amount of water is bound into the solution. An increase in viscosity can decrease the filtration rate during the dewatering process (Allaedini and Zhang 2019).

\subsection{AMD Sludge Characterization}

\subsubsection{Geotechnical Index Properties of Different Sludges}

To be able to properly treat and dewater the field samples collected for laboratory studies at West Virginia University's geotechnical lab, a greater understanding of characteristics of not only sludges but other mine-related products were obtained (Table 1). These characteristics included the geotechnical properties of low-density slurry, AMD sludges, hard-rock tailings, and minesoils. The origins of these samples were divided between West Virginia and eastern Canada. By looking at the varying characterizations of materials from these areas, a better understanding of the material examined in the following case study, which originates in West Virginia as well, can be cultivated due to underlying geological similarities. 
Table 1. Geotechnical properties of a variety of mining generated waste materials.

\begin{tabular}{|c|c|c|c|c|c|c|c|}
\hline Parameters & \multicolumn{2}{|c|}{ Low Density AMD Slurry } & \multicolumn{3}{|c|}{ AMD Sludge } & \multirow{3}{*}{$\begin{array}{c}\text { Hard Rock Tailings } \\
\text { Ontario, Canada } \\
-\end{array}$} & \multirow{3}{*}{$\begin{array}{c}\text { Mine Soil } \\
15 \text { West Virginian } \\
\text { Mines } \\
-\end{array}$} \\
\hline Origin & \multicolumn{2}{|c|}{ Abitibi, Quebec } & \multicolumn{2}{|c|}{ West Virginia } & \multirow{2}{*}{$\begin{array}{c}11 \text { Canadian } \\
\text { Mines } \\
-\end{array}$} & & \\
\hline & Initial & Final & Omega & Sludge 2 & & & \\
\hline Initial Water Content (\%) & 809 & 503 & 2340 & 482 & - & - & - \\
\hline Solid Content (\%) & - & - & - & - & $2.4-32.8$ & - & - \\
\hline pH & - & - & - & - & $8.2-10.8$ & - & $3.3-6.9$ \\
\hline Grain Size Distribution & - & - & fine SP & fine SP & - & $\begin{array}{l}\text { fine sand/silt-sized } \\
\text { particles }\end{array}$ & $\begin{array}{c}16-67 \% \text { sand } \\
20-63 \% \text { silt } \\
13-38 \% \text { clay }\end{array}$ \\
\hline Specific Gravity & 3.1 & & $1.23-3.0$ & $2.4-2.5$ & $2.32-5.02$ & - & - \\
\hline Redox Potential (mV) & - & - & - & - & $58-315$ & - & - \\
\hline Void Ratio & 25.4 & 15.8 & - & - & - & & - \\
\hline Bulk Density $\left(\mathrm{g} / \mathrm{cm}^{\mathbf{3}}\right)$ & - & - & - & - & $1.05-1.37$ & & $0.8-1.7 \times 10^{-9}$ \\
\hline Hydraulic Conductivity $(\mathrm{cm} / \mathrm{s})$ & $0.8-1.7 \times 10^{-5}$ & $8.0 \times 10^{-6}$ & - & - & - & order of $10^{-2}-10^{-7}$ & - \\
\hline Consolidation $\left(\mathrm{m}^{2} / \mathrm{s}\right)$ & $6.0 \times 10^{-9}$ & $2.0 \times 10^{-2}$ & - & - & - & order of $10^{-5}-10^{-7}$ & - \\
\hline Compression Index & 4.0 & 12.0 & - & - & - & $0.05-0.54$ & - \\
\hline Compressibility $\left(\mathrm{kPa}^{-1}\right)$ & -1.0 & -2.1 & - & - & - & - & - \\
\hline Liquid Limit, LL (\%) & - & - & 0 & 0 & - & $>40$ & - \\
\hline Plastic Limit, PL (\%) & - & - & 0 & 0 & - & $0-15$ & - \\
\hline Friction Angle (degrees) & - & - & - & - & - & $30-42$ & - \\
\hline Effective Cohesion (kPa) & - & - & - & - & - & 0 & - \\
\hline Reference & (Pedroni et & 1. 2006) & (WV & 2020) & $\begin{array}{c}\text { (Zinck et al. } \\
\text { 1997) }\end{array}$ & (Bussiere 2007) & $\begin{array}{c}\text { (Johnson and } \\
\text { Skousen 1995) }\end{array}$ \\
\hline
\end{tabular}




\subsubsection{Low Density AMD Slurry}

Pedroni et al. (2006) created a homogenous mixture from a kaolin sludge from an AMD treatment facility in Quebec. This sludge underwent consolidation testing to determine the behavior of sludge after it is discharged from treatment and enters disposal areas. The test undertaken investigates the geotechnical properties of mine waste sludge after $14.56 \mathrm{kPa}$ of stress is applied to a column of sludge to understand their consolidation behaviors (Pedroni et al. 2006).

Testing involved a Plexiglas column with the height of $180 \mathrm{~cm}$ and inner diameter of $15 \mathrm{~cm}$ is filled with the sludge, and the pressure transducers are activated. The test is run for 3 to 15 days until the sludge enters a semi-steady state. Once this is achieved, a perforated plate applies incremental pressure to the top of the column of sludge. Twice a week throughout the duration of the experiment radioactive gamma ray of samarium 153 is transmitted from a case located on the side of the column. On the opposite side of the column at the same elevation a detector picks up the transferred rays. The fraction of emitted rays is proportional to the relative density of the sludge and can also be used to determine the chemical composition and pore water. In extreme cases the test can take up to 3 months. This specific test conducted by Penroni et al. (2006) took over 50 days.

\subsubsection{AMD Sludge}

The acid mine drainage sludges were collected and examined at the Geotechnical Soils Lab of West Virginia University. The AMD sludges originated at the Omega coal fired power plant in West Virginia. The Omega sludge was treated with a cationic flocculant and dewatered using geotextile tubing. Sludge 2 came from the same source but underwent different treatment.

In a similar area of focus, Zinck et al. (1997) investigate general characteristics of AMD treatment sludges, both fresh and aged, originating in Canada. These specific characteristics include physical, chemical, and leaching. During the process of dewatering, three different types of flocculation agents were used to encourage settlement of the sludge. The flocculants were anionic in charge and had high molecular weights.

Zinck et al. (1997) used a Microtrac X100 for the particle size analysis. For understanding the percent solids for the different sludges, the samples were dried using three different methods for comparison. These methods included being oven dried at $110^{\circ} \mathrm{C}$, oven dried at $60^{\circ} \mathrm{C}$ for 24 hours and finally by a Sartorius moisture balance. 


\subsubsection{Hard Rock Tailings}

Bussiere (2007) investigated the stability, chemical, and physical characteristics of hard rock tailings from metal mines in Ontario. The hydrogeotechnical properties of rock tailings included but was not limited to hydraulic conductivity, consolidation characteristics, and grain-size distribution.

To determine the shear strength of the hard rock tailings, Bussiere (2007) used a combination of consolidated drained (CD), consolidated undrained (CU), and direct shear testing. When finding the hydraulic conductivity of the different specimens, both remolded and undisturbed samples were investigated to draw a relative comparison between their consolidating characteristics, void ratios, and Unified Soil Classification System (USCS). Sieve analysis was undertaken to determine grain size distribution, and Atterberg limits testing deduced the liquid and plastic limits of the tailings.

\subsubsection{Minesoil}

To aid in the reestablishment of mining facilities and to alleviate the amount of stockpiled waste from mines, the minesoil can be restored to the earth to facilitate revegetation. Johnson and Skousen (1995) investigated minesoil characteristics from 15 abandoned mines in West Virginia to ensure the assigned vegetation cover would be well suited and successful in reclamation of the natural environment and in erosion prevention.

\subsection{Filtration of Other Types of Sludge}

\subsubsection{Overview}

Mining is not the only industry that produces waste materials that can be treated through the process of dewatering. It is estimated that a volume to the order of a billion cubic meters of waste is generated worldwide from a combination of paper mills, mining projects, agriculture, dredging projects, municipal waste treatment plants, and general industry (Liao and Bhatia 2003). A look beyond mining waste has been taken to fully understand the dewatering abilities of geotextile tubes and resulting characteristics of produced materials.

\subsubsection{Sludge with Similar Gradation to AMD}

Several studies that explored the geotechnical properties of waste sludge from wastewater treatment plants were used to compile the data found in Table 2 (i.e., Lo et al. 2002, O'Kelly 2006, Zhan et al. 2014). While these studies were done in a variety of locations from Ireland to China, the objectives were similar. O'Kelly (2006) dewatered the sludge, allowed it to degrade, and then tested for the material's geotechnical characteristics to ensure disposal in geosynthetic lined landfills would be adequate long-term storage for the waste product. In Chengdu, China, Zhan et al. (2014) not only tested sludges to obtain 
geotechnical properties but also determined the collected sludge has layered characteristics in relation to depth in the collection pit. Finally, Lo et al. (2002) from the Hong Kong University of Science and Technology investigated whether degrees of mixing dewatered sewage sludge with other solid waste would improve long standing storage in landfills.

Table 2. Geotechnical properties of sewage sludges.

\begin{tabular}{|c|c|c|c|}
\hline Parameters & & Sewage Sludge & \\
\hline Origin of sludges & Tullamore, Ireland & Stonecutter Island, China & Chengdu, China \\
\hline $\begin{array}{l}\text { Initial water content } \\
(\%)\end{array}$ & 720.0 & 180.0 & 210.0-790.0 \\
\hline Organic content $(\%)$ & $50-70$ & - & $18.5-51.8$ \\
\hline Specific gravity & $1.55-1.8$ & 1.55 & $1.8-2.3$ \\
\hline $\begin{array}{l}\text { Grain size } \\
\text { distribution }\end{array}$ & - & - & $\begin{array}{l}30 \% \text { silt-size grains } \\
45 \% \text { clay-size grains }\end{array}$ \\
\hline Void ratio & 11.0 & 3.0 & $11.0-13.0$ \\
\hline Plastic limit, PL (\%) & 55.0 & - & 106.0 \\
\hline Liquid limit, LL (\%) & 315.0 & - & 353.0 \\
\hline Plasiticity index, PI & 260.0 & - & - \\
\hline pH & 8.0 & - & - \\
\hline $\begin{array}{l}\text { Hydraulic } \\
\text { conductivity }(\mathrm{m} / \mathrm{s})\end{array}$ & $1.0 \times 10^{-9}$ & $1.0 \times 10^{-11}$ & $3.0 \times 10^{-9}-4.0 \times 10^{-9}$ \\
\hline Consolidation & 7.0 & - & $1.5-5.5$ \\
\hline $\begin{array}{l}\text { Effective angle of } \\
\text { internal friction }\left({ }^{\circ}\right)\end{array}$ & $32.0-37.0$ & $26.1-31.9$ & $10.0-15.0$ \\
\hline Effect cohesion (kPa) & 0.0 & $8.3-14.4$ & 0.0 \\
\hline $\begin{array}{l}\text { Dewatering } \\
\text { Mechanism }\end{array}$ & Belt filter press & - & - \\
\hline References & O'Kelly 2006 & Lo et al. 2002 & Zhan et al. 2014 \\
\hline
\end{tabular}




\subsection{Particle Size Analysis Procedures for Highly Saturated Sludges}

\subsubsection{Overview}

To create a geosynthetic with the proper AOS parameters to retain desired flocculants, the dewatered Omega sludge's grain size distribution must be fully understood. While a general understanding can be obtained through soil tests such as wet and dry sieve analyses and hydrometer testing, more in depth and detailed examinations were also conducted. These magnified explorations included X-ray diffraction and scanning electron microscopy.

\subsubsection{X-Ray Diffraction}

When using an X-ray diffractor to view microscopic particles, X-ray beams focused on a sample are absorbed and retransmitted by the valence electrons. The diffracted rays are reabsorbed and translated according to their different angles and wavelengths within the atomic structure of the sample (Dutrow and Clark 2020). The output data provides information on crystalline structure, phases, preferred orientation (texture), average grain size, crystallinity, strain, and crystal defects.

According to West Virginia University's Shared Research Facility website, X-Ray Diffractors and other equipment available through WVU within the Engineering Department include a PANalytical X'Pert Pro X-ray Diffractometer (XRD) and a Physical Electronics PHI 5000 VersaProbe X-Ray Photoelectron Spectroscopy (XPS/UPS). The PANalytical X'Pert Pro XRD specializes in identification of single-phase materials and quantitative determination of amounts of different phases in multi-phase mixture. The Physical Electronics PHI 5000 shows depth profile analysis of structures and interfaces, micro-area element composition, and chemical state determination at material surface. Finally, the Bruker Contour GT K0 Optical Profiler uses synchronous pulsed fluorescence illumination for microscopic view of particles.

\subsubsection{Microscopic Analysis}

Scanning Electron Microscopes (SEMs) use electrons focused in a direct beam to generate high resolution, three-dimensional images with resolutions between 1-20 $\mathrm{nm}$. The output information provides data of the topography, morphology, and chemical composition (Swapp 2017).

SEMs available through West Virginia University's shared facilities labs include the Hitachi S-4700 Scanning Electron Microscope. The viewing tables of SEMs are under high vacuum, so specimens must be dried in viewing preparation. All sample preparation will be conducted by the technician in the specific lab. According to Dr. Marcela Redigolo of West Virginia University, a maximum of $1 \mathrm{~cm}^{3}$ is required for the testing and duplicates of the sample are highly recommended especially for nonhomogeneous samples (personal communication, 2020). 


\subsection{Omega Sludge Characteristics}

\subsubsection{Introduction of Omega AMD Sludge}

An in-depth investigation of an acid mine drainage (AMD) sludge was undertaken in the Geotechnical Soils Laboratory of West Virginia University to determine the soil classification. The AMD sludge is sourced from a treatment station operated by the Department of Environmental Protection and is located south of Morgantown, West Virginia. The raw AMD was sourced from the underground mine, treated by precipitation at a $\mathrm{pH}$ around 3.2 and is then clarified where the $\mathrm{pH}$ is raised to 6.7 using calcium hydroxide (lime). The supernatant is settled through a series of ponds and then released into the environment through a National Pollutant Discharge Elimination System (NPDES) discharge point. The solids produced during the clarification process is concentrated, flocculated with polymers concentrated at $20 \mathrm{ppm}$ to create filterable flock, and dewatered through a series of geotextile tubes. The sample sludge tested in the laboratory was collected from a filled geotextile tube, not actively receiving sludge, during the dewatering phase. The following tests were conducted on the sludge to determine its geotechnical properties (Table 3).

Table 3. Geotechnical property tests undertaken on the AMD sludge.

\begin{tabular}{cc}
\hline Test & ASTM Standard \\
\hline Moisture Content & D-2216 \\
Sieve / Hydrometer & D-422 \\
Specific Gravity of Soils & D-1140 \\
Atterberg Limits (LL, PL) & D-854 \\
\hline
\end{tabular}

\subsubsection{Moisture Content}

After overnight heating at $110^{\circ} \mathrm{C}$, the moisture content of the specimen was determined in accordance with the ASTM Dewatering and Stabilizing Fine-Grained Soils with Very High Moisture Content (Howard and Carruth 2014). The equation for moisture content ( $\omega$ ) (Equation 1) and total solids by weight (TS) (Equation 2) are as follows:

$$
\begin{gathered}
\omega=\left(\frac{w_{w}}{w_{s}}\right)(100) \\
T S=\left(\frac{w_{s}}{w_{w}+w_{s}}\right)(100)
\end{gathered}
$$

where:

$w_{w}=$ mass of water, $\mathrm{g}$ 
$w_{s}=$ mass of dry sample, $\mathrm{g}$

The moisture content and total solids by weight were determined as $1,645 \%$ and $5.75 \%$, respectively, for the Omega sludge.

\subsubsection{Particle-Size Analysis}

To be able to optimize filtration and retention of the desired particulate during the dewatering process, an in-depth analysis of the grain size distribution of the material was undertaken starting with dry sieve analysis. The AMD sludge was dried, and the specimen was divided into two even portions. Then following the Standard Test Method for Particle Size Analysis of Soils ASTM D422, each dried soil portion underwent two repetitive sieve analyses. The duplication of sample groups and tests runs was created for statistical evaluation. The following shows the four trails and their collective distributions (Figure 2). Due to the high percentage passing the number 200 sieve, a hydrometer test was conducted to determine the distribution of the finest particles. For further analysis, a wet sieve analysis was completed for a broader examination of the material's grain size distribution. 


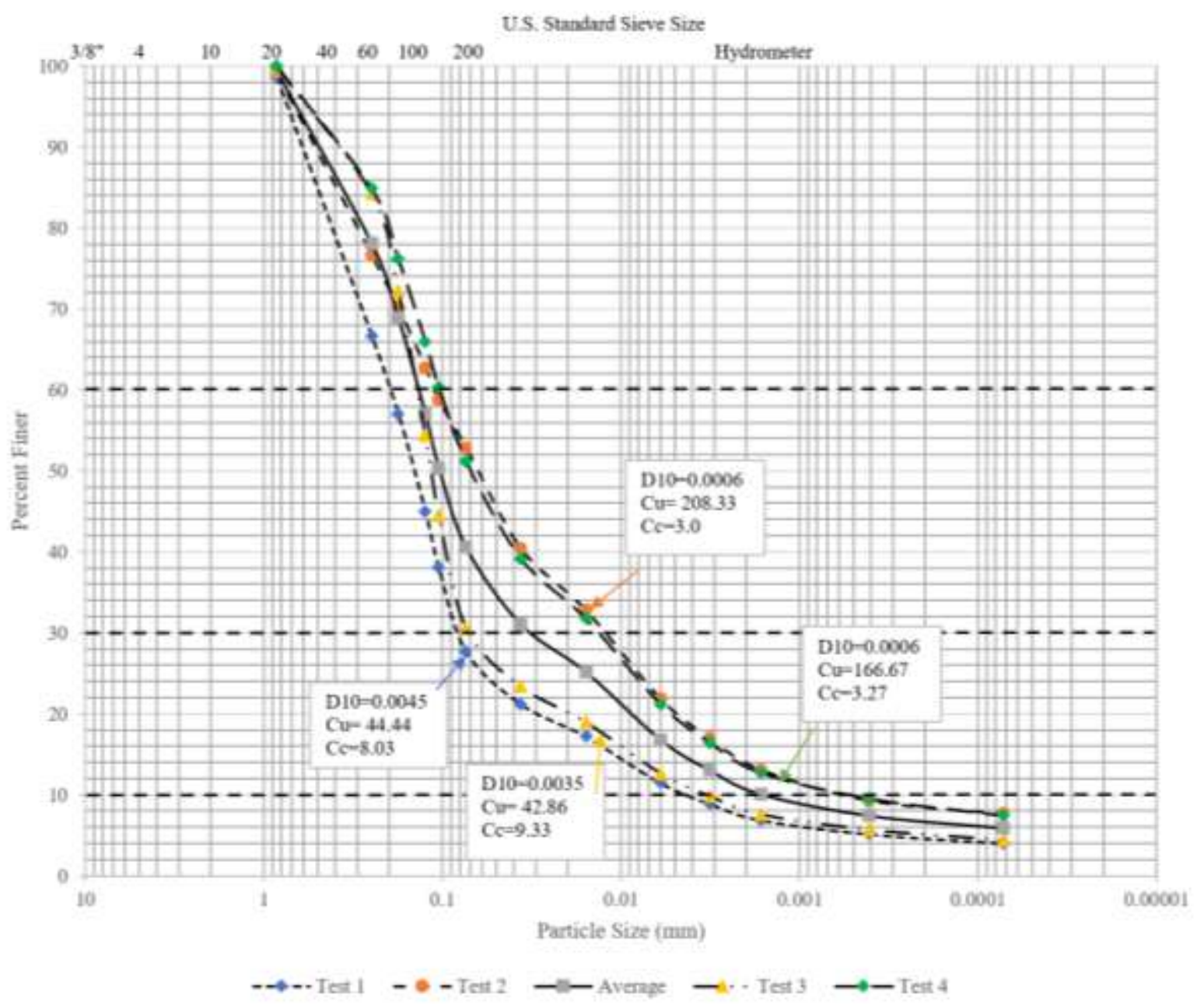

Figure 2. Grain size distribution curves from dry sieve.

Wet sieving allows for a more efficient and complete separation of larger particles when working with materials that are considerably finer than a No. 200 sieve or 75 micrometers in particle diameter (ASTM D1140). The wet sieve was undertaken in two trials. For the first, $250 \mathrm{ml}$ of water was added to $250 \mathrm{~g}$ of air dired sludge and was let to sit for 30 minutes. Prior to wet sieving, the sludge was minimally agitated and some clumps of flocculated sludge were left intact. The highly saturated sludge was sieved through the No. 20, 40, 60, 140, and 200 sieves. The weight retained on the No. 20 sieve created an inaccurate representation of anticipated retention percentages due to lack of mixing and particulate disturbance. To create a more authentic distribution, the No. 20 sieve data was negated when creating the graphical 
representation of the grain size analysis (Figure 3). To avoid this situation in the second trial more homogenous mixing was undertaken when preparing the saturated sludge for wet sieve analysis.

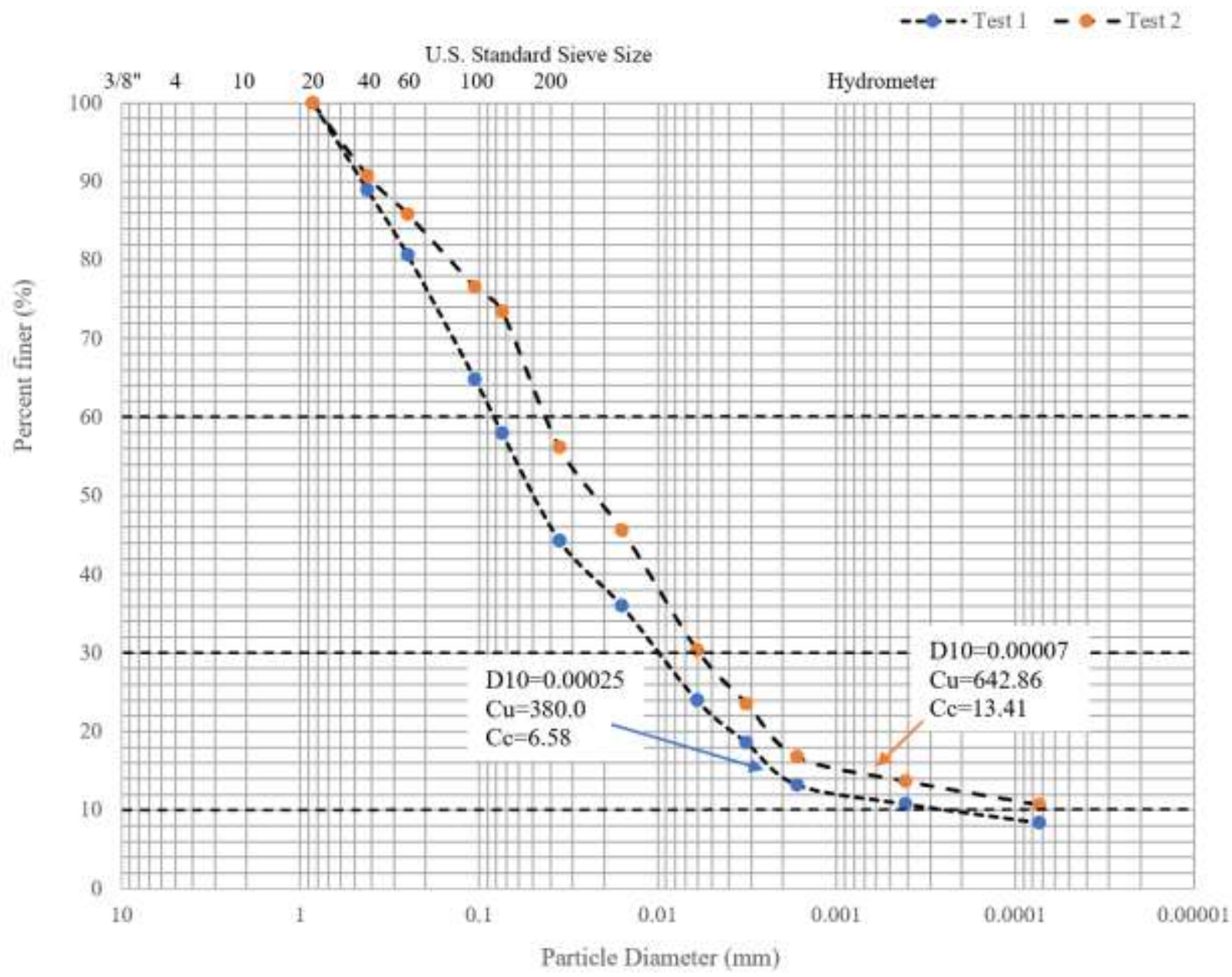

Figure 3. Grain size distribution determined by wet sieve analysis.

\subsubsection{Specific Gravity of Soil Solids by Water Pycnometer}

Following the ASTM D854, three trails were tested to determine the specific gravity of the Omega sludge specimen. The sludge had been previously tested and was found to have a specific gravity of 2.9 to 3.0 (Table 4 ), but in this most recent testing the specific gravity averaged out to 2.48 (Table 5 ). The differences in these values could be a product of miscalculation and human error. It was also noticed during testing that the dried sludge samples absorb moisture from the air at a rapid rate. If samples are left exposed to the air for an extended period, the reabsorption of this moisture could create inaccurate weights and measurements in data. 
Table 4. Previously identified specific gravity of Omega.

\begin{tabular}{|c|c|c|c|}
\hline \multicolumn{2}{|c|}{ Soil Sample } & \multicolumn{2}{c|}{ Sludge 1 } \\
\hline Mass of Dry Soil (g) & $\begin{array}{c}\text { Mass of pycnometer + 500 } \\
\text { ml de-aired water (g) }\end{array}$ & $\begin{array}{c}\text { Mass of pycnometer + 500 ml } \\
\text { slurry of soil (g) }\end{array}$ & Specific Gravity \\
\hline 50.11 & 650.72 & 683.58 & 2.9 \\
\hline 50.03 & 650.25 & 683.44 & 3.0 \\
\hline 50.05 & 668.01 & 701.55 & 2.9 \\
\hline 50.19 & 668.22 & 700.84 & 2.9 \\
\hline 49.99 & 667.77 & 700.51 & 2.9 \\
\hline & & & Average \\
\hline & & Standard Deviation & $\mathbf{0 . 1}$ \\
\hline
\end{tabular}

Table 5. Recorded data and calculated specific gravity of Omega.

\begin{tabular}{|c|c|c|c|c|}
\hline $\begin{array}{c}\text { Mass of Dry } \\
\text { Soil (g) }\end{array}$ & $\begin{array}{c}\text { Mass of Empty } \\
\text { Pycnometer } \mathbf{( g )}\end{array}$ & $\begin{array}{c}\text { Mass of Pycnometer + } \\
\text { 500ml of De-aired Water } \mathbf{( g )}\end{array}$ & $\begin{array}{c}\text { Mass of Pycnometer + } \\
\text { 500ml Soil Slurry (g) }\end{array}$ & $\begin{array}{c}\text { Specific } \\
\text { Gravity }\end{array}$ \\
\hline 50.0 & 159.47 & 658.05 & 687.84 & 2.47 \\
\hline 50.0 & 155.99 & 654.42 & 684.29 & 2.48 \\
\hline 50.0 & 161.01 & 659.60 & 689.50 & 2.49 \\
\hline & & & Average & $\mathbf{2 . 4 8}$ \\
\hline
\end{tabular}

\subsubsection{Atterberg Limits}

Due to the consistency and rust-like characteristics of the completely dried sludge material, the procedure for determining the liquid limit from the ASTM D-4318 was slightly modified. Opposed to starting with a dry soil and progressively adding water to find the proper window of moisture, the dewatered, moist sludge was tested initially and then dried in an oven at $110^{\circ} \mathrm{C}$ for segments of time. The liquid limit was tested after each segment of time.

The sludge was mixed in preparation for the application onto the liquid limit device for each test. During mixing it was observed that the water content of the material increased with stirring even after drying in the oven. If the material were not stirred, the groove created within the brass cup would never close even after more than 75 blows were conducted. After 24 hours of air drying the sample was tested again for the liquid limit. For the initial test, the sludge was undisturbed, and the number of blows conducted exceeded 50 indicating extreme rigidity. Then, the dried sludge was stirred, and upon testing consolidation was immediate.

These characteristics show that the material is meta-stable. The polymers added to induce flocculation are held together by Vander Waals attraction that realigns and affects the equilibrium of the particles within the sludge. This in turn changes the free water saturation, the moisture content of the bound water, 
and the void ratio. Overall, the charge of the flocculated particles in relation to their surface area is extremely high, and the behavior of the sludge is remarkably comparable to expansive clay.

In summary, the average of the liquid limits found was 1297.23, and the estimated liquid limit at 25 blows was configured to be 759.65 . The average of the plastic limit came out to 222.88 therefore making the plastic index to be 1012.78 .

\subsubsection{Visual Classification}

In relation to the ASTM D2488 Visual Procedure for Description and Identification of Soils, the general description of the specimen could be described as a fine-grained sand. The color varies from coarse grains of brown to super fine grains of rusty orange. The dry samples lack any noticeable odor and were not tested for reaction to hydrochloric acid. For more in depth understanding of the particle structure and variance, the specimen will be examined with X-ray diffraction and a scanning electron microscope. These resources will be available through WVU's Shared Research Facility.

When dried the specimen has a very hard consistency and moderate cementation. Since more than 50\% of the material passed the No. 200 sieve, it has characteristics similar to a lean, elastic silt.

\subsection{Summary}

Major results for this section are summarized as:

- Geosynthetic material, artificially crafted polymers, play a significant role in construction reinforcement, drainage, and specifically filtration.

- Clarification and remediation of acid mine drainage can be fashioned in a variety of different methods most notably being the flocculation and dewatering by means of geotextile tubes.

- Flocculation of mine drainage through the addition of specific polymers enables the retention and separation of specific particles within the effluent material during dewatering processes.

- Understanding of the physical geotechnical properties of other waste products, including materials from mining origins and wastewater treatment, enhances the creation and efficient flocculation and filtration of mine waste for further use and reestablishment.

- The precipitated AMD sludge produced at the Omega mine site had elastic characteristics dependent on the material's composition at the time of its dewatering. 


\section{Chapter 3: Sediment Management for Sludge Impoundments}

\subsection{Introduction}

\subsubsection{Impoundments}

Coal impoundments are long-term storage for both coarse and fine-grained coal refuse (Figure 4). Impoundment configurations can be broken down into four general classifications: i) cross-valley impounding embankments, ii) incised impoundments, iii) side-hill impounding embankments, and iv) diked impounding embankments (D'Appolonia Engineering, Inc. 2009). While the primary purpose of impoundments is waste storage, the second key component is water retention. The water existing in impoundments has several different origins including overland runoff from the surrounding watershed, direct precipitation from storm events, and residual water from the coal cleaning process. The combination of present water with the decreased cohesive properties of coal refuse increases the rate of soil loss and erosion in impoundment especially after closure due to decreased surveillance and maintenance (D’Appolonia Engineering, Inc. 2009, Liu et al. 2015).

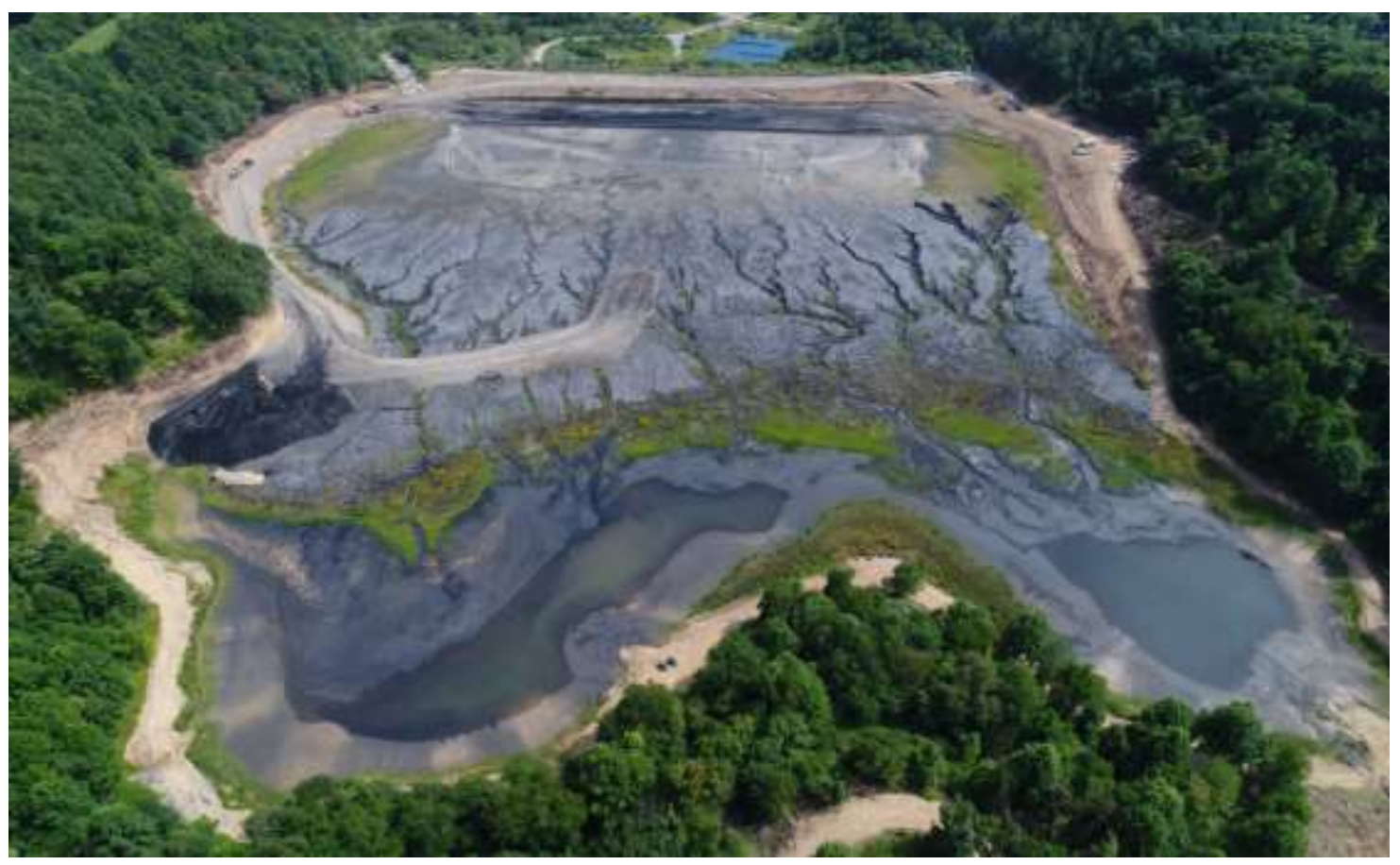

Figure 4. Century coal refuse impoundment prior to reclamation. Earth dam located at the top of the photo with ponded water collected at the bottom of the photo (north end). 
The responsibilities of impoundment management must meet several physical requirements before closure and abandonment in accordance with the state government's permitting process. Physically, the impoundment must be drained of collected water contents properly without creating damaging acid mine drainage to the surrounding environment. Once drained and regraded, the cultivation of vegetation to the site will aid in soil retention. The presence of vegetation will serve to block the soil from direct impact of precipitation and provide underground soil stability through the interlacing root systems. Finally, the creation of sustainable drainage channels aids in preventing rill channels from cutting through the reestablished impoundment when runoff from precipitation events occur (Sawatsky et al. 1996).

\subsubsection{Water Erosion Prediction Project (WEPP)}

Originally designed by the USDA's Agricultural Research Service (ARS) in 1985 to replace the Universal Soil Loss Equation (USLE), Water Erosion Prediction Project (WEPP) is a process-based computer modeling program created to anticipate soil displacement, loss, and deposition during singular or continuous storm events. The scale of the project area can vary from a singular hillside or segments of roads to full watersheds. Using the foundation of hydrology and hydraulics, plant science, and soil and erosion mechanics, WEPP input and field parameters can include the surrounding topography of the area, climate conditions, soil properties, vegetation, and stream flow data (Renschler and Harbor 2001, Wu et al. 2012, Flanagan et al. 2012). Several case studies that utilized the computational and predictive abilities of WEPP are summarized as follows (Table 7).

Wu et al. (2012) focused on creating a collaborative computer program package for reclamation planning and soil erosion control specifically tailored for alkaline surface coal mines located in the western part of the United States. This software package was tested and achieved by combining WEPP and WEPP Watershed Online GIS (Geographic Information Systems) interface (Table 6). In this case study, WEPPMine was used to simulate ten hydraulic structures to find their effects on sediment control and runoff. These structures included hydraulic ponds, filter fences, perforated risers, straw bales, culverts, and spillways. The WEPP-Mine modeling showed the simulated runoff amount occurred in the range observed in the modeling with the greatest amount of precision coming from larger structures such as the emergency and drop spillways.

Liu et al. (2015) utilized WEPP to examine how soil texture and hydraulic properties are affected by mining activities and to determine the extent of the first-year soil erosion risk at the Rosebud Surface Coal Mine in the northern Powder River Coal Basin of Montana (Table 6). They investigated four differentiating areas of the mine: undisturbed natural areas, roughly graded mine spoils, replaced topsoil prior to seeding and revegetated areas. Of these areas, WEPP modeling determined long-term runoff and soil erosion in the undisturbed natural areas and revegetated areas were low and not notably different. 
Oppositely, the stockpiled topsoil and roughly graded mine spoils showed higher potentials for soil erosion and consequently where the areas of highest sediment delivery according to the WEPP simulations.

Flanagan et al. (2012) conducted two case studies outside of the mining industry to examine a hillslope profile under single storm runoff conditions and following soil loss evaluations at natural gas well sites in Texas and soil erosion in a watershed due to the effects of land management practices in the immediate area in Iowa (Table 6). WEPP was ideal for these studies due to its fewer amount of required observance of runoff and soil loss in relative comparison to USLE. From the study sites in Texas, it was determined that WEPP possesses the ability to effectively simulate runoff and soil loss with high accuracy. The WEPP model results for the subwatershed in Iowa successfully modeled the runoff and sediment loss quantities. The results aid in identifying regions that could benefit from additional conservation practices.

Table 6. Case studies utilizing WEPP.

\begin{tabular}{|c|c|c|c|c|}
\hline Parameters & \multicolumn{2}{|c|}{ Surface Coal Mine } & $\begin{array}{c}\text { Natural Gas } \\
\text { Well Sites }\end{array}$ & Water Catchment \\
\hline Origin & \multicolumn{2}{|c|}{ Colstrip, MT } & Texas & Iowa \\
\hline Site & $\begin{array}{l}\text { Rosebud and Big } \\
\text { Sky Mines }\end{array}$ & Rosebud Mine & $\begin{array}{l}\text { Clay loam hillslope } \\
\text { and flex base pad }\end{array}$ & $\begin{array}{l}\text { South Amana } \\
\text { subwatershed }\end{array}$ \\
\hline Objective & $\begin{array}{l}\text { To develop a user- } \\
\text { friendly software } \\
\text { simulation package } \\
\text { specialized in } \\
\text { sediment control } \\
\text { and reclamation } \\
\text { plans for surface } \\
\text { coal mines }\end{array}$ & $\begin{array}{l}\text { To determine the } \\
\text { effects of surface } \\
\text { mining on } \\
\text { geotechnical } \\
\text { properties of the } \\
\text { surrounding soil and } \\
\text { to investigate first- } \\
\text { year erosion risks }\end{array}$ & $\begin{array}{l}\text { To determine factors } \\
\text { of erodibility, critical } \\
\text { hydraulic shear stress, } \\
\text { and effective hydraulic } \\
\text { conductivity }\end{array}$ & $\begin{array}{l}\text { To examine the effects } \\
\text { of land management } \\
\text { practices on soil } \\
\text { erosion in } \\
\text { subwatershed }\end{array}$ \\
\hline Program & WEPP-Mine & WEPP v2012.8 & WEPP & WEPP \\
\hline Time Frame & \multicolumn{2}{|c|}{ 30-year simulations } & 20 storm runoff events & 100-year event \\
\hline Reference & Wu et al. 2012 & Liu et al. 2015 & \multicolumn{2}{|l|}{ Flanagan et al. 2012} \\
\hline
\end{tabular}

\subsection{Methods}

\subsubsection{Site Description}

The slurry impoundment investigated in this study is a part of the West Virginia Land Stewardship Corporation for the West Virginia Department of Environmental Protection (WVDEP 2018) in the Division of Land Restoration and the Office of Special Reclamation. The site is located in Barbour 
County east of the township of Century (Figure 5). The impoundment is roughly 12 hectares (29 acres) and has a mean elevation around $470 \mathrm{~m}(1,540 \mathrm{ft})$ from sea level. Located within the Southern Unglaciated Allegheny ecoregion, annual precipitation amounts are average around $122 \mathrm{~cm}$ (48 in) (NWS 2020, WVGISTC 2000). During the winter, temperatures range between $22^{\circ} \mathrm{F}$ to $40{ }^{\circ} \mathrm{F}$, and summer temperatures fall between $61^{\circ} \mathrm{F}$ and $83^{\circ} \mathrm{F}$ (NWS 2020).

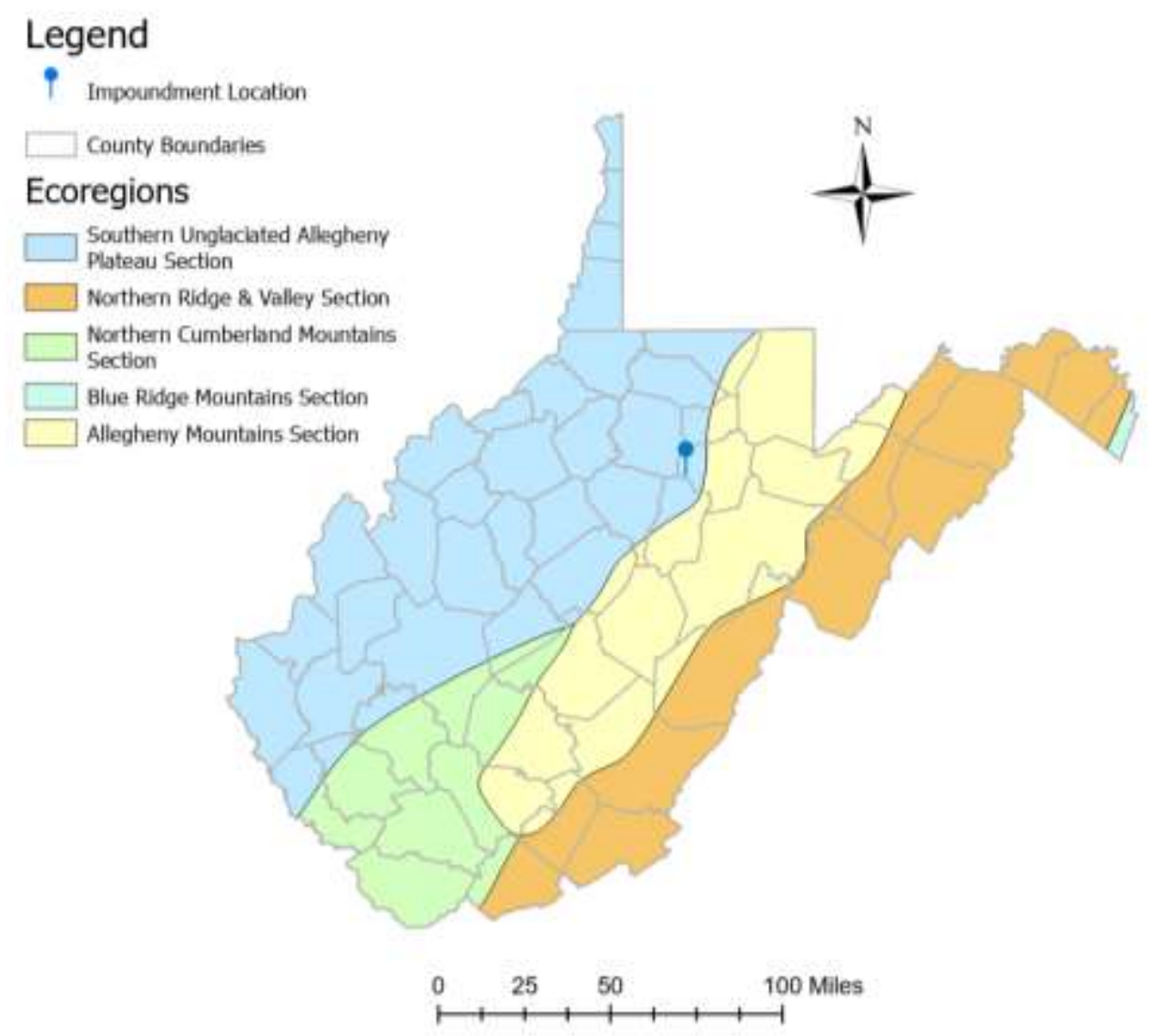

Figure 5. Location of the Refuse Impoundment within West Virginia.

Once the facility was no longer required for refuse storage, the impoundment was regraded to eradicate the areas of pooling and to ensure extremely moderate sloping to enable even precipitation discharge. A crest running from north to south in the center of the impoundment was established, and the surrounding area is filled and graded to a $2.4 \%$ slope from the crest to east and west sides of the property. Finally, the regarded area was planted with a native mix of vegetation to aid in natural reestablishment.

\subsubsection{Field Methods}

After an initial visit and introduction to the WVDEP crew assigned to the regrading of the impoundment and the property owner, Sara Dalen and Dr. Hopkinson returned to the impoundment November 17, 2020 
to gather soil samples, evaluate ground cover, and soil infiltration rates. For the WEPP modeling, the impoundment was divided into three separate hillslopes. The hillslope on the far easterly side of the impoundment (Hillslope 1) is roughly half the size of the two other hillslopes (Hillslopes 2 and 3), so five sampling locations were used in Hillslope 1 and ten locations in each of Hillslope 2 and 3 (Figure 6).

When determining sampling locations, a variation of a method created by Davis (2015) was used to maintain unbiased and random sampling locations. An initial sampling location was chosen in the middle portion of the southerly end of the impoundment hillslope sections. The number of paces was selected from a non-sequential number table generated by first selecting a number between one and four that corresponds to four columns and a second number between one and 50 that corresponds to 50 rows in the number table (Appendix B). The number in the corresponding cell from the two numbers chosen became the total paces to the next sampling location in a northerly direction. Each sampling location's GPS coordinates and elevation was marked with a Garmin etrex20 handheld GPS. All data collected were recorded in individual field forms for each sampling location. Field measurements of infiltration, ground cover, and soil samples were completed as described in the following sections.

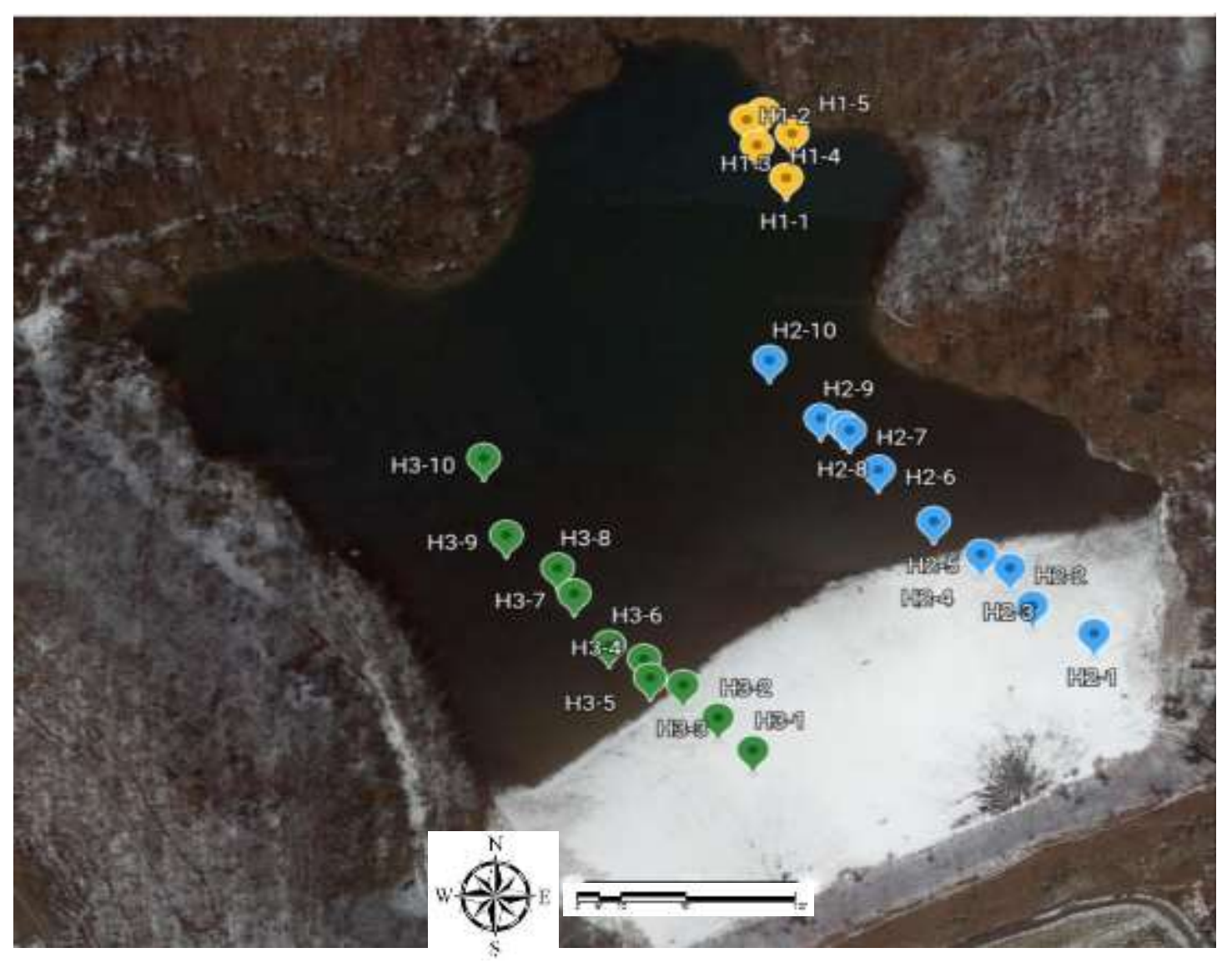

Figure 6. Sampling locations from November 2020, distance measured in meters (H1=hillslope 1; H2=hillslope 2; H3=hillslope 3). 


\subsubsection{Vegetation}

In November of 2020, a vast majority of the regarded impoundment was covered in a young, annual grass crop ranging in height from new growth of less than $2.54 \mathrm{~cm}$ (1 in) to $30.5 \mathrm{~cm}$ (12 in). To measure the ground cover, a portable point frame (PPF) was used following the methods of Davis 2015 and Elzinga et al. 1998. The frame is $1 \mathrm{~m}$ by $1 \mathrm{~m}(3.28 \mathrm{ft} \times 3.28 \mathrm{ft})$ and consists of two layers of $10 \times 10$ string grids. Aerial analysis determined whether the ground directly beneath the 100 cross hairs of the string grids could be categorized as grass, straw, or bare ground (Figure 7). The presence of grass aids in soil retention and erosion prevention due to the soil surface area coverage and the cohesiveness of the underlying root systems. In areas where vegetation was not growing, the minimal presence of straw aids in soil retention by obstructing the direct impact of precipitation to the soil's surface (Sawatsky and Cooper 1996).

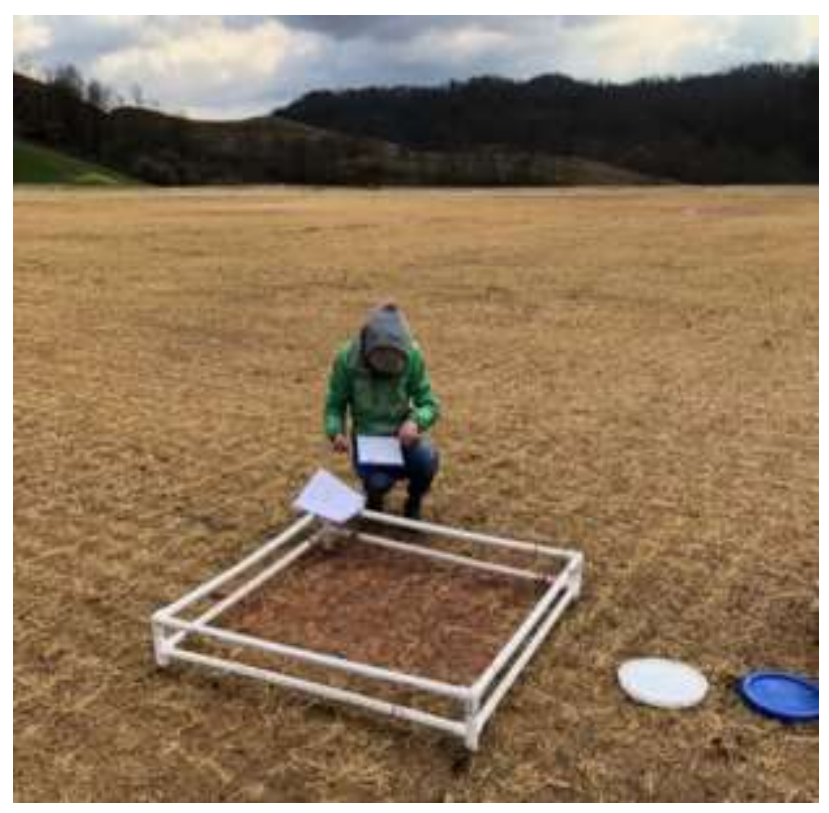

Figure 7. Portable Point Frame used for Ground Cover calculations. 


\subsubsection{Infiltration}

A Turf-Tec Infiltrometer IN2-W was used to discern the infiltration rate of the soils of the impoundment (Figure 8). The first reading was taken in the first hillslope section, and a second reading was measured at the crest of the impoundment between the second and third hillslopes. Prior to the site visit, the weather had been very rainy leaving the impoundment soil completely saturated. Ponding was observed. Due to these conditions, the water within the inner infiltration ring was never absorbed, and proper infiltration rates were unable to be determined.

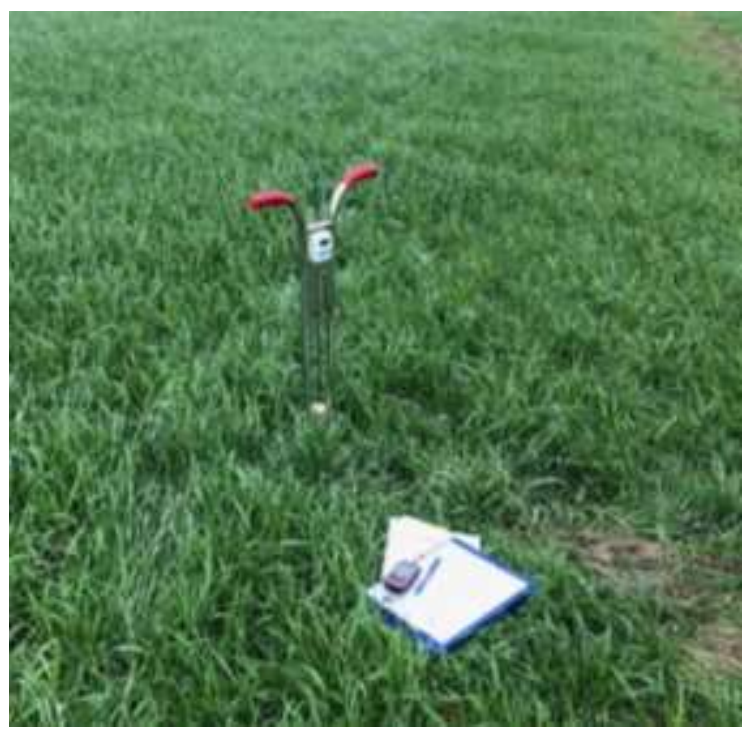

Figure 8. Turf-Tec Infiltrometer.

\subsubsection{Soil Samples}

At each sampling point in the three hillslopes, $15-\mathrm{cm}$ (6-in) deep soil samples were taken with a 6.4-cm (2.5-in) diameter soil auger once vegetation was removed. Five soil samples were collected from H1 due to its relatively smaller size, and ten samples were collected from each of the other hillslopes. Samples were combined in five-gallon buckets for each hillslope $(\mathrm{H} 1, \mathrm{H} 2$, and $\mathrm{H} 3)$ resulting in a composite sample for each experimental slope. In the geotechnical lab at West Virginia University, data was acquired from the moisture content, specific gravity, dry sieve, and hydrometer analysis tests determined in alignment with ASTM D2216 standard for moisture content, the specific gravity following the ASTM D854, the particle size analysis based upon the D422 standard, and the hydrometer analysis using the ASTM D7928. From this information, the distribution of soil particle size and percent soil composition could be determined. Finally, the soil was classified following the ASTM D2487.

Soil samples collected in November 2020 were also used to determine the percentage of organic content and cation-exchange capacity (CEC) of the soil. This test was conducted by the WVU Soil Testing 
Laboratory. The testing to determine the organic content and CEC of the soil followed the Loss on Ignition method.

\subsection{WEPP Methods}

Prior to the initiation of investigative field work, the WEPP Hillslope/Watershed Model Version 2012.800 computer software was utilized to determine estimated soil loss and erosion. To model the profile hillslopes, the impoundment was portioned into three portions according to the regrading and created water channels to ensure proper flow paths of precipitation and soil runoff (Figure 9).

Due to the modeling nature of WEPP, the organic shapes of the three hillslopes' dimensions were averaged into proportional rectangles (Figure 10 and Table 7). Hillslope 1 is averaged into a rectangular shape with dimensions of $146 \mathrm{~m}$ (480 ft) in length and $98 \mathrm{~m}$ (320 ft) in width. For Hillslope 2, the length

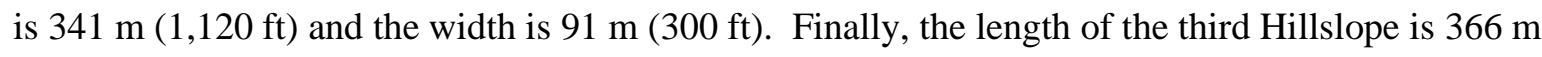
$(1200 \mathrm{ft})$ and $186 \mathrm{~m}(610 \mathrm{ft})$ in width. The total acreage of the impoundment is roughly $12 \mathrm{ha}(29 \mathrm{ac})$, and the total area of the rectangles is $11 \mathrm{ha}(28 \mathrm{ac})$. 


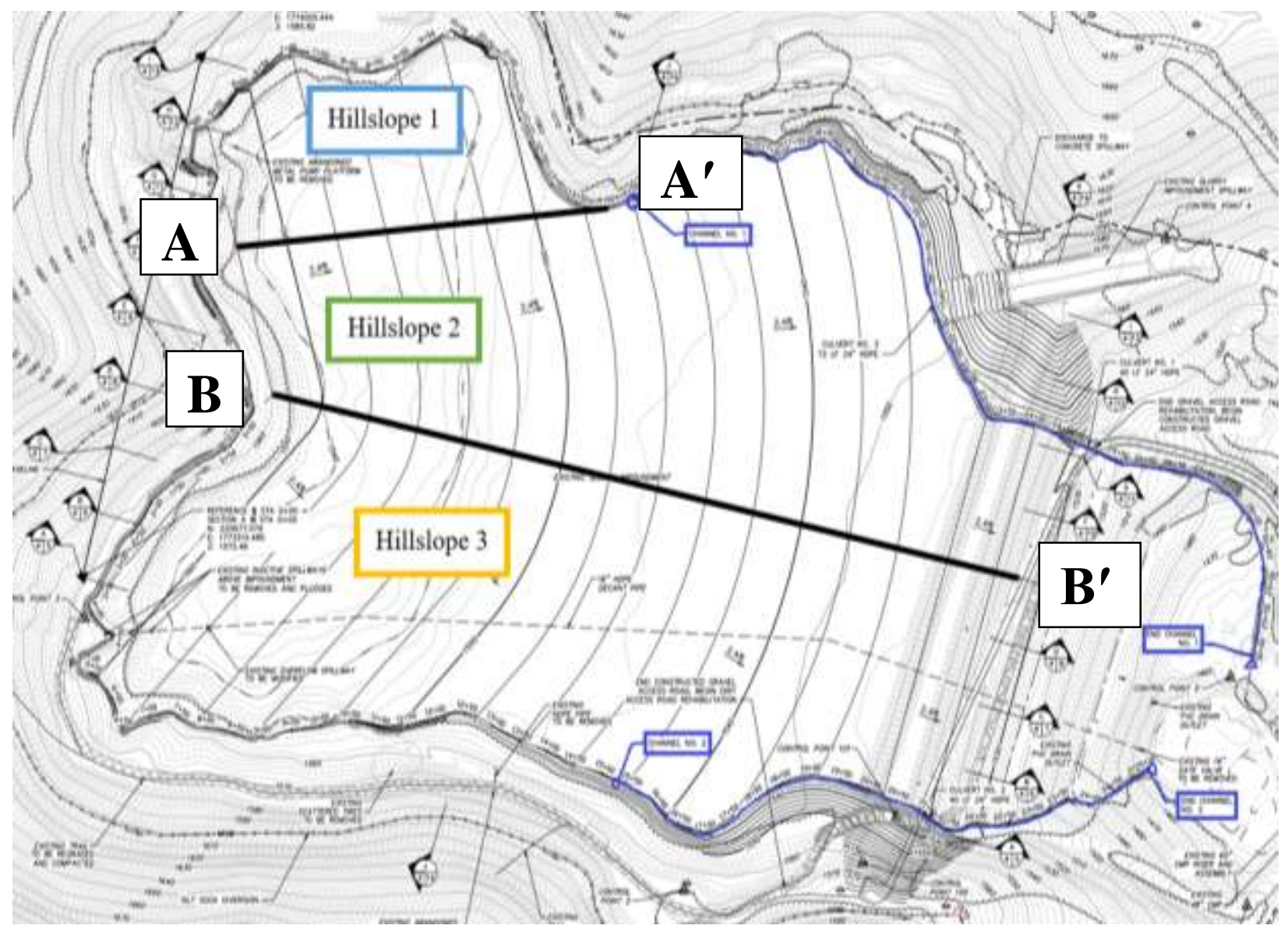

Figure 9. Division of the impoundment into three hillslopes. 


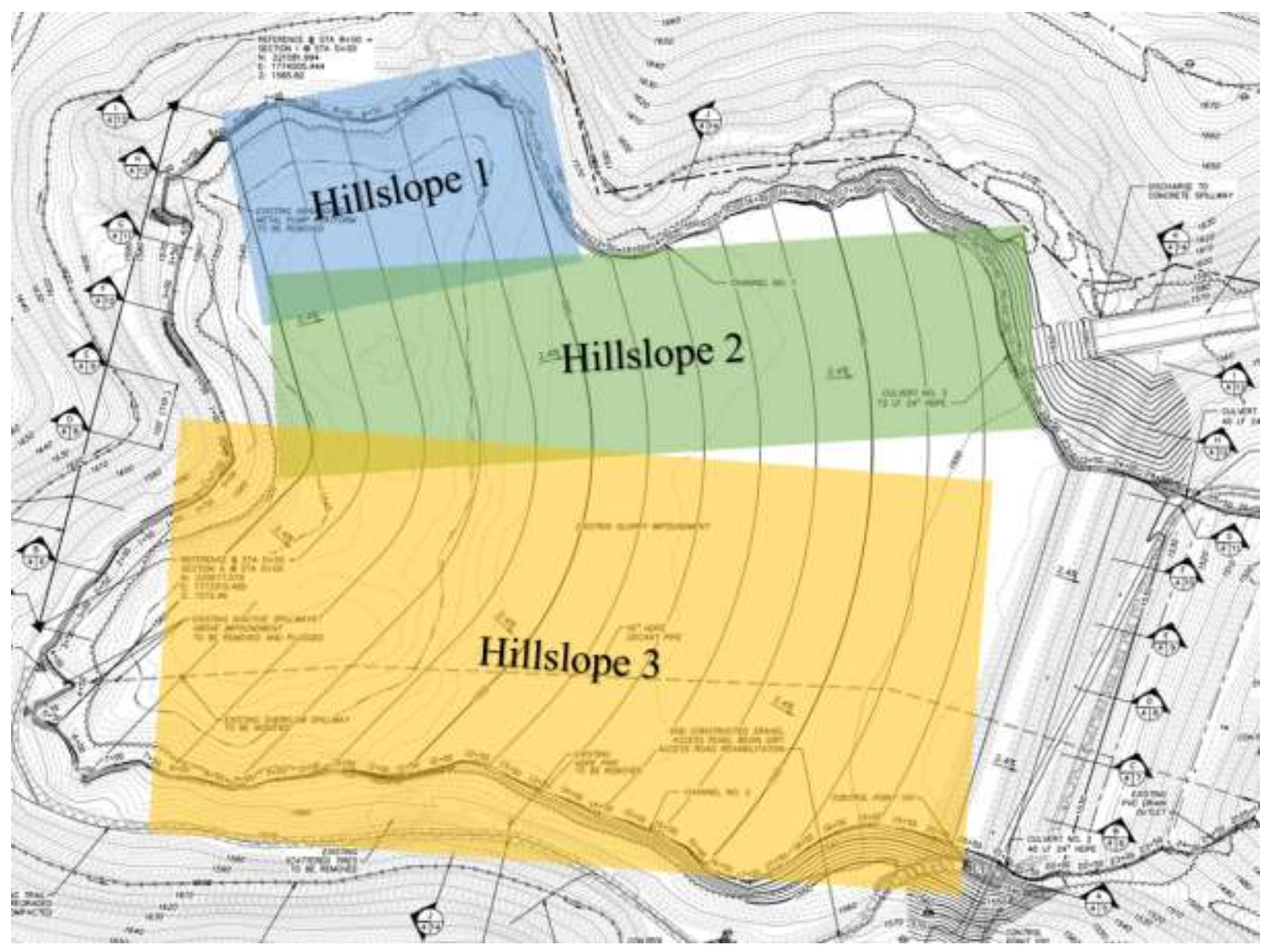

Figure 10. Rectangular areas of the individual hillslopes for WEPP modeling. 


\subsubsection{Model Inputs}

While three independent hillslope profiles were created for the different segments, the general settings for each profile are synonymous since they originate from the same environments such as the management of the land and slope profiles. The management is registered as grass covered based on the ground cover acquired from field collections. The slope is a mild, continuous $2.4 \%$ grade. These two layers compromise the top two profiles of the hillslopes. The registered depth of the topsoil is $304.8 \mathrm{~mm}(1 \mathrm{ft})$ (Table 7). The underlying soil conditions were determined after field collections and laboratory testing were conducted.

Table 7. WEPP inputs for the three separate hillslopes of the impoundment.

\begin{tabular}{|l|l|c|c|c|l|}
\hline Category & Input & H1 & H2 & H3 & Reference \\
\hline \multirow{4}{*}{ Hillslope Design } & Width, m (ft) & $98(320)$ & $91(300)$ & $186(610)$ & \\
\cline { 2 - 5 } & Length, m (ft) & $146(480)$ & $341(1120)$ & $366(1200)$ & WVDEP \\
\cline { 2 - 4 } & Slope (\%) & & 2.4 & \\
\cline { 2 - 4 } & Slope Profile & \multicolumn{3}{|c|}{ Uniform } & \\
\hline
\end{tabular}

\subsubsection{Soil Physical Composition and Classification}

Using soil samples from the three sections of the impoundment, the soil's grain size distribution was determined after conducting the sieve and hydrometer analyses and specific gravity. Finally, from the grain size distribution curve, the percentages of gravel, sand, silt, and clay were obtained for the following empirical equations, and the soil texture and classification were identified (Table 8).

\subsubsection{Erodibility, Conductivity and Albedo Values}

When evaluating the topsoil aspects of the impoundment, the soil parameters can be assigned according to the results from the previously mentioned physical testing and equations acquired from the WEPP User Summary produced by the USDA (Flanagan and Livingston 1995). These characteristics are modelled within the third layer in the hillslope profile of WEPP. The three hillslopes had slightly fluctuating characteristics due to variance in topsoil composition.

The erodibility parameters, including interrill erodibility $\left(K_{i}\right)$, rill erodibility $\left(K_{r}\right)$, and critical hydraulic shear $\left(\tau_{c}\right)$, where determined using the following equations:

$$
\begin{gathered}
K_{i}=2728000+192100 P_{V F S} \\
K_{r}=0.00197+0.0003 P_{V F S}+003863 \mathrm{e}^{\left(-1.83 P_{O M}\right)}
\end{gathered}
$$




$$
\tau_{c}=2.67+0.065 P_{C}-0.058 P_{V F S}
$$

where $P_{V F S}$ is the percentage of very-fine sand, $P_{O M}$ is the percent of organic matter, and $P_{C}$ is the percent of clay of the topsoil's composition.

The baseline effective conductivity $\left(K_{b}\right)$ was estimated for the three hillslopes using the equation for soils with $\leq 40 \%$ clay composition:

$$
K_{b}=-0.265+0.0086 P_{S}^{1.8}+11.46 C E C^{-0.75}
$$

where $P_{S}$ is the percent of sand content and $C E C$ is the cation-exchange of the soil measure in (meq/100g). It is important to note this value is not completely synonymous with the saturated conductivity. WEPP takes this difference into account by internally calculating the wetting front matric potential in relation to the soil type, moisture content, and bulk density (Flanagan and Livingston 1995).

Since the effective conductivity was baseline value determined from the soil's percentage calculation, the effective hydraulic conductivity $\left(K_{e}\right)$ was also cross calculated to ensure the individual $K_{b}$ values for each hillslope where in appropriate regions. The following equation was referenced from the WEPP User Summary (Flanagan and Livingston 1995):

$$
K_{e}=\frac{56.82 K_{e f}^{0.286}}{1+0.051 \mathrm{e}^{0.062 C N}}-2
$$

where $K_{e f}$ is the adjusted effective hydraulic conductivity of fallow soil in relation to the hydrologic soil group and management practice, and $C N$ is the curve number of the impoundment obtained from the USDA's Urban Hydrology for Small Watersheds (1986). The hydrologic soil group was identified as Group B from the USDA, NRCS's National Engineering Handbook (2009) due to its percent clay ranging between $10-20 \%$, the percent sand being between $50-90 \%$ and the texture being sandy loam.

Soil albedo is the quantified fraction of solar radiation that reflects off the ground surface and back into the atmosphere measured on a scale from zero to one. Within WEPP, the albedo value creates an estimate for the net radiation landing on the soil's surface which is then applied to the internal evapotranspiration calculations. WEPP can then adjust the albedo under the effects of soil moisture, vegetation, residue, and snow cover (Flanagan and Livingston 1995).

The soil albedo $(S)$ for a dry surface can be calculated using the following equation:

$$
S=\frac{0.6}{\mathrm{e}^{\left(0.4 P_{O M}\right)}}
$$

where the $P_{O M}$ is the percent of organic matter in the surface soil. 
Table 8. Soil characteristic inputs for WEPP hillslope modeling.

\begin{tabular}{|c|c|c|}
\hline Soil Characteristic & Description & Reference \\
\hline Texture & Soil sample analysis & ASTM D2487 \\
\hline Albedo & Empirical equation 5 & \multirow{6}{*}{ Flanagan and Livingston 1995} \\
\hline Initial Saturation Level (\%) & Assumed from reference text & \\
\hline Interrill Erodibility $\left(\mathrm{kg} \mathrm{s} / \mathrm{m}^{4}\right)$ & Empirical equation 1 & \\
\hline Rill Erodibility (s/m) & Empirical equation 2 & \\
\hline Critical Shear (Pa) & Empirical equation 3 & \\
\hline $\begin{array}{l}\text { Effective Hydraulic } \\
\text { Conductivity (mm/hr) }\end{array}$ & Empirical equation 4 & \\
\hline Depth (mm) & Site design plans & WVDEP 2018 \\
\hline Sand $(\%)$ & \multirow{3}{*}{ Soil sample analysis } & ASTM D422-63 \\
\hline Clay (\%) & & ASTM D854-10 \\
\hline Rock (\%) & & ASTM D2216-10 \\
\hline Organic (\%) & Loss on ignition method & \multirow[b]{2}{*}{ WVU Soil Testing Laboratory } \\
\hline CEC (meq/100g) & $\begin{array}{l}\text { Calculated from elemental } \\
\text { composition }\end{array}$ & \\
\hline
\end{tabular}

\subsubsection{Management}

The recorded seed mixes were acquired from the West Virginia Department of Environmental Protection. Due to limitations of the internally registered perennial grasses within WEPP, a long-term management plan was created to incorporate extended growth of the ryegrass mix. As of now, the landowner plans to use the parcel of land for their cattle farming. With this plan, it can be assumed the property will not experience annual tillage, and the seed mix will be cultivated long-term.

\subsubsection{Model Scenarios}

To obtain a broader understanding of the long- and short-term effects the local climate will have on the amounts of annual soil loss of the impoundment, several different climate scenarios were obtained and utilized within the WEPP modeling software. The climate models include future climates that incorporate the continual and inevitable effects climate change will have on the local weather and a smaller, more current time frame to understand the immediate effects of the local climate has on soil loss. 


\subsubsection{Short Term Climate Modeling}

To understand the immediate erosion effects the impoundment will experience, a single storm simulation was carried out in WEPP. For this simulation, all the soil and physical parameters inputs required the same. To understand the effects of the regional climate most immediately in the form of single storms, Technical Release (TR)-55 single storm modeling was conducted internally within WEPP. Point precipitation frequency estimates created from annual maxima series-based precipitation frequency estimates with $90 \%$ confidence intervals for 24-hour durations were acquired from the Hydrometeorological Design Studies Center of the National Oceanic and Atmospheric Administration (NOAA)'s National Weather Service (2017). The precipitation amounts for 2-, 5-, 10-, 25-, 50-, 100-, and 500-year frequencies sourced from the weather station in Philippi, WV were exported into WEPP to create individual TR-55 single storm climate input files.

\subsubsection{Future Climate Modeling}

WEPP uses Climate Generator (CLIGEN) input files to apply climate variables to study areas (Trotochaud et al. 2016). Creating the future climate models was undertaken using Trotochaud's Instructional Manual (2014). This method uses the MarkSim DSSAT Weather Generator to create continuous climate data from the Markov Chain process calibrated with the WorldClim dataset. This process uses data based on past recordings from the National Oceanic and Atmospheric Administration's National Climate Data Center Global Historical Climatology Network (NOAA NCDC GHCN) past weather data (Trotochaud et al. 2016).

Trotochaud (2014) also created an extensive macrobook within Microsoft Excel to aid in computing the data collected from the MarkSim DSSAT weather file generator. Trotochaud notes how the MarkSim creates projected weather data by creating daily weather data that is partitioned equally in half with the earlier portion leading up to the desired future data and the other half coming chronologically after the date of interest to create a more accurate time slice around the future data of interest. The farthest date in the future the MarkSim can project to is 2095, so six 15-year time slices were created beginning with 2020 and following in the years 2035, 2050, 2065, 2080, and finally 2095.

Once the data were collected for each of these time slices, it was uploaded into the Excel macroworld to create the corresponding CLIGEN input files. With these six predictive climate files created, they can be uploaded into the WEPP hillslope models for each of the three hillslopes within the impoundment. 


\section{Chapter 4. Results and Discussion}

\subsection{Ground Cover}

After the impoundment was regraded, a permanent seed mixture was planted. This mixture was composed of 20\% Orchardgrass (Dactylis glomerata), 20\% Birdsfoot Trefoil (Lotus corniculatus), 13\% Red Clover (Trifolium pratense), 20\% Annual Ryegrass (Lolium multiflorum), 1\% Bicolor Lespedeza (Lespedeza biocolor), and 26\% Malabar Wheat (Triticum asetivum). In accordance with WV's Erosion and Sediment Control Best Management Practice Manual (2016), ground cover should be not less than $70 \%$ to ensure effective erosion control. As of November of 2020, the site was relatively evenly distributed with healthy, young vegetation establishment and some patches of bare ground with straw dusting. Each of the hillslopes had adequate ground cover, $89.6 \% 92.9 \%$, and $80.5 \%$ between hillslopes 1, 2, and 3, respectively (Figure 11 and 12).

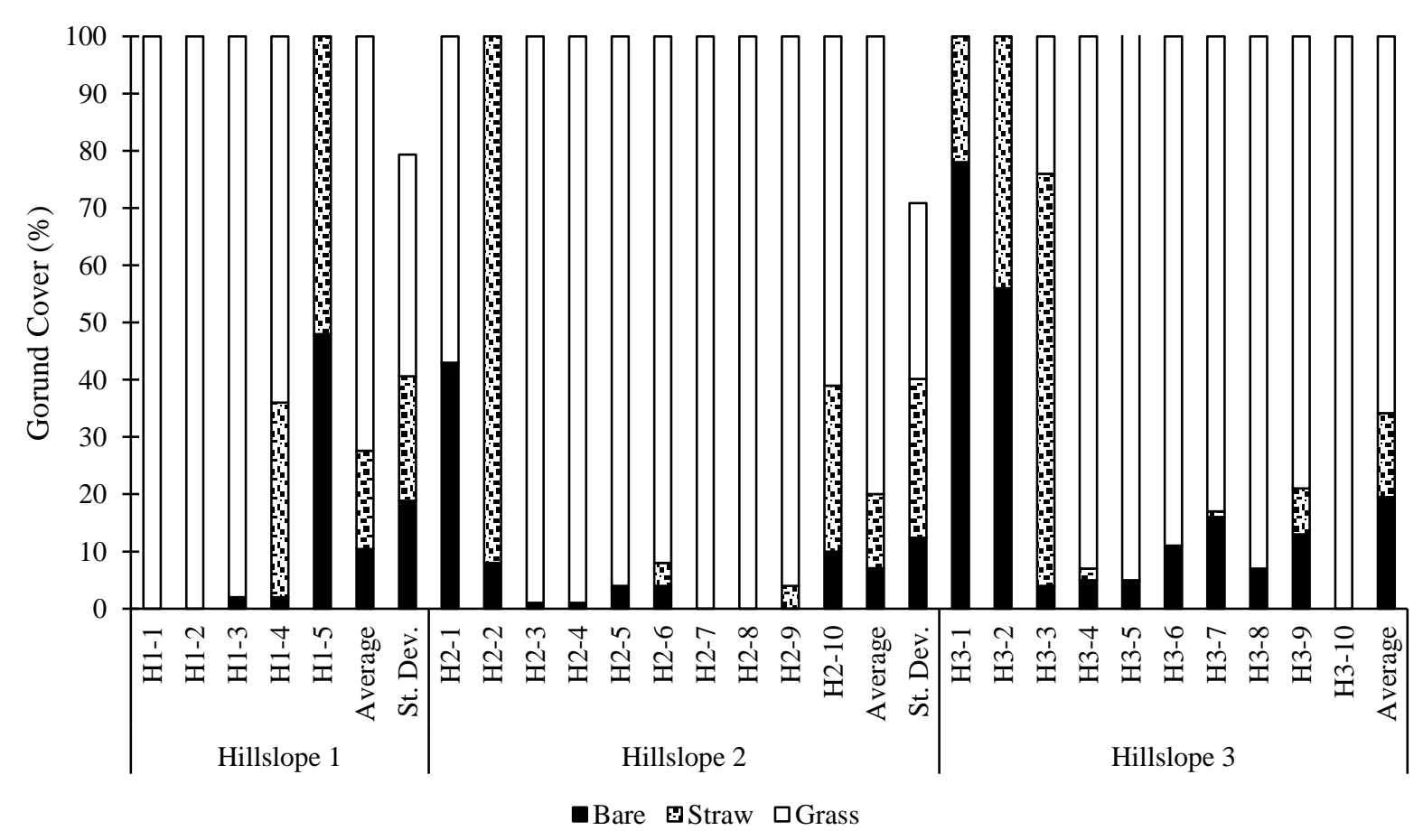

Figure 11. Collective grass, straw, and bare ground percentages from each sample point of the three hillslopes. 


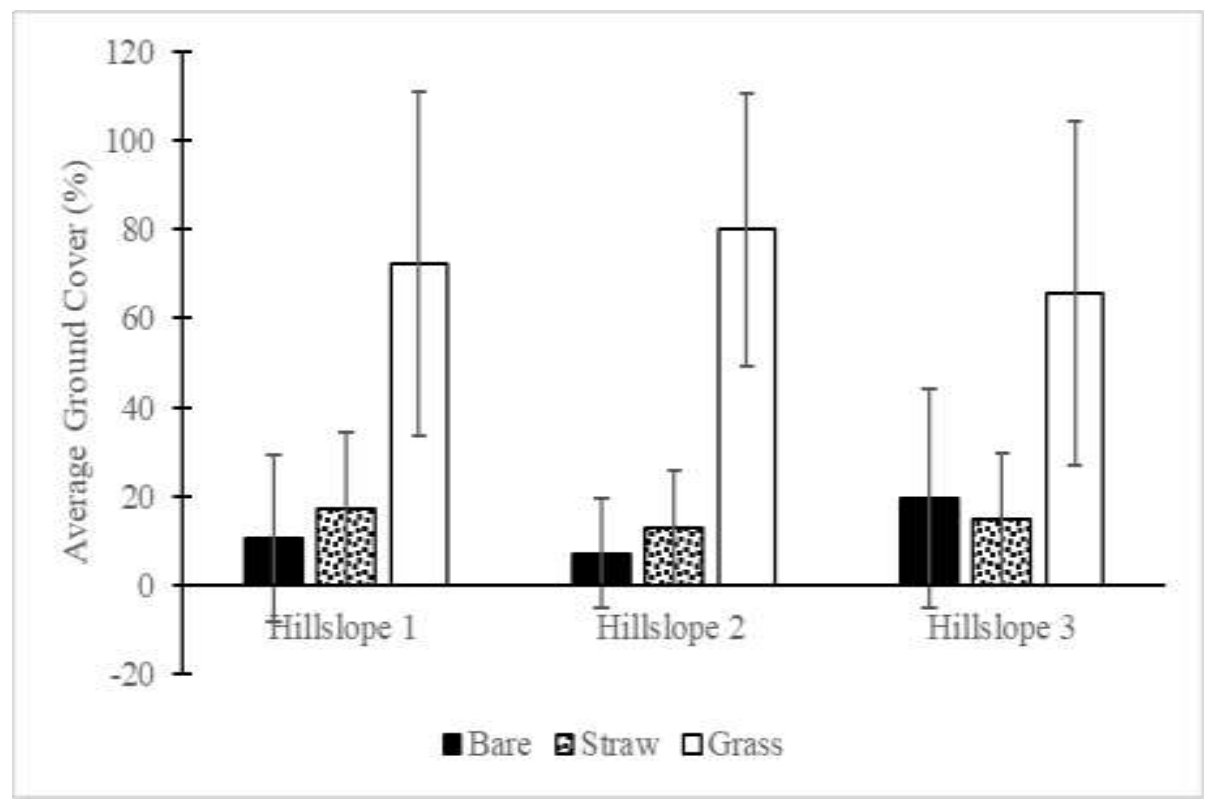

Figure 12. Averaged percentages of grass, straw, and bare coverages for the three hillslopes.

\subsection{Soil Characteristics}

\subsubsection{Grain Size Distribution}

From the soil analysis tests conducted in the WVU Geotechnical Soils Lab, it was decided that the soil samples from the three hillslope divisions were similar enough to all be classified as a sandy loam.

Hillslope 1 contained $64 \%$ sand, $15.4 \%$ very fine sand (VFS), $1.2 \%$ silt, and $17.3 \%$ clay. Hillslope 2 was composed of 55.6\% sand, 23.1\% VFS, 2.2\% silt, $19.6 \%$ clay. Hillslope 3 samples were 55\% sand, $19.8 \%$ VFS, $2.5 \%$ silt, and $22.2 \%$ clay. 


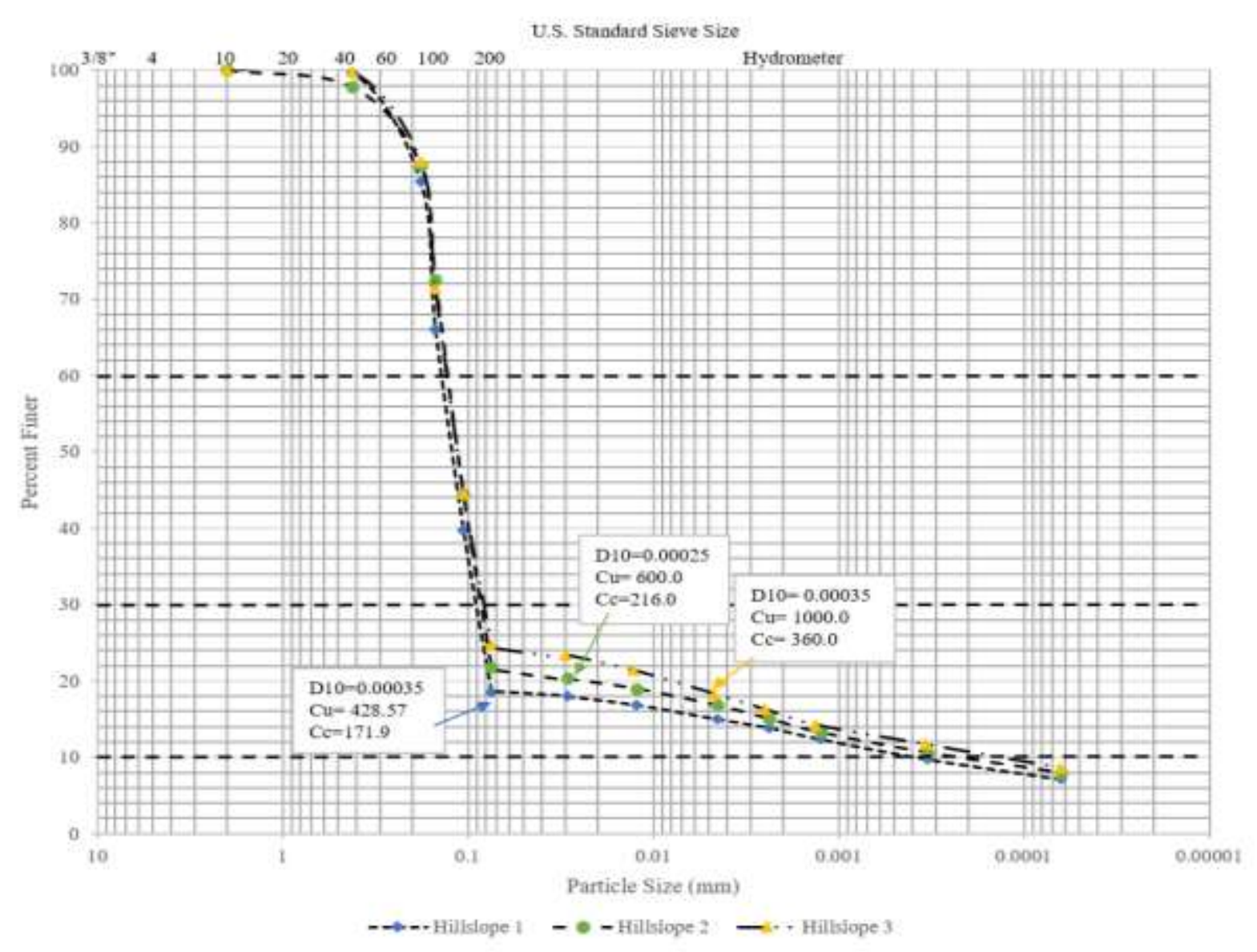

Figure 13. Grain size distributions of the three hillslopes with respective coefficients of uniformity $\left(C_{u}\right)$, curvature $\left(C_{c}\right)$, and effective particle size $\left(D_{10}\right)$.

To have a better understanding of how the clay portion of the soil samples would affect the characteristics of dispersion, a double hydrometer analysis was undertaken (Figure 14). The percent dispersion was calculated from the ratio of percentages of dry soil passing the $0.005 \mathrm{~mm}$ diameter of the sample lacking the chemical dispersant (sodium hexametaphosphate solution) and the soil sample with the dispersing agent (Knodel 1991, ASTM D422-63 2007). With a percent dispersion of 89\%, the soil can be classified as a dispersive clay. Knowing the degree of disperison provides insight into the mechanical characteristics of the soil material. Therefore this soil with high dispersion will have proportionally lower shear strength, stability, and permeability in comparison to more aggregated clays. Dispersive characteristics also tend to have higher shrink-swell potential (ASTM D4221-11). 


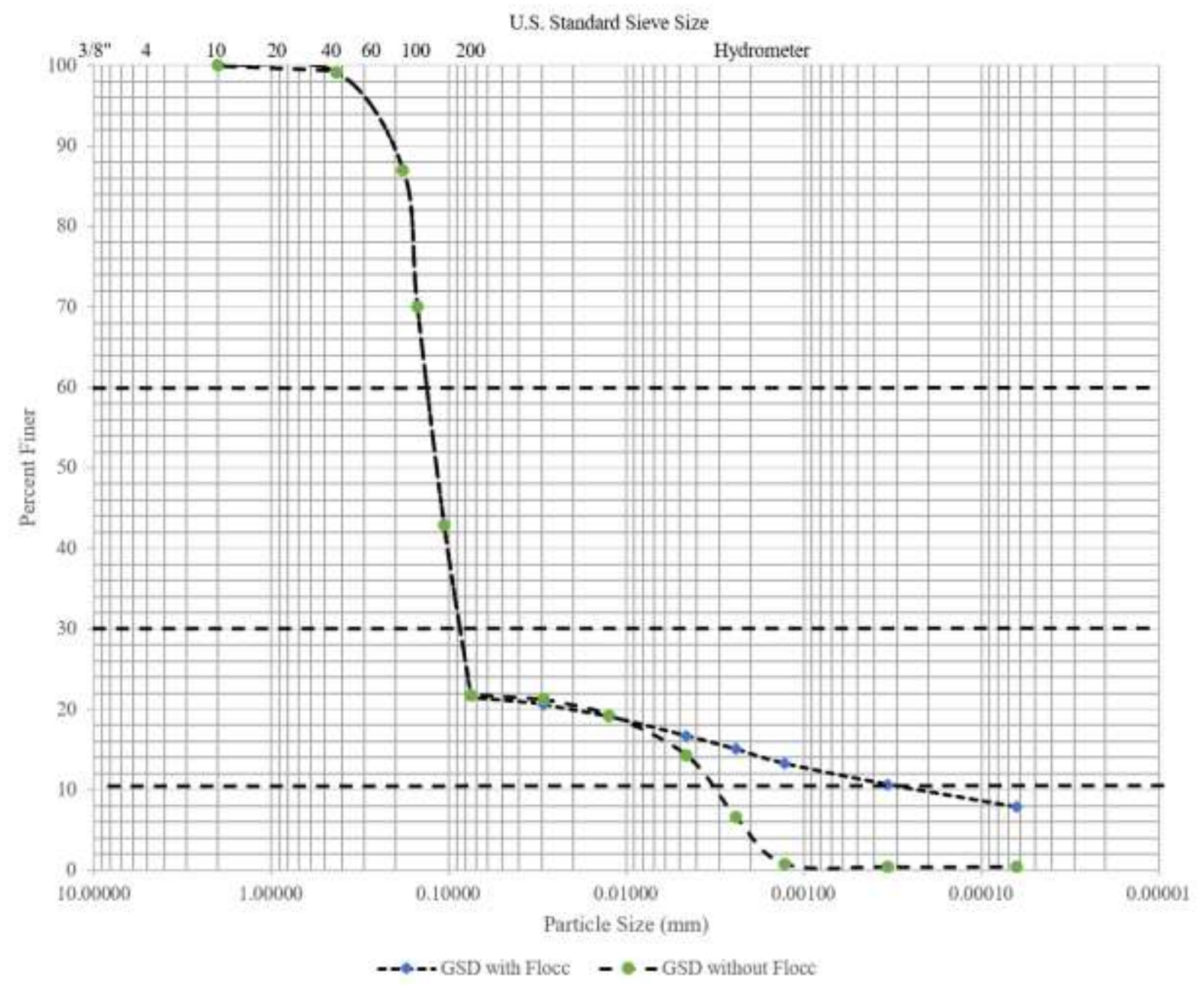

Figure 14. Double hydrometer test of the impoundment soils to discern dispersive qualities. 


\subsection{WEPP}

\subsubsection{Modeling Layout}

The WEPP model consists of a three-tier system where the top layer represents the management of the topsoil (vegetation growth or the lack thereof). The second layer models the physical and slope design, and the third layer represents the soil characteristics (Figure 15). Note that the WEPP layout is not to scale.

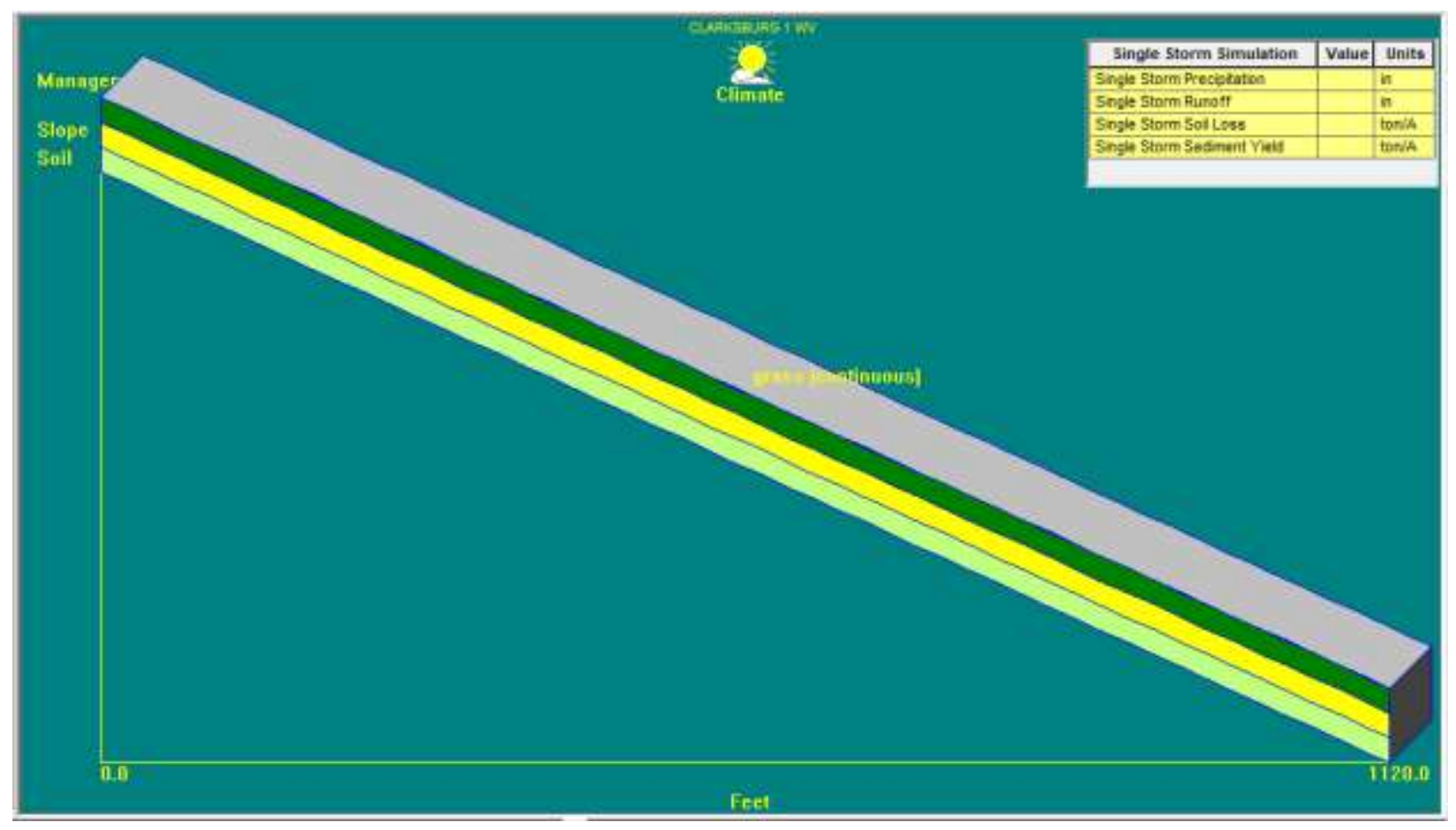

Figure 15. Example of the WEPP modeling window of Hillslope 2 (Model not to scale). 


\subsubsection{Model Inputs}

After the soil parameters were identified, the soil characteristics were calculated and input into the WEPP model (Table 9).

Table 9. Specific inputs of the impoundment used in the WEPP modeling.

\begin{tabular}{|c|c|c|c|c|}
\hline \multirow{2}{*}{ Category } & \multirow{2}{*}{ Input } & \multicolumn{3}{|c|}{ Description } \\
\hline & & H1 & H2 & H3 \\
\hline \multirow{4}{*}{ Hillslope Design } & Width, m (ft) & $98(320)$ & $91(300)$ & $186(610)$ \\
\hline & Length, $\mathrm{m}$ (ft) & $146(480)$ & $341(1120)$ & $366(1200)$ \\
\hline & Slope (\%) & \multicolumn{3}{|c|}{2.4} \\
\hline & Slope Profile & \multicolumn{3}{|c|}{ Uniform } \\
\hline \multirow{15}{*}{ Soil Characteristics } & Soil Texture & \multicolumn{3}{|c|}{ Sandy Loam } \\
\hline & Albedo & 0.16 & 0.09 & 0.13 \\
\hline & $\begin{array}{l}\text { Initial Saturation Level } \\
(\%)\end{array}$ & 90 & 90 & 90 \\
\hline & Interrill Erodibility, & $4,720,013$ & $5,708,919$ & $5,279,016$ \\
\hline & $\mathrm{kg} \mathrm{sec} / \mathrm{m}^{4}\left(\mathrm{lb} \mathrm{sec} / \mathrm{ft}^{4}\right)$ & $(89,798)$ & $(108,612)$ & $(100,433)$ \\
\hline & Rill Erodibility, & 0.006688 & 0.008903 & 0.007928 \\
\hline & $\mathrm{s} / \mathrm{m}(\mathrm{s} / \mathrm{ft})$ & $(0.00204)$ & $(0.00271)$ & $(0.00242)$ \\
\hline & Critical Shear, Pa (psi) & $\begin{array}{l}2.90216 \\
(0.00042)\end{array}$ & $\begin{array}{c}2.60413 \\
(0.00038)\end{array}$ & $\begin{array}{c}2.96887 \\
(0.00043)\end{array}$ \\
\hline & $\begin{array}{l}\text { Effective Hydraulic } \\
\text { Conductivity, } \\
\text { mm/hr (in/hr) }\end{array}$ & $\begin{array}{l}32.35 \\
(1.27)\end{array}$ & $\begin{array}{l}31.97 \\
(1.26)\end{array}$ & $\begin{array}{l}31.47 \\
(1.24)\end{array}$ \\
\hline & Depth, mm (in) & \multicolumn{3}{|c|}{$304.8(12)$} \\
\hline & Sand $(\%)$ & 79.43 & 78.69 & 75.26 \\
\hline & Clay (\%) & 17.34 & 19.59 & 22.23 \\
\hline & Rock (\%) & 0.0 & 0.0 & 0.0 \\
\hline & Organic (\%) & 3.3 & 4.8 & 3.9 \\
\hline & CEC (meq/100g) & 1.2 & 1.2 & 0.2 \\
\hline
\end{tabular}




\subsubsection{Single Storm}

Across the three hillslopes, the amounts of precipitation runoff and soil loss were nearly identical (Table 10). The differences most likely originate from the total area differences as well as the slight variance in the soil characteristic composition. Collectively, the annual soil loss can be predicted to be 0.36 tonnes ( 0.397 tons) for a two-year return period, 0.60 tonnes ( 0.661 tons) for a five-year return period, 0.80 tonnes ( 0.879 tons) for a 10-year return period, 1.13 tonnes (1.245 tons) during a 25 -year return period, 1.44 tonnes (1.588 tons) from a 50-year event, 1.74 tonnes (1.922 tons) during a 100-year event, and finally a total of 2.29 tonnes (2.525 tons) of soil lost during a 500-year return event from the impoundment.

Table 10. TR-55 Single storm predictions for the individual hillslopes.

\begin{tabular}{|c|c|c|c|c|c|c|c|}
\hline \multirow{2}{*}{ Return Period (yr) } & \multirow{2}{*}{ Precipitation (cm) } & \multicolumn{3}{|c|}{ Runoff (cm) } & \multicolumn{3}{c|}{ Soil Loss (tonnes/ha) } \\
\cline { 3 - 8 } & & H1 & H2 & H3 & H1 & H2 & H3 \\
\hline 2 & 6.05 & 2.72 & 2.74 & 2.74 & 0.28 & 0.31 & 0.30 \\
\hline 5 & 7.77 & 3.76 & 3.78 & 3.78 & 0.48 & 0.51 & 0.49 \\
\hline 10 & 8.99 & 4.50 & 4.52 & 4.52 & 0.63 & 0.69 & 0.65 \\
\hline 25 & 10.64 & 5.51 & 5.51 & 5.51 & 0.88 & 0.99 & 0.92 \\
\hline 50 & 11.94 & 6.30 & 6.30 & 6.30 & 1.11 & 1.27 & 1.18 \\
\hline 100 & 13.28 & 7.80 & 7.82 & 7.82 & 1.35 & 1.52 & 1.44 \\
\hline 500 & 16.66 & 10.52 & 10.54 & 10.57 & 1.72 & 2.03 & 1.91 \\
\hline
\end{tabular}

\subsubsection{Long-term Modeling}

\subsubsection{Pasture Management Modeling}

For the future predictions of soil loss from the impoundment, the climate-variant models were utilized for the climate inputs. Each of the six models $(2020,2035,2050,2065,2080$, and 2095) were individually used as climate models for the WEPP modeling when investigating the soil loss under the pasture conditions. This modeling was created to estimate predictions of the impoundment if the current agricultural practices continue till the end of the century.

It should be noted that the sediment erosion is measured as soil detached that considers the changing climate and is evaluated based on annual averaged values. To determine the amount of soil leaving the impoundment, the sediment delivery ratio (SDR) of 0.65 could be applied to the detached sediment quantities (Roehl 1962). 


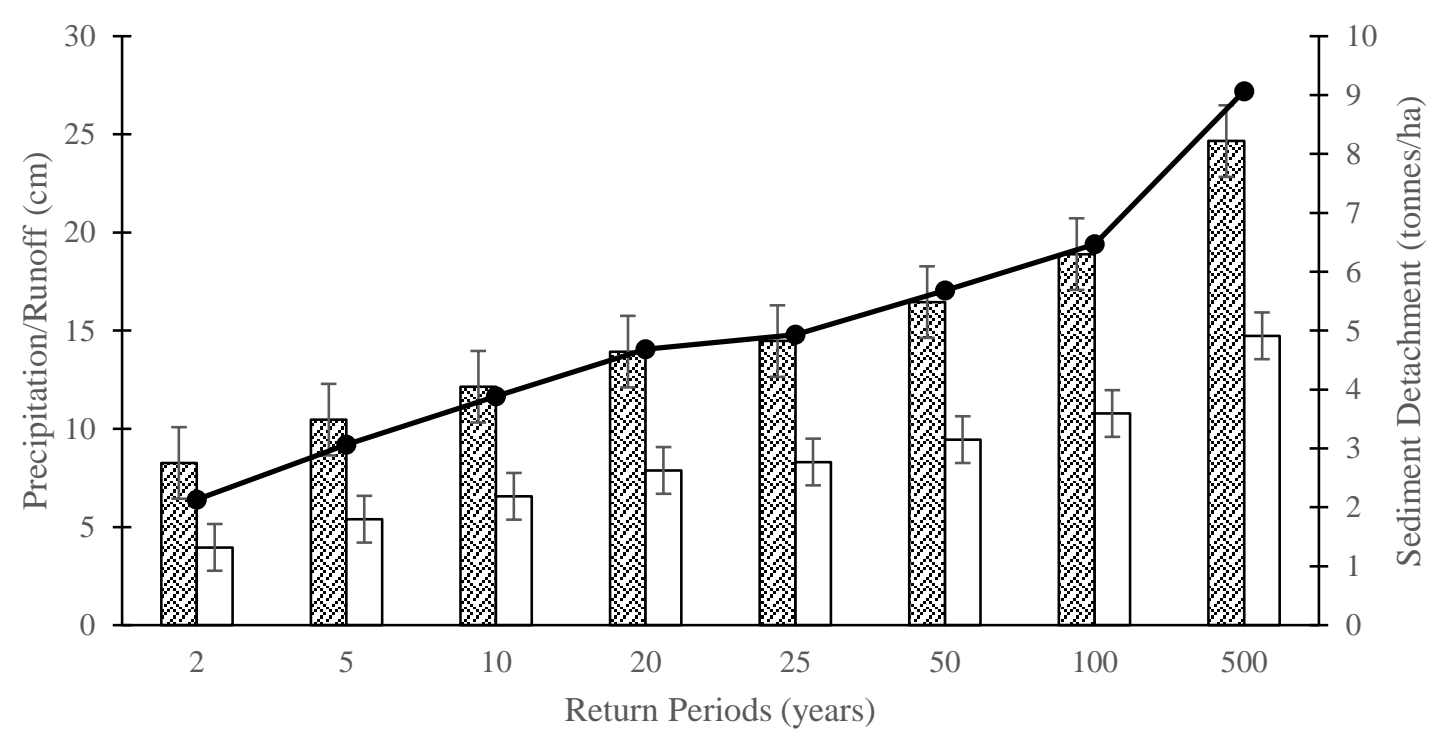

एRorrecipitation $\square$ Runoff $\longrightarrow$ Sediment Detachment

Figure 16. Future predictions for Hillslope 1 under pasture management $(n=6)$.

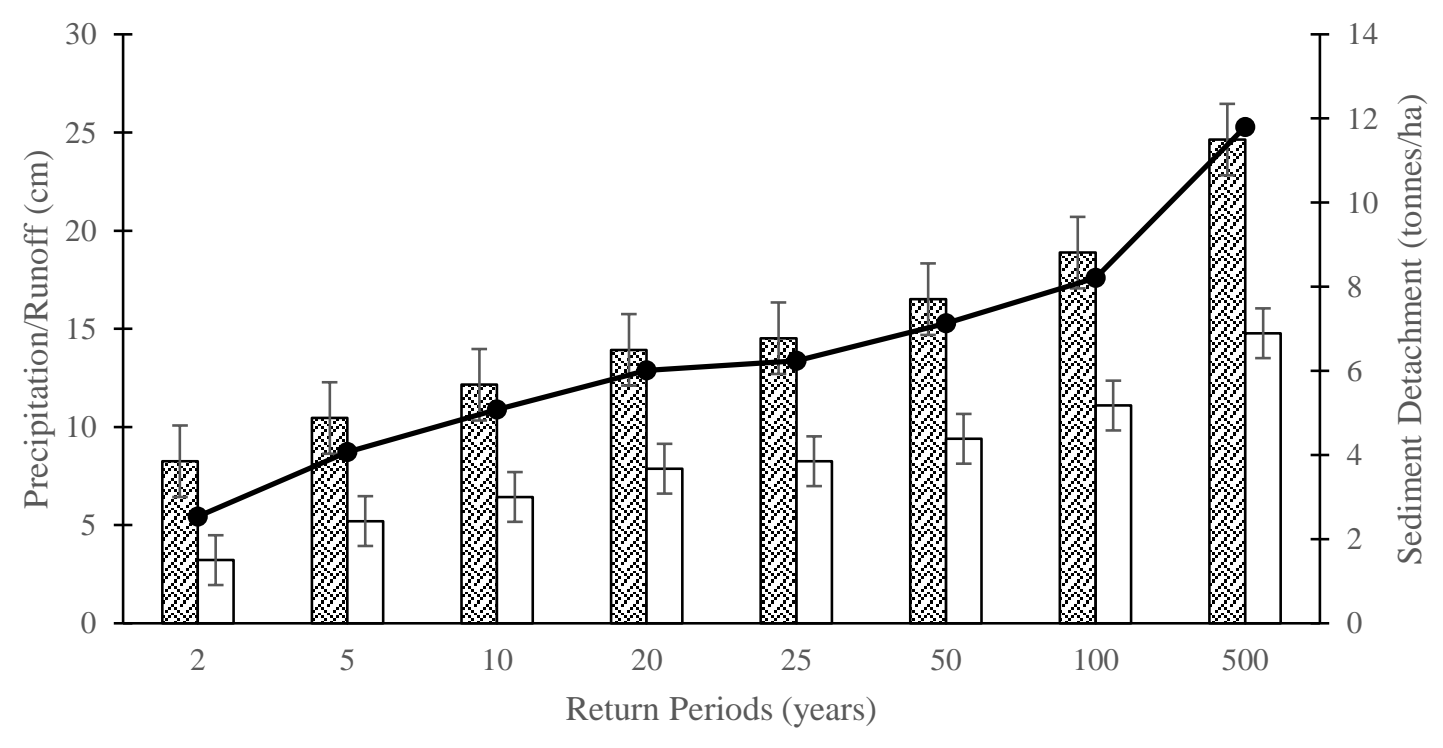

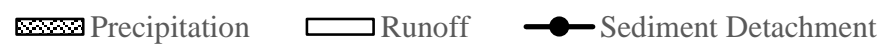

Figure 17. Future predictions for Hillslope 2 under pasture management (n=6). 


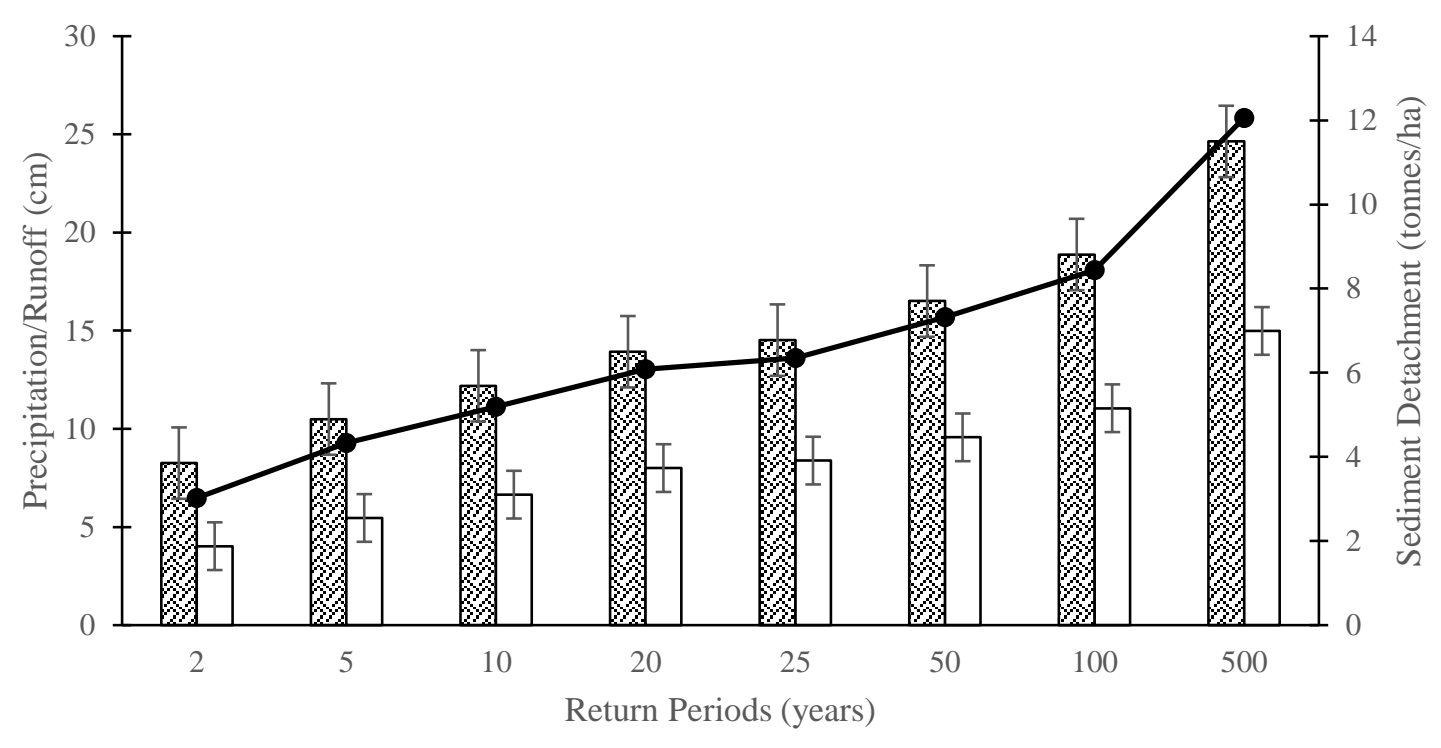

ש\%०D Precipitation $\square$ Runoff $\quad$ Sediment Detachment

Figure 18. Future predictions for Hillslope 3 under pasture management (n=6).

\subsubsection{Reestablished Forest Management Predictions}

Should the reestablished impoundment not be maintained long-term as an agricultural pasture, additional modeling was created to estimate the soil loss under forested conditions. For this modeling, the 2095 climate prediction model was used as the climate input.

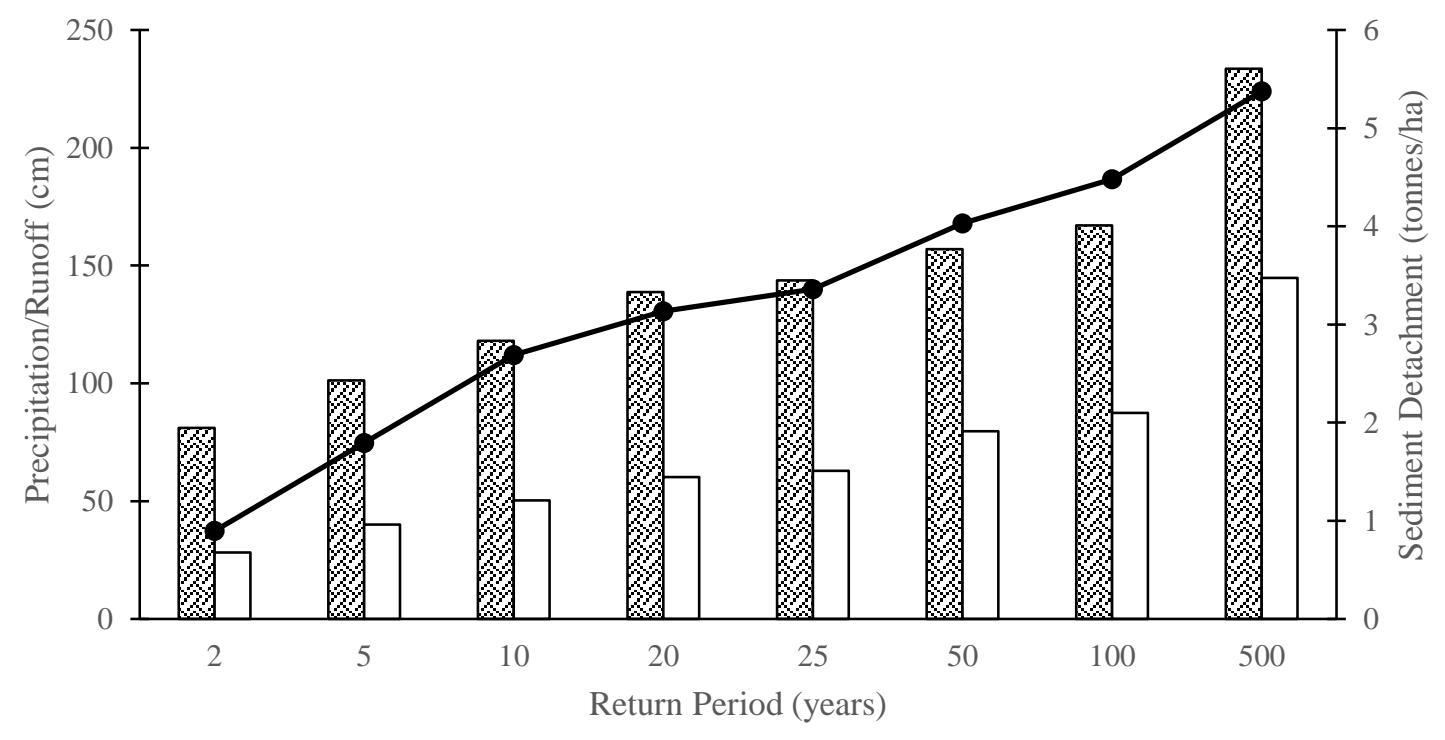

ॠ Precipitation $\square$ Runoff $\rightarrow$ Sediment Detachment

Figure 19. Forested impoundment future predictions of Hillslope 1. 


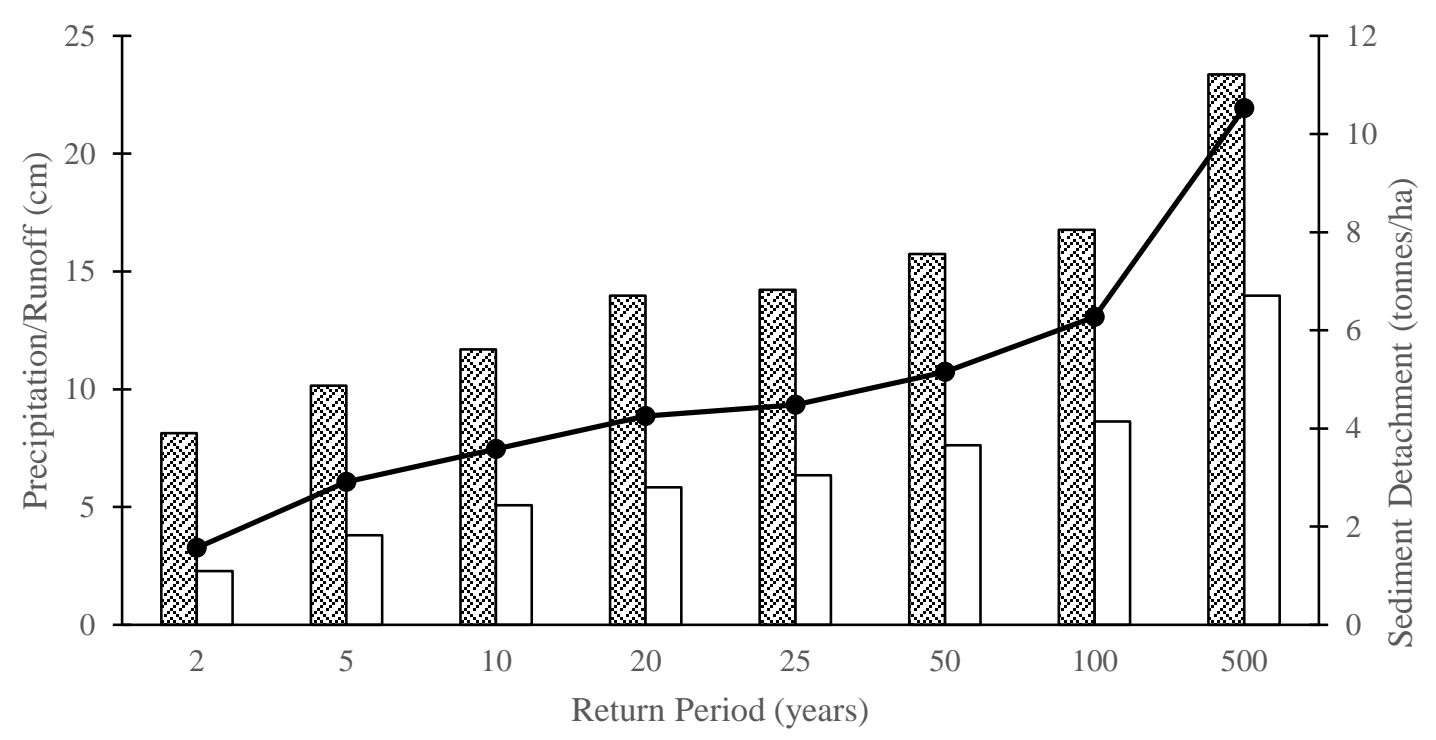

$\square$ Precipitation $\square$ Runoff $\longrightarrow$ Sediment Detachment

Figure 20. Forested impoundment future predictions of Hillslope 2.

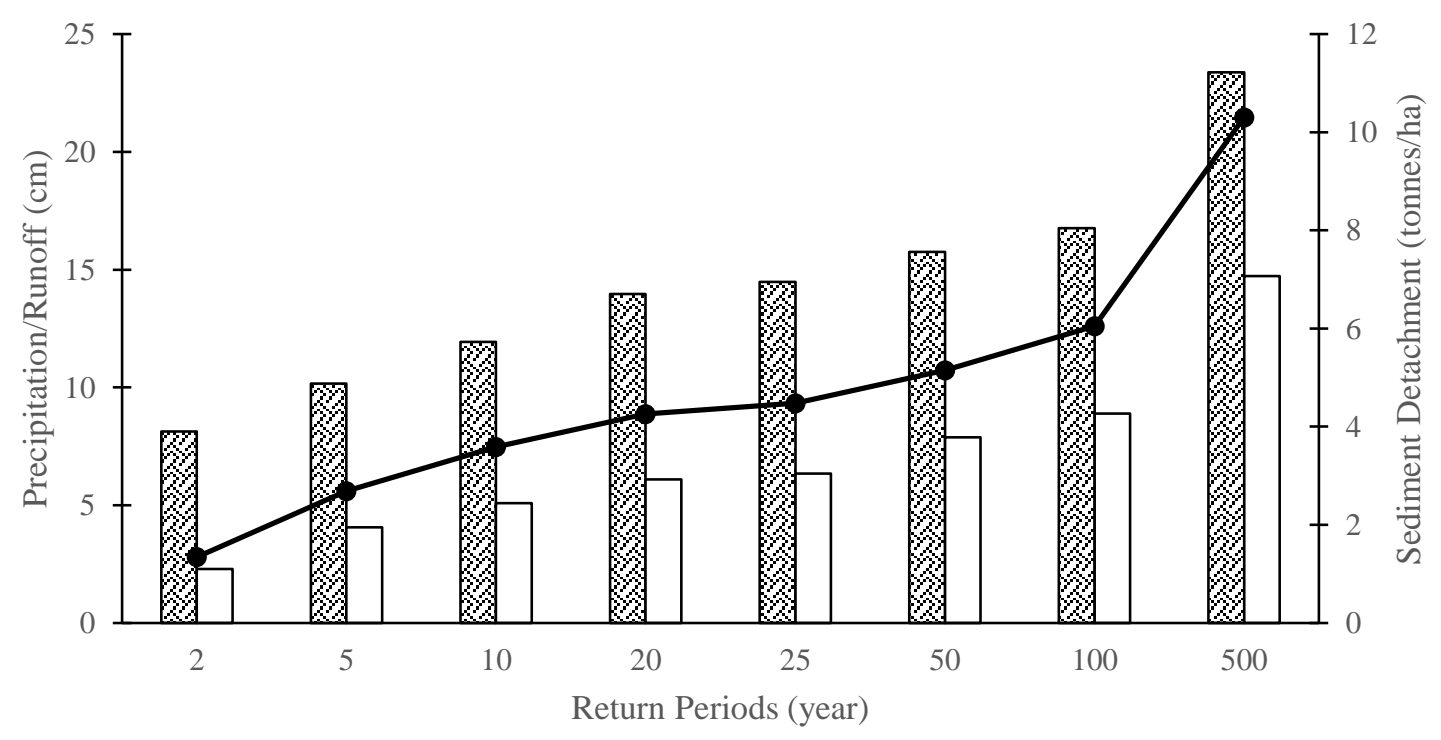

ॠ Precipitation $\square$ Runoff $\longrightarrow$ Sediment Detachment

Figure 21. Forested impoundment future predictions of Hillslope 3. 


\subsection{Discussion}

Overall, the future model of the impoundment reclaimed by forest conditions will be able to retain more soil due to the cohesive properties the underlying root systems provide along with the aerial coverage the tree canopies offer to aid in the obstruction of the direct impact of the precipitation. For the 2-, 5-, 10-, 20-, 25-, 50-, and 100-year return periods, the forested impoundment would shed less precipitation in runoff volumes (Table 11). During a 500-year event however, the precipitation runoff of the forested impoundment would exceed that of a maintained pasture condition. When evaluating the impoundment collectively with the three hillslopes combined with weighted averages, the model maintaining open pasture vegetation conditions will experience a greater amount of sediment detachment during each of the return periods (Table 12).

Table 11. Average runoff volume leaving the impoundment (centimeters).

\begin{tabular}{|l|c|c|c|c|c|c|c|c|}
\hline & \multicolumn{8}{|c|}{ Return Period (year) } \\
\hline Management & $\mathbf{2}$ & $\mathbf{5}$ & $\mathbf{1 0}$ & $\mathbf{2 0}$ & $\mathbf{2 5}$ & $\mathbf{5 0}$ & $\mathbf{1 0 0}$ & $\mathbf{5 0 0}$ \\
\hline Pasture & 3.6 & 5.1 & 6.3 & 7.6 & 8.0 & 9.1 & 10.6 & 14.3 \\
\hline Forested & 2.4 & 4.0 & 5.1 & 6.0 & 6.4 & 7.8 & 8.8 & 14.5 \\
\hline
\end{tabular}

Table 12. Average sediment detachment (tonnes/hectares).

\begin{tabular}{|l|c|c|c|c|c|c|c|c|}
\hline & \multicolumn{8}{|c|}{ Return Period (year) } \\
\hline Management & $\mathbf{2}$ & $\mathbf{5}$ & $\mathbf{1 0}$ & $\mathbf{2 0}$ & $\mathbf{2 5}$ & $\mathbf{5 0}$ & $\mathbf{1 0 0}$ & $\mathbf{5 0 0}$ \\
\hline Pasture & 2.8 & 5.1 & 6.3 & 7.6 & 8.0 & 9.1 & 10.6 & 14.3 \\
\hline Forested & 1.3 & 2.6 & 3.5 & 4.1 & 4.3 & 5.0 & 5.9 & 9.7 \\
\hline
\end{tabular}

Due to the minimal degree of percent rise of the slope (i.e., 2.4\%), it can be predicted that the impoundment will not experience copious amounts of soil loss for the foreseeable future as long as the vegetation cover is maintained. Due to the invaluable importance of healthy vegetation in relation to the prevention of soil erosion, measures should be taken to reestablish the minimum ground cover (WVDEP 2016). If deterioration of vegetation occurs, redistribution of permanent seed mixture in addition to the topical application of potassium and phosphorus fertilizers should be applied to the impoundment. 


\section{Chapter 5: Conclusion}

To ensure the sustainable use of one of West Virginia's precious resources, preservation and conscientious consumption do not solely lie in the extraction process of coal but transcends further into the long-term management and environmental preservation of where it was taken from and where the residual waste returns to. This thesis focused on the following main topics: i) the dewatering process of acid mine drainage (AMD) sludge, and ii) an investigation of soil loss predictions of a decommission coal refuse impoundment. Major conclusions for each main topic are discussed in the following sections.

\subsection{Acid Mine Drainage Dewatering}

The residual earthen waste that is created after the extraction of coal during mining operations contains high levels of water adsorption. Prior to long-term storage, this waste must be dewatered, the act of extracting water from a saturated substance (Franks et al. 2011). This work investigated AMD dewatering techniques. Major conclusions include the following:

- Geosynthetic material, artificially crafted polymers, play a significant role in construction reinforcement, drainage, and specifically filtration.

- Clarification and remediation of acid mine drainage can be fashioned in a variety of different methods most notably being the flocculation and dewatering by means of geotubes.

- Flocculation of mine drainage through the addition of specific polymers enables the retention and separation of specific particles within the effluent material during dewatering processes.

- Understanding of the physical geotechnical properties of other waste products, including materials from mining origins and wastewater treatment, enhances the creation and efficient flocculation and filtration of mine waste for further use and reestablishment.

- The precipitated AMD sludge produced at the Omega mine site had elastic characteristics dependent on the material's composition at the time of its dewatering.

\subsection{Soil Erosion of an Impoundment}

The closure of an impoundment involves the breach and drainage of the earthen dam. The compiled coal refuse is then mixed with topsoil, reestablished to the semi-natural land contour, and revegetated to ensure nondestructive water runoff occurs during precipitation events (Skousen 2019). This work evaluated closed impoundments as potential sources for sediment loads with the assistance of WEPP. Summary and conclusions include the following: 
- Originally designed by the USDA's Agricultural Research Service (ARS) in 1985 to replace the Universal Soil Loss Equation (USLE), WEPP is a process-based computer modeling program created to anticipate soil displacement, loss, and deposition during singular or continuous storm events.

- Field measurements of infiltration, ground cover, and soil samples were collected from the impoundment and analyzed to determine the unique characteristics of the coal refuse impoundment.

- With TR-55 single storm predictions, the annual soil loss can be predicted to be 0.36 tonnes ( 0.397 tons) for a two-year return period, 0.60 tonnes ( 0.661 tons) for a five-year return period, 0.80 tonnes ( 0.879 tons) for a 10 -year return period, 1.13 tonnes (1.245 tons) during a 25 -year return period, 1.44 tonnes (1.588 tons) from a 50-year event, 1.74 tonnes (1.922 tons) during a 100 -year event, and finally a total of 2.29 tonnes (2.525 tons) of soil lost during a 500-year return event from the impoundment.

- For long-term climate variant predictions, the 2, 5, 10, 20, 25, 50, and 100-year return periods, the forested impoundment would shed less precipitation in runoff volumes.

- Final variation of the long-term modeling occurred during a 500-year return period where the precipitation runoff of the forested impoundment exceeded that of a maintained pasture condition.

\subsection{Future Work}

Due to the invaluable importance of healthy vegetation in relation to the prevention of soil erosion, measures should be taken to reestablish the minimum ground cover (WVDEP 2016). If deterioration of the vegetation cover were to occur, reseeding and fertilization of the area are highly recommended. While the mild, $2.4 \%$ slope was well created for soil retention, the establishment of trees would inevitably aid in extenuated land preservation and the reestablishment of organically rich soil.

It should be noted that the full extent of future management practices was created from estimations of the landowner's intentions for the property. For more precise long-term predictions, a further tailored, topsoil management plan could be designed. 


\section{Chapter 6: References}

Allaedini, G., and Zhang, P. 2019. "Treatment of Phosphoric Acid Sludge for Rare Earths Recovery I: Effect of Polymeric Flocculant Properties on Filtration and Recovery." International Journal of Surface Engineering and Interdisciplinary Materials Sciences, 7(2), 1-18. DOI: 10.4018/IJSEIMS.2019070101.

ASTM Designation D1140-00. "Standard Test Method for Amount of Material in Soils Finer Than the No. 200 (75-um) Sieve.” Annual Book of ASTM Standards, American Society of Testing Materials, West Conshohocken, PA.

ASTM Designation D2216-19. 2019. "Standard Test Methods for Laboratory Determination of Water (Moisture) Content of Soil and Rock by Mass." Annual Book of ASTM Standards, American Society of Testing Materials, West Conshohocken, PA.

ASTM Designation D2487-17. 2010. "Standard Practice for Classification of Soils for Engineering Purposes (Unified Soil Classification System).” Annual Book of ASTM Standards, American Society of Testing Materials, West Conshohocken, PA.

ASTM Designation D422-63. 2007. "Standard Test Method for Particle-Size Analysis of Soils." Annual Book of ASTM Standards, American Society of Testing Materials, West Conshohocken, PA.

ASTM Designation D4221-11. 2011. "Standard Test Method for Dispersive Characteristics of Clay Soil by Double Hydrometer." Annual Book of ASTM Standards, American Society of Testing Materials, West Conshohocken, PA.

ASTM Designation D4318-17. "Standard Test Methods for Liquid Limit, Plastic Limit, and Plasticity Index of Soils." Annual Book of ASTM Standards, American Society of Testing Materials, West Conshohocken, PA.

ASTM Designation D7928-17. 2017. "Standard Test Method for Particle-Size Distribution (Gradation) of Fine-Grained Soils Using the Sedimentation (Hydrometer) Analysis." Annual Book of ASTM Standards, American Society of Testing Materials, West Conshohocken, PA.

ASTM Designation D854-14. 2014. "Standard Test Methods for Specific Gravity of Soil Solids by Water Pycnometer." Annual Book of ASTM Standards, American Society of Testing Materials West Conshohocken, PA.

Bussiere, B. 2007. "Colloquium 2004: Hydrogeotechnical properties of hard rock tailings from metal mines and emerging geoenvironmental disposal approaches." Canadian Geotechnical Journal, 44(2007), 1019-1052. DOI:10.1139/T07-040.

D’Appolonia Engineering, Inc. 2009. "Engineering and Design Manual: Coal Refuse Disposal Facilities." U.S. Mine Safety and Health Administration, Pittsburgh, PA.

Dils, C., Werft, L., Walter, H., Zwanzig, M., Krshiwoblozki, M., and Schneider-Ramelow, M. 2019. "Investigation of the Mechanical and Electrical Properties of Elastic Textile/Polymer Composites for Stretchable Electronics at Quasi-Static or Cyclic Mechanical Loads.” Multidisciplinary Digital Publishing Institute, 2019(12), 1-18. DOI:10.3390/ma12213599. 
Dutrow, B.L. and Clark, C.M. 2020. X-ray Powder Diffraction (XRD),

$<$ https://serc.carleton.edu/research education/geochemsheets/techniques/XRD.html\#: :text=X\%2Dray\%2 0diffraction\%20is\%20based,rays\%20and\%20a\%20crystalline\%20sample.\&text=This\%20law\%20relates

$\% 20$ the $\% 20$ wavelength,then $\% 20$ detected $\% 2 \mathrm{C} \% 20$ processed $\% 20$ and $\% 20$ counted.> (accessed 3 July 2020).

Elzinga, C. L., Salzer, D. W., and Willoughby, J. W. 1998. "Measuring and monitoring: Plant population." US Bureau of Land Management, Denver, Colo. Technical Reference 1730-1, <http://www.blm.gov/nstc/library/pdf/MeasAndMon.pdf $>$

Franks, D.M., Boger, D.V., Côte, C.M., and Mulligan, D.R. 2011. "Sustainable Development Principles for the Disposal of Mining and Mineral Processing Wastes." Resources Policy, 36(2), 114-122.

Flanagan, D.C and Livingston, S.J. 1995. "WEPP User Summary.” USDA - Water Erosion Prediction Project, 1(1), 1-141.

Flanagan, D.C., Frankenerger, J.R., Ascough II, J.C. 2012. "WEPP Model Use, Calibration, and Validation." American Society of Agricultural and Biological Engineers, 55(4), 1463-1477.

Gaffney, D., Chambers, M., Fatheringham, C., and Munoz, R. 2011. "The Value of Chemical Conditioning with Geotexile Tube Dewatering." Geo-Frontiers, 2011, 2152-2162.

Hopkinson, L.C., Davis, E., and Hilvers, G. 2016. "Vegetation cover at right of way locations." Transportation Research Part D: Transport and Environment, 43(2016), 28-39.

Hopkinson, L.C., Lorimer, J.T., Stevens, J.R., Russell, H.R., Hause, J., Quaranta, J.D., and Ziemkiewicz, P.F. 2017. Geomorphic landform design principles applied to an abandoned coal refuse pile in Central Appalachia. Journal of the American Society of Mining and Reclamation. 6(2): 1-18.

Howard, I. and Carruth, W. 2014. "Dewatering and Stabilizing Fine-Grained Soils with Very High Moisture Content." Advances in Civil Engineering Materials 3, 3(1), 220-237. DOI: 10.1520/ACEM20130089

Johnson, B. 1995. "Acidophilic Microbial Communities: Candidates for Bioremediation of Acidic Mine Effluents.” International Biodeterioration \& Biodegradation, 35(1), 41-58.

Johnson, C.D., and Skousen, J.G. 1995. "Minesoil Properties of 15 Abandoned Mine Land Sites in West Virginia.” Journal of Environmental Quality, 4(24), 635-643.

Knodel, P.C. 1991. "Characteristics and Problems of Dispersive Clay Soils." U.S. Department of the Interior, Bureau of Reclamation. R-91-09, 1-24.

Koerner, R. 2005. Designing with Geosynthetics, Pearson Prentice Hall, Upper Saddle River, NJ.

Levi, J., Franks, K., Schultz, S., and Brady, P. 2000. "Biosolids Technology Fact Sheet: Belt Filter Press.” Environmental Protection Agency, EPA 832-F-00-057, 1-7.

Liao, K., and Bhatia, S. 2003. "Geotextile Tube: Filtration Performance of Woven Geotextiles Under Pressure." TC Mirafi, 1-15. 
Liu, X., Wu, J.Q., Conrad, P.W., Dun, S., Todd, C.S., McNearny, R.L., Elliot, W.J., Rhee, H., and Clark, P. 2015. "Impact of surface coal mining on soil hydraulic properties." Transactions of the Society for Mining, Metallurgy \& Exploration, 338, 381-392.

Lo, M.C., Zhou, W.W., and Lee, K.M. 2002. "Geotechnical characterization of dewatered sewage sludge for landfill disposal.” Geotechnical Journal, National Research Council Canada, 39(2002) 1139-1149.

Müller, W., and Saathoff, F. 2015. "Geosynthetics in geoenvironmental engineering." Science and Technology of Advanced Materials, 16.3(034605), 1-20. DOI: 10.1088/1468-6996/16/3/034605.

National Oceanic and Atmospheric Administration. 2017. NOAA Atlas 14 Point Precipitation Frequency Estimates: WV, https://hdsc.nws.noaa.gov/hdsc/pfds/pfds_map_cont.html?bkmrk=wv (accessed 16 February 2021).

National Weather Service. 2020. "Local Climate Data and Plots." National Oceanic and Atmospheric Administration, < https://www.weather.gov/rlx/climate> (accessed 3 March 2021).

Newman, P., Hodgson, M., Rosselot, E. 2003. "The disposal of tailings and minewater sludge using geotextile dewatering techniques.” Minerals Engineering, 17(2004), 115-121.

O'Kelly, B.C. 2006. "Geotechnical properties of municipal sewage sludge.” Geotechnical and Geological Engineering, 24(2006), 833-850. DOI 10.1007/s10706-005-6611-8.

Pedroni, L., Dromer, J.B., Aubertin, M., and Kennedy, G. 2006. "Properties of Treatment Sludge During Sedimentation and Consolidation Tests." American Society of Mining and Reclamation, 1531-1544.

Redigolo, M. 2020. "Email message to author."

Renschler, C.S., and Harbor, J. 2001. "Soil erosion assessment tools from point to regional scales - the role of geomorphologists in land management research and implementation." Geomorphology, 47 (2002), 189-209.

Roehl, J.E. 1962. "Sediment source areas, and delivery ratios influencing morphological factors." International Association of Hydrologic Science, 59, 202-213.

Sawatsky, L.F., Cooper, D.L., McRoberts, E., and Ferguson, H. 1996. "Strategies for reclamation of tailings impoundments." International Journal of Surface Mining and Reclamation, 10(3), 131-134. DOI: 10.1080/09208119608964816

Skousen, J.G., Ziemkiewicz, P.F., and McDonald, L.M. 2019. "Acid mine drainage formation, control and treatment: Approached and strategies." The Extractive Industries and Society, 6(2019), 241-249.

Stewart, B.W., Capo, C.R., Hedin, B.C., and Hedin, R.S. 2016. "Rare earth element resources in coal mine drainage and treatment precipitates in the Appalachian Bain, USA." International Journal of Coal Geology, 169(2017), 28-39.

Swapp, S. 2017. Scanning Electron Microscopy (SEM), $<$ https://serc.carleton.edu/research education/geochemsheets/techniques/SEM.html > (accessed 3 July 2020). 
Trotochaud, J. 2014. "WEPP/SWAT Future Climate Input File Generator: Instructions Manual.” Purdue University, Department of Agricultural and Biological Engineering, 1(1), 1-18.

Trotochaud, J., Flanagan, D.C., and Engel, B.A. 2016. "A Simple Technique for Obtaining Future Climate Data Inputs for Natural Resource Models." American Society of Agricultural and Biological Engineers, 32(3), 371-381.

WVDEP (West Virginia Department of Environmental Protection). 2016. "Erosion and Sediment Control Best Management Practice Manual." Department of Environmental Protection, Division of Water and Waste Management, Washington, DC.

WVDEP. 2018. "Personal communication with the author."

WV GIS Technical Center. 2000. “Ecoregions.” West Virginia GIS Technical Center, < http://wvgis.wvu.edu/data/dataset.php?ID=154> (accessed 28 February 2021).

West Virginia University Shared Research Facilities. 2020. "Electron Microscopy."

<https://sharedresearchfacilities.wvu.edu/facilities/electron-microscopy> (accessed July 2020).

Wu, J.Q., Rhee, H., Dun, S., McNearny, R.L., and Conrad, P.W. 2012. “Developing WEPP-Mine: A Management Tool for Western Alkaline Surface Coal Mines.” Washington State University, 1-18.

United States Department of Agriculture, Natural Resources Conservation Service. 1986. "Urban Hydrology for Small Watersheds, TR-55." Conservation Engineering Division, 210-VI-TR-55(2), 1-164.

United States Department of Agriculture, Natural Resources Conservation Service. 2007. "Chapter 7: Hydrologic Soil Groups.” Hydrology National Engineering Handbook, 210(2009), 1-13.

Zhan, T.L., Zhan, X., Lin, W., Lou, X., and Chen, Y. 2014. "Field and laboratory investigation on geotechnical properties of sewage sludge disposal in a pit at Changan landfill, Chengdu, China." Engineering Geology, 170(2014), 24-32.

Zinck, J.M., Wilson, L.J., Chen, T.T., Griffith, W., Mikhail, S., and Turcotte, A.M. 1997. "Characterization and Stability of Acid Mine Drainage Treatment Sludges." Mining and Mineral Sciences Laboratories, Job No. 51144, 1-319. 


\section{Chapter 7: Appendices}

\section{Appendix A: Omega Lab Data}

Table 13. Initial sieve analysis results for material passing No. $20(0.85 \mathrm{~mm})$ Sieve.

\begin{tabular}{|l|l|c|c|c|c|c|c|c|c|}
\hline \multicolumn{8}{|c|}{ Initial Dry Sieve Analysis of Sludge Passing No. 20 Sieve } \\
\hline $\begin{array}{l}\text { Sieve } \\
\text { No. }\end{array}$ & $\begin{array}{l}\text { Particle } \\
\text { dia. }\end{array}$ & Wt. retained & \multicolumn{2}{c|}{ \% Retained } & \multicolumn{2}{c|}{ Cumulative \% } & \multicolumn{2}{c|}{ Percent Finer } \\
\hline $\begin{array}{l}\text { Trial } \\
\text { No. }\end{array}$ & & 1 & 2 & 1 & 2 & 1 & 2 & 1 & 2 \\
\hline 20 & 0.85 & 1.34 & 0.89 & 1.41 & 0.94 & 1.41 & 0.94 & 98.59 & 99.06 \\
\hline 60 & 0.25 & 30.33 & 21.33 & 31.88 & 22.42 & 33.29 & 23.36 & 66.71 & 76.64 \\
\hline 80 & 0.177 & 9.19 & 6.20 & 9.66 & 6.52 & 42.95 & 29.87 & 57.05 & 70.13 \\
\hline 120 & 0.125 & 11.45 & 7.00 & 12.03 & 7.36 & 54.98 & 37.23 & 45.02 & 62.77 \\
\hline 140 & 0.105 & 6.66 & 3.83 & 7.00 & 4.03 & 61.98 & 41.25 & 38.02 & 58.75 \\
\hline 200 & 0.074 & 9.82 & 5.59 & 10.32 & 5.88 & 72.30 & 47.13 & 27.70 & 52.87 \\
\hline Pan & & 26.35 & 20.10 & 27.70 & 21.13 & 100.0 & 100.0 & 0.00 & \\
\hline & Total & 95.14 & 64.94 & & & & & & \\
\hline
\end{tabular}

Table 14. Secondary sieve analysis of sludge passing No. $20(0.85 \mathrm{~mm})$ Sieve.

\begin{tabular}{|r|l|c|c|c|c|c|c|c|c|}
\hline \multicolumn{8}{|c|}{ Second Dry Sieve Analysis of Sludge Passing No. 20 Sieve } \\
\hline $\begin{array}{r}\text { Sieve } \\
\text { No. }\end{array}$ & $\begin{array}{l}\text { Particle } \\
\text { dia. }\end{array}$ & Wt. retained & \multicolumn{2}{c|}{ \% Retained } & \multicolumn{2}{c|}{ Cumulative \% } & \multicolumn{2}{c|}{ Percent Finer } \\
\hline $\begin{array}{l}\text { Trial } \\
\text { No. }\end{array}$ & & 1 & 2 & 1 & 2 & 1 & 2 & 1 & 2 \\
\hline 20 & 0.85 & 0.11 & 0.03 & 0.13 & 0.04 & 0.13 & 0.04 & 99.87 & 99.96 \\
\hline 60 & 0.25 & 13.00 & 12.57 & 15.64 & 15.12 & 15.77 & 15.16 & 84.23 & 84.84 \\
\hline 80 & 0.177 & 9.91 & 7.22 & 11.92 & 8.69 & 27.70 & 23.85 & 72.30 & 76.15 \\
\hline 120 & 0.125 & 14.90 & 8.48 & 17.93 & 1.20 & 45.63 & 34.05 & 54.37 & 65.95 \\
\hline 140 & 0.105 & 8.21 & 4.69 & 9.88 & 5.64 & 55.50 & 39.69 & 44.50 & 60.31 \\
\hline 200 & 0.074 & 11.57 & 7.56 & 13.92 & 9.10 & 69.43 & 48.79 & 30.57 & 51.21 \\
\hline Pan & & 25.41 & 42.56 & 30.57 & 51.21 & 0 & 0 & 0.00 & 0.00 \\
\hline & Total & 83.11 & 83.11 & & & & & & \\
\hline
\end{tabular}


Table 15. Dry sieve data of Omega.

\begin{tabular}{|l|r|r|r|r|}
\hline \multicolumn{5}{|c|}{ Results - Dry Grain Size Sieve Analysis } \\
\hline & \multicolumn{5}{|c|}{ Raw Sample } \\
\hline & Test 1 & Test 2 & Test 3 & Test 4 \\
\hline D60 & 0.2 & 0.15 & 0.125 & 0.1 \\
\hline D30 & 0.085 & 0.07 & 0.015 & 0.014 \\
\hline Effective Size, D10 & 0.0045 & 0.0035 & 0.0006 & 0.0006 \\
\hline Uniformity Coefficient, Cu & 44.44 & 42.86 & 208.33 & 166.67 \\
\hline Coefficient of Curvature, Cc & 8.028 & 9.33 & 3.0 & 3.27 \\
\hline
\end{tabular}

Table 16. Wet sieve analysis of Omega from two trials.

\begin{tabular}{|c|c|c|c|c|c|c|c|c|c|}
\hline \multicolumn{9}{|c|}{ Wet Sieve Analysis of Sludge Passing No. 20 Sieve } \\
\hline $\begin{array}{c}\text { Particle } \\
\text { Size } \\
(\mathrm{mm})\end{array}$ & $\begin{array}{c}\text { Sieve } \\
\text { Number }\end{array}$ & \multicolumn{2}{c|}{ Wt. Retained (g) } & \multicolumn{2}{c|}{ \% Retained } & \multicolumn{2}{c|}{ Cumulative \% } & \multicolumn{2}{c|}{ Percent Finer } \\
\hline Trial No. & & 1 & 2 & 1 & 2 & 1 & 2 & 1 & 2 \\
\hline 0.85 & 20 & & 0.67 & & 3.07 & & 3.07 & & 96.93 \\
\hline 0.42 & 40 & 0.85 & 1.35 & 11.08 & 6.20 & 11.08 & 9.27 & 88.92 & 90.73 \\
\hline 0.24 & 60 & 0.64 & 1.07 & 8.34 & 4.91 & 19.43 & 14.18 & 80.57 & 85.82 \\
\hline 0.105 & 140 & 1.21 & 2.02 & 15.78 & 9.28 & 35.20 & 23.46 & 64.80 & 76.54 \\
\hline 0.074 & 200 & 0.53 & 0.69 & 6.91 & 3.16 & 42.11 & 26.62 & 57.89 & 73.38 \\
\hline 0.0 & Bowl & 4.44 & 15.96 & 57.89 & 73.38 & 100.00 & 100.00 & 0.00 & 0.00 \\
\hline
\end{tabular}

Table 17. Wet sieve data of Omega.

\begin{tabular}{|l|r|r|}
\hline \multicolumn{3}{|c|}{ Results - Wet Grain Size Sieve Analysis } \\
\hline & \multicolumn{2}{|c|}{ Raw Sample } \\
\hline & Test 1 & Test 2 \\
\hline D60 & 0.095 & 0.045 \\
\hline D30 & 0.0125 & 0.0065 \\
\hline Effective Size, D10 & 0.00025 & 0.00007 \\
\hline Uniformity Coefficient, Cu & 380.00 & 642.86 \\
\hline Coefficient of Curvature, Cc & 6.58 & 13.41 \\
\hline
\end{tabular}


Table 18. Data collected from hydrometer testing.

\begin{tabular}{|l|l|l|l|l|l|l|}
\hline \multicolumn{7}{|c|}{ Hydrometer Test of Omega Sludge } \\
\hline Time (min) & $\begin{array}{l}\text { Hydrometer } \\
\text { Reading }\end{array}$ & $\begin{array}{l}\text { Actual } \\
\text { Reading }\end{array}$ & $\begin{array}{l}\text { Sedimentation } \\
\text { Distance }(\mathrm{cm})\end{array}$ & $\begin{array}{l}\text { Velocity of } \\
\text { Settlement } \\
(\mathrm{cm} / \mathrm{min})\end{array}$ & $\begin{array}{l}\text { Particle } \\
\text { Diameter } \\
(\mathrm{mm})\end{array}$ & $\begin{array}{l}\text { Percent } \\
\text { Finer }(\%)\end{array}$ \\
\hline 2 & 37 & 36.986 & 10.224 & 5.112 & 0.0355 & 76.52 \\
\hline 5 & 30 & 29.986 & 11.372 & 2.274 & 0.0158 & 62.04 \\
\hline 15 & 20 & 19.986 & 13.012 & 0.867 & 0.0060 & 41.35 \\
\hline 30 & 15.5 & 15.486 & 13.750 & 0.458 & 0.0032 & 32.04 \\
\hline 60 & 12 & 11.986 & 14.324 & 0.239 & 0.0017 & 24.80 \\
\hline 250 & 9 & 8.986 & 14.816 & 0.059 & 0.0004 & 18.59 \\
\hline 1440 & 7 & 6.986 & 15.144 & 0.011 & 0.0001 & 14.45 \\
\hline
\end{tabular}

Table 19. Additional information needed for hydrometer corrections and calculations.

\begin{tabular}{|l|l|l|l|l|}
\hline $\begin{array}{l}\text { Initial Soil Mass } \\
(\mathrm{g})\end{array}$ & Temp. $\left({ }^{\circ} \mathrm{C}\right)$ & Specific Gravity & $\begin{array}{l}\text { Conversion } \\
\text { Factor, } \mathrm{K}^{*}\end{array}$ & $\begin{array}{l}\text { Correction Factor, } \\
\mathrm{a}^{*}\end{array}$ \\
\hline 50.17 & 22.5 & 0.01389 & 1.038 \\
\hline \multicolumn{3}{|r|}{} & *linearly interpolated from ASTM Tables \\
\hline
\end{tabular}




\section{Appendix B: Random Number Generator}

Table 20. Random number generator used for sampling locations.

\begin{tabular}{|c|c|c|c|c|c|}
\hline & 1 & 2 & 3 & 4. & 5 \\
\hline 1 & 8 & 24 & 39 & 46 & 22 \\
\hline 2 & 43 & 41 & 49 & 34 & 34 \\
\hline 3 & 25 & 1 & 1 & 5 & 22 \\
\hline 4) & 38 & 39 & 19 & 27 & 28 \\
\hline 5 & 37 & 46 & 6 & 34 & 15 \\
\hline 6 & 27 & 35 & 16 & 8 & 35 \\
\hline 7 & 19 & 34 & 21 & 47 & 45 \\
\hline 8 & 3. & 46 & 39 & 25 & 42 \\
\hline 9 & 22 & 15 & 3. & 40 & 29 \\
\hline 10 & 31 & 12 & 39 & 12 & 41 \\
\hline 11 & 19 & 22 & 6) & 28 & 32 \\
\hline 12 & 5 & 23 & 20 & 5. & 9 \\
\hline 13 & 31 & 3 & 35 & 3 & 15 \\
\hline 14 & 11 & 13 & 13 & 38 & 14 \\
\hline 15 & 12 & 30 & 11 & 11 & 40 \\
\hline 16 & 3. & 22 & 50 & 45 & 11 \\
\hline 17 & 23 & 14 & 29 & 22 & 5 \\
\hline 18 & 22 & 5] & 16 & 38 & 40 \\
\hline 19 & 15 & 13 & 5 & 26 & 42 \\
\hline 20 & 46 & 23 & 17 & 37 & 3 \\
\hline 21 & 7 & 27 & 17 & 19 & 28 \\
\hline 22 & 41 & 24 & 19 & 38 & 32 \\
\hline 23 & 25 & 50 & 50 & 38 & 4 \\
\hline 24 & 3 . & 7 & 36 & 49 & 18 \\
\hline 25 & 40 & 16 & 20 & 50 & 15 \\
\hline 26 & 22 & 17 & 40 & 27 & 48 \\
\hline 27 & 9 & 27 & 26 & 29 & 7 \\
\hline 28 & 38 & 16 & 38 & 3 & 35 \\
\hline 29 & 2 & 4. & 5 & 16 & 30 \\
\hline 30 & 50 & 27 & 3 & 9 & 42 \\
\hline 31 & 48 & 33 & 12 & 15 & 42 \\
\hline 32 & 7 & 25 & 34 & 10 & 35 \\
\hline 33 & 42 & 3 & 29 & 22 & 24 \\
\hline 34 & 1 & 23 & 3 & 31 & 26 \\
\hline 35 & 27 & 12 & 10 & 27 & 39 \\
\hline 36 & 39 & 7 & 13 & 4 & 5 \\
\hline 37 & 50 & 6 & 39 & 15 & 13 \\
\hline 38 & 3 & 43 & 28 & 3 & 39 \\
\hline 39 & 13 & 17 & 44 & 40 & 2 \\
\hline 40 & 23 & 37 & 15 & 34 & 31 \\
\hline 41 & 1 & 25 & 12 & 17 & 42 \\
\hline 42 & 2 & 33 & 9) & 48 & 18 \\
\hline 43 & 3 & 11 & 3 & 45 & 29 \\
\hline 44 & 20 & 10 & 17 & 25 & 47 \\
\hline 45 & 28 & 3 & 32 & 10 & 12 \\
\hline 46 & 19 & 3 & 36 & 7 & 12 \\
\hline 47 & 34 & 50 & 19 & 37 & 31 \\
\hline 48 & 42 & 37 & 44 & 38 & 11 \\
\hline 49 & 27 & 20 & 14 & 7 & 36 \\
\hline 50 & 14 & 11 & 7] & $41]$ & 37 \\
\hline
\end{tabular}




\section{Appendix C: Field Forms}

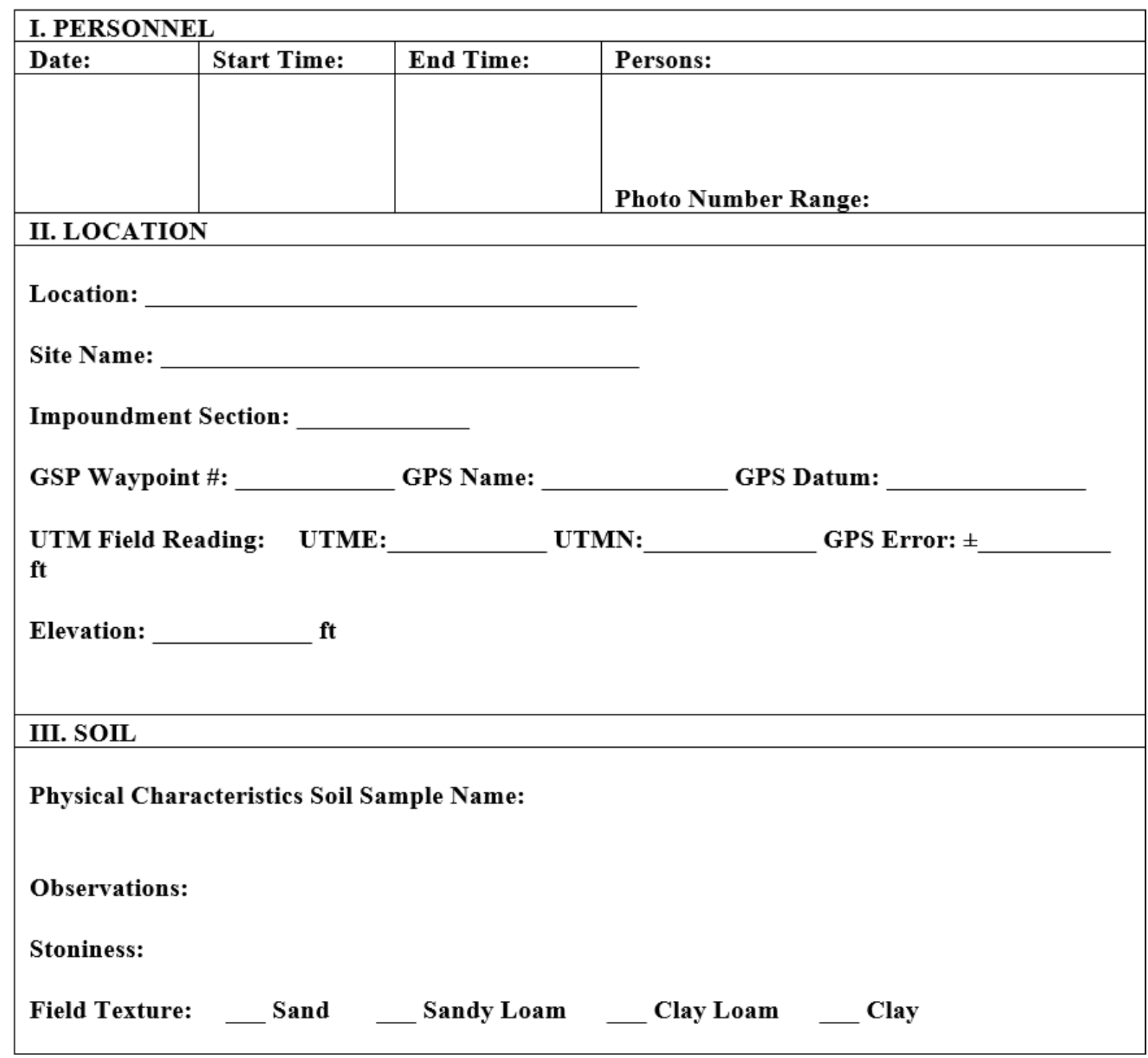

Figure 22. Field work form - hillslope location 


\begin{tabular}{|c|c|c|c|c|c|c|c|c|c|c|}
\hline \multicolumn{11}{|c|}{ IV. VEGETATION PERCENT COVER } \\
\hline \multicolumn{5}{|c|}{ Impoundment Section: } & \multicolumn{5}{|c|}{ Subplot Number: } & \multirow[b]{2}{*}{$\mathbf{J}$} \\
\hline & $\mathbf{A}$ & $\mathbf{B}$ & $\mathbf{C}$ & $\mathbf{D}$ & $\mathbf{E}$ & $\mathbf{F}$ & $\mathbf{G}$ & $\mathbf{H}$ & $\mathbf{I}$ & \\
\hline 1 & & & & & & & & & & \\
\hline 2 & & & & & & & & & & \\
\hline 3 & & & & & & & & & & \\
\hline 4 & & & & & & & & & & \\
\hline 5 & & & & & & & & & & \\
\hline 6 & & & & & & & & & & \\
\hline 7 & & & & & & & & & & \\
\hline 8 & & & & & & & & & & \\
\hline 9 & & & & & & & & & & \\
\hline 10 & & & & & & & & & & \\
\hline
\end{tabular}

Note: If intersection has cover, mark with a "C". If no cover, leave box blank.

Number of Cover:

Number of Bare: $\%$

Percent Cover Photo Number:

Description:

\section{Compaction Test Form}

Tip Size Used:

$\begin{array}{ll}\text { 3" Color: } & \text { Range: } \\ \text { 6" Color: } & \text { Range: } \\ \text { 9" Color: } & \text { Range: } \\ \text { 12" Color: } & \text { Range: } \\ \text { 15" Color: } & \text { Range: } \\ \text { 18" Color: } & \text { Range: }\end{array}$

Observations:

Figure 23. Field work form - sub-site location (front) 


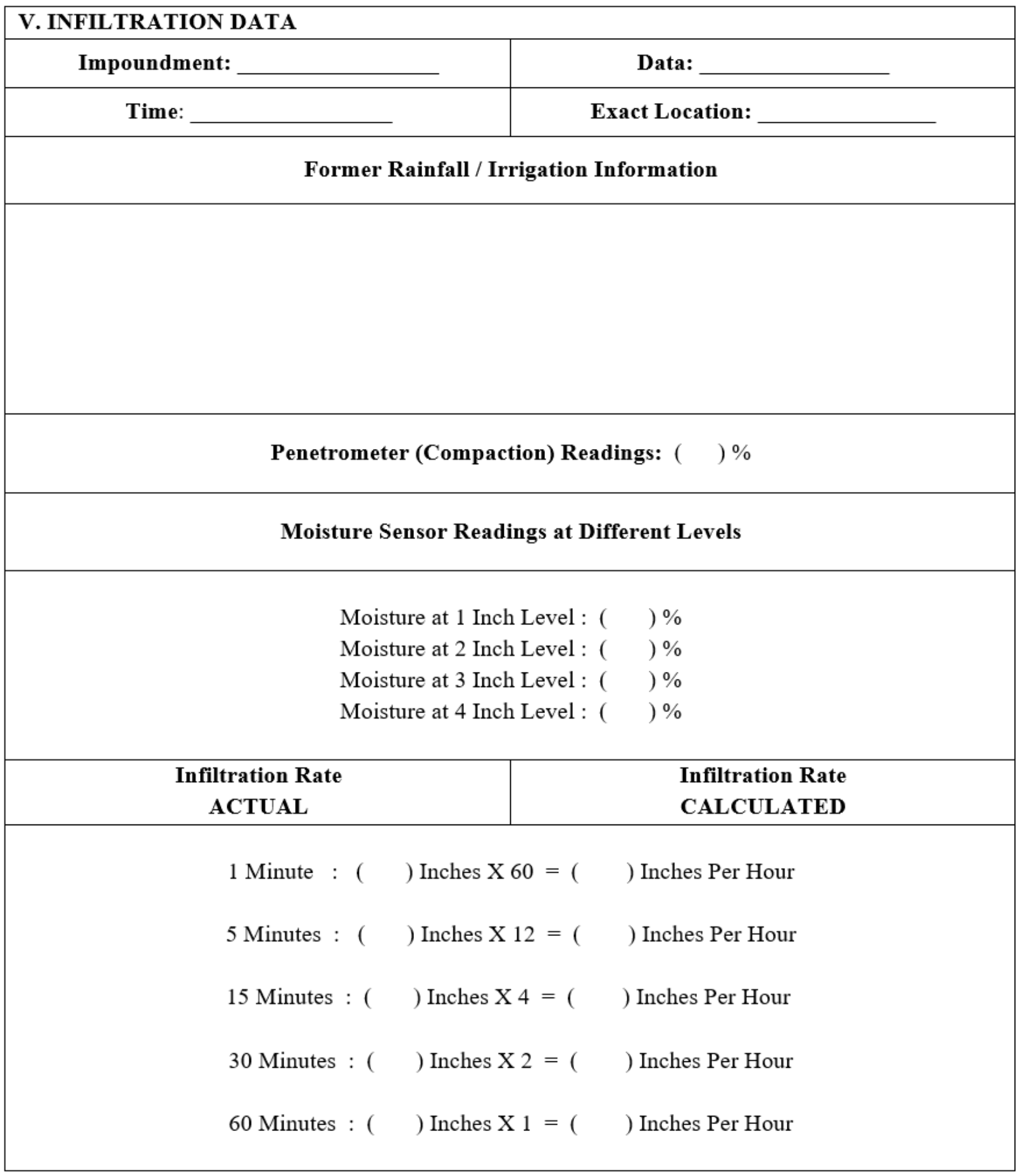

Figure 24. Field work form - sub-site location (back) 
VI. PHOTO LOG

Location:

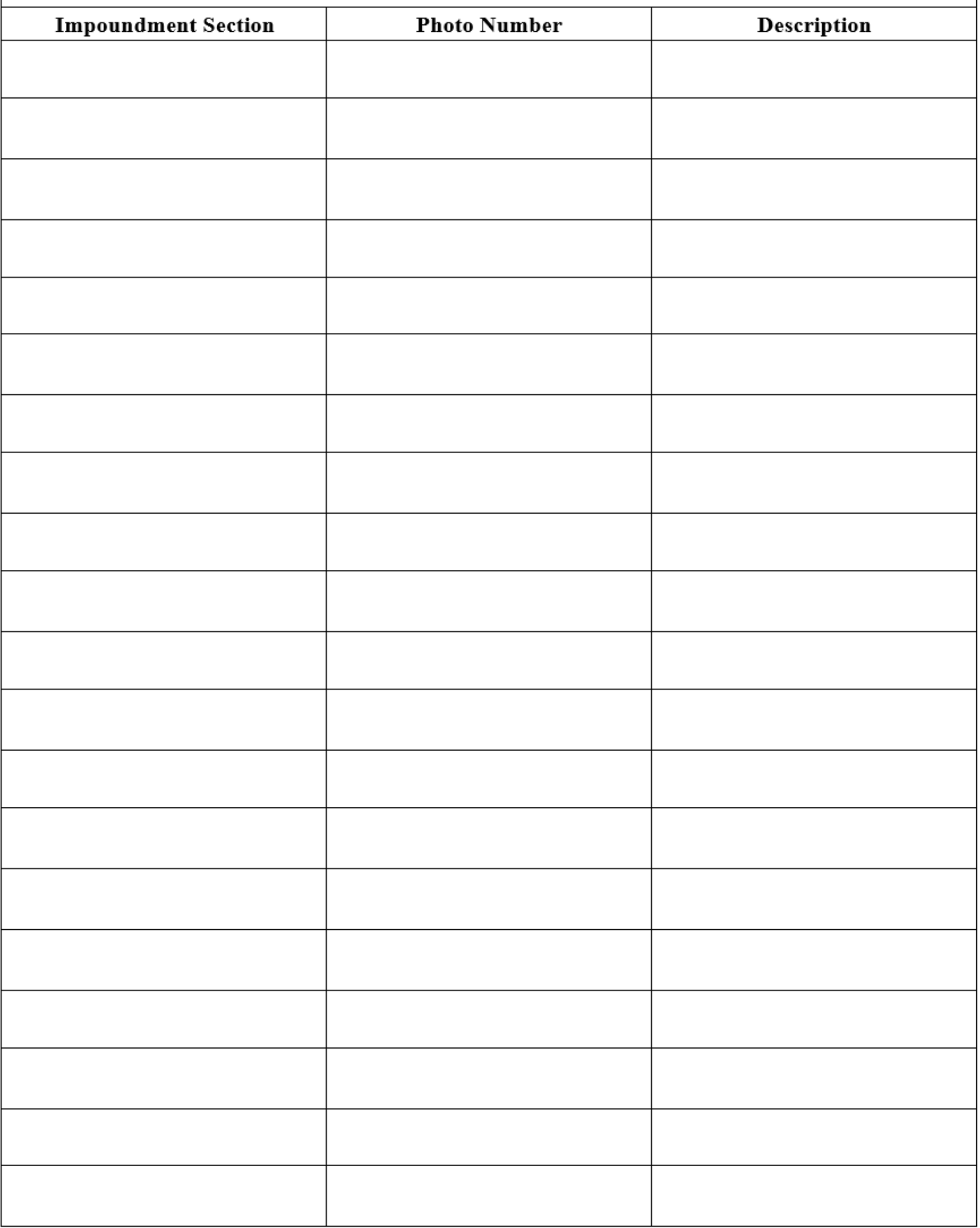

Figure 25. Field work form - hillslope photo log 


\section{Appendix D: Ground Cover Photo Log}

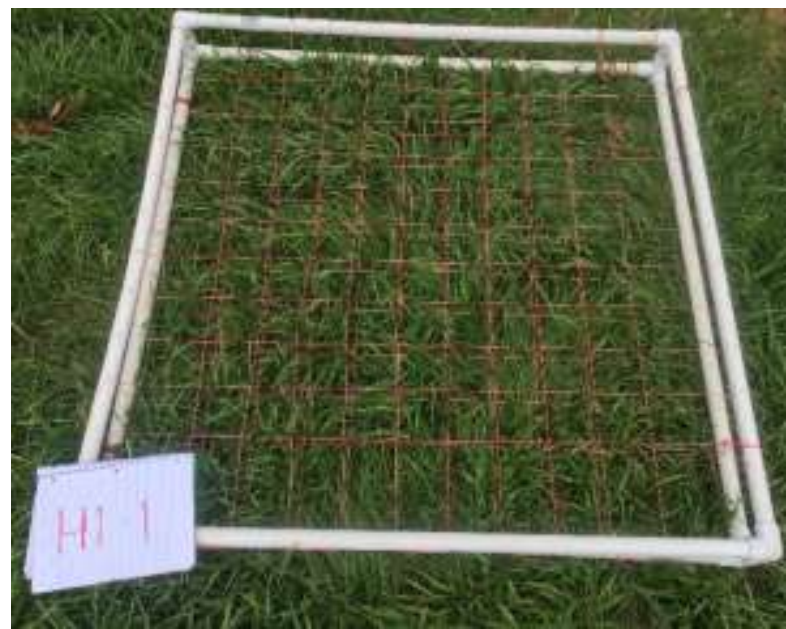

(a)

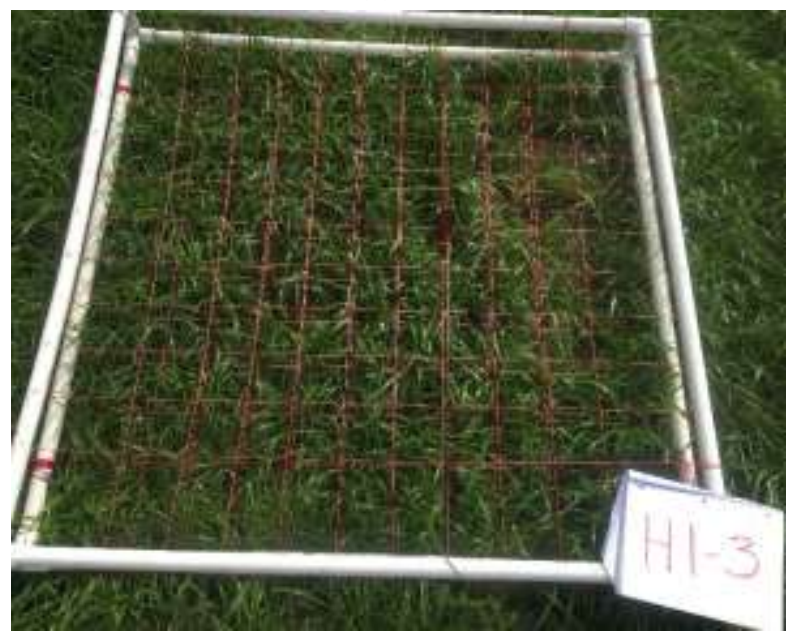

(c)

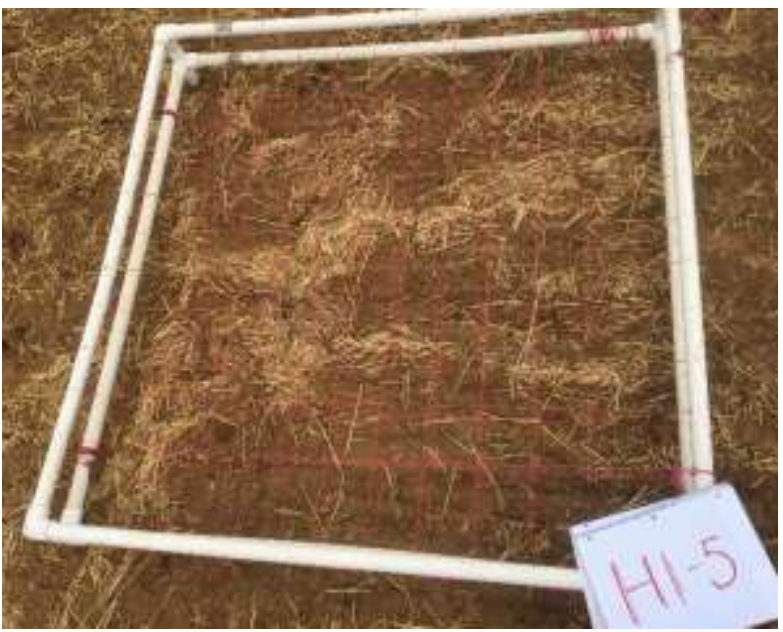

(e)

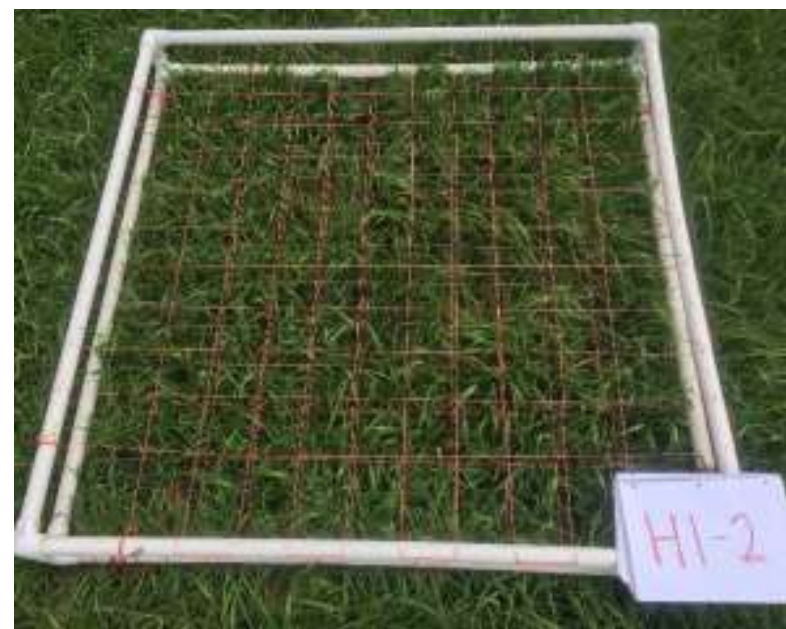

(b)

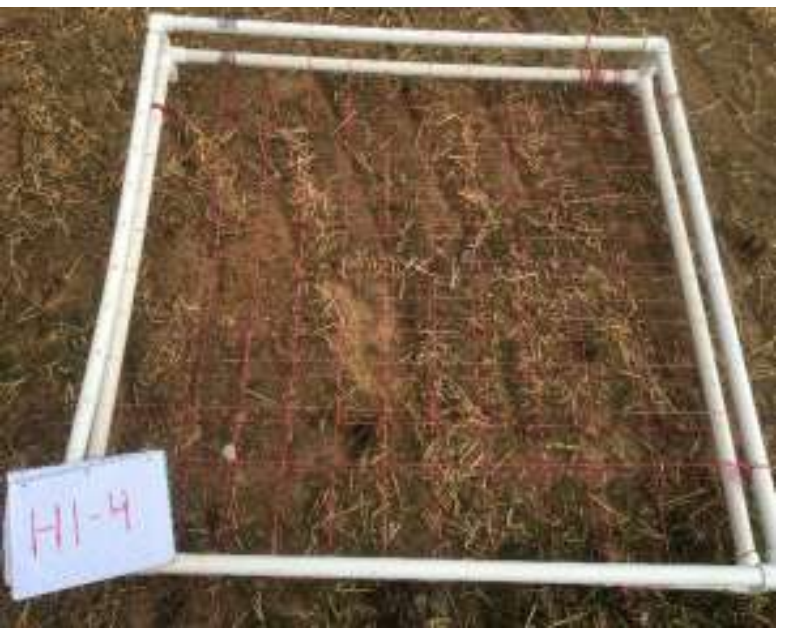

(d)

Figure 26. Hillslope 1 Portable Point Frames at the five sampling locations ( $a, b, c, d$, and e) 


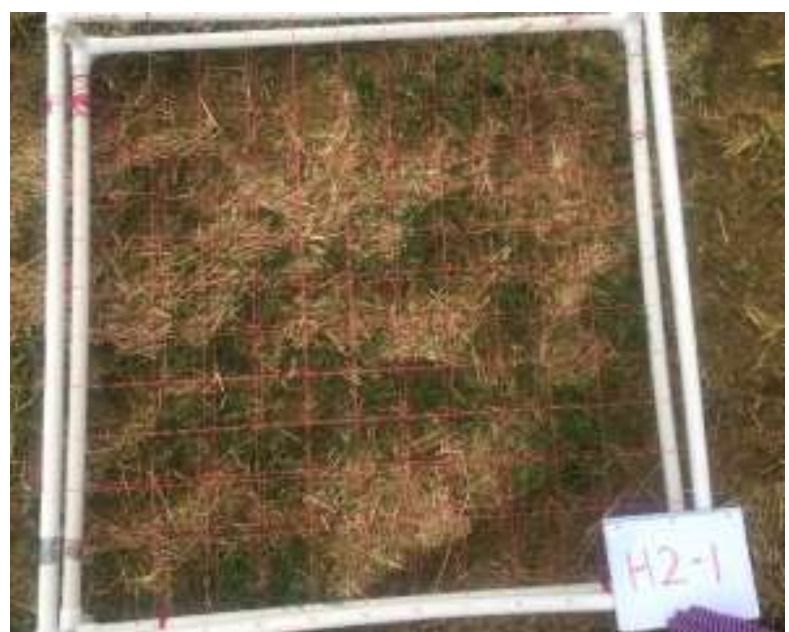

(a)

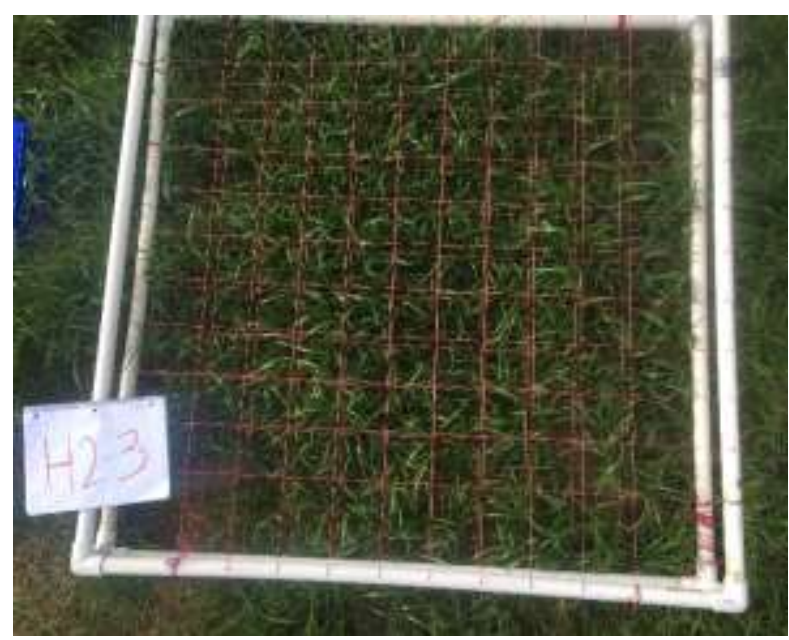

(c)

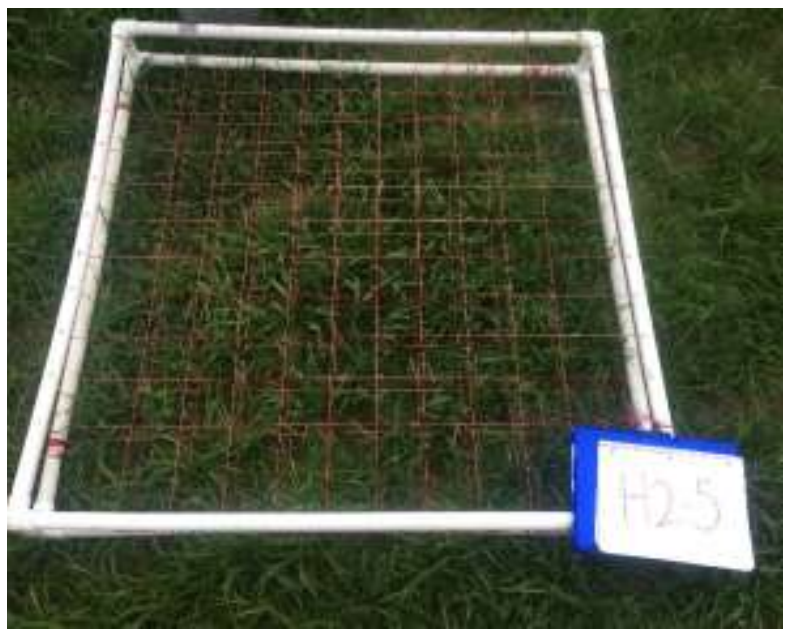

(e)

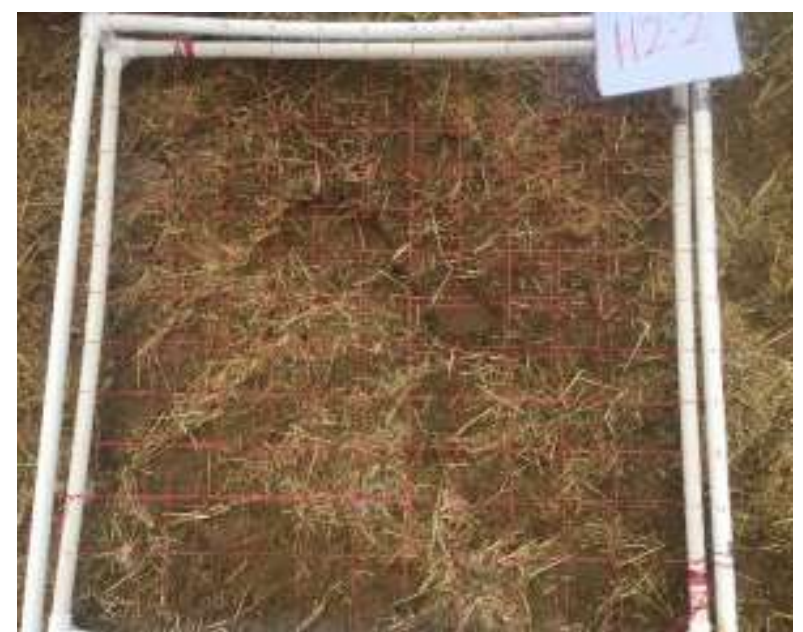

(b)

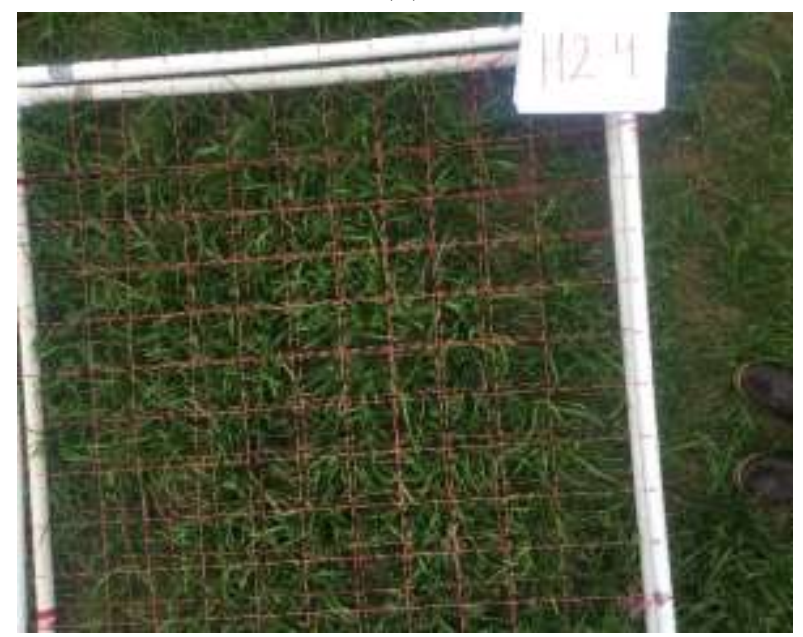

(d)

Figure 27. Hillslope 2 Portable Point Frames at the five sampling locations ( $a, b, c, d$, and e). 


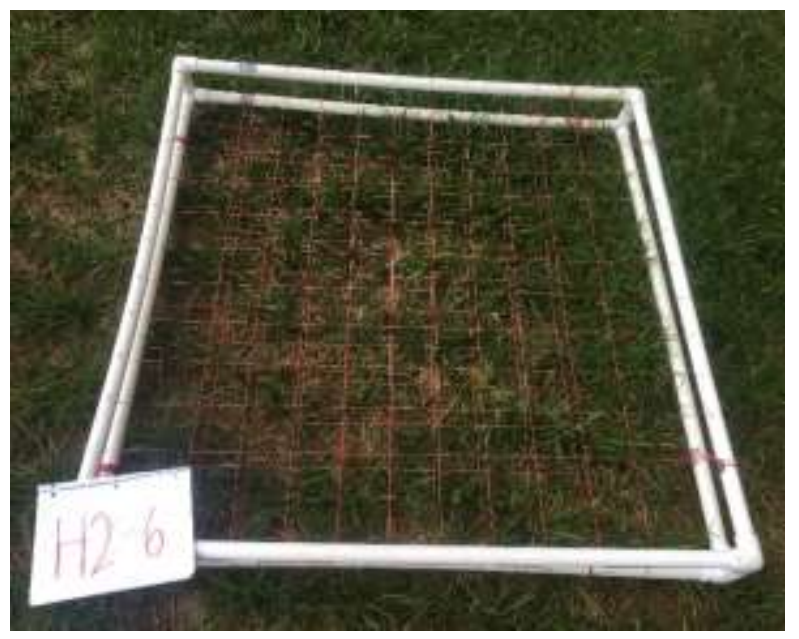

(f)

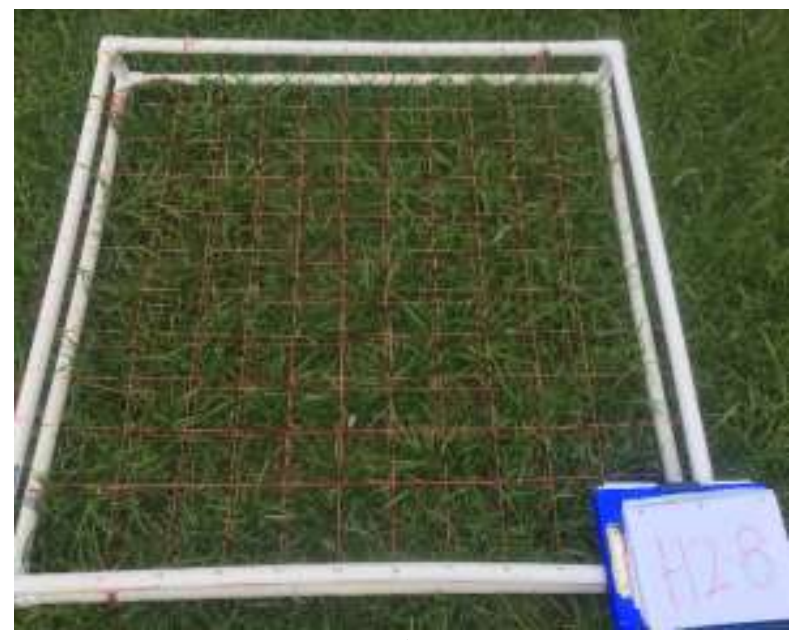

(h)

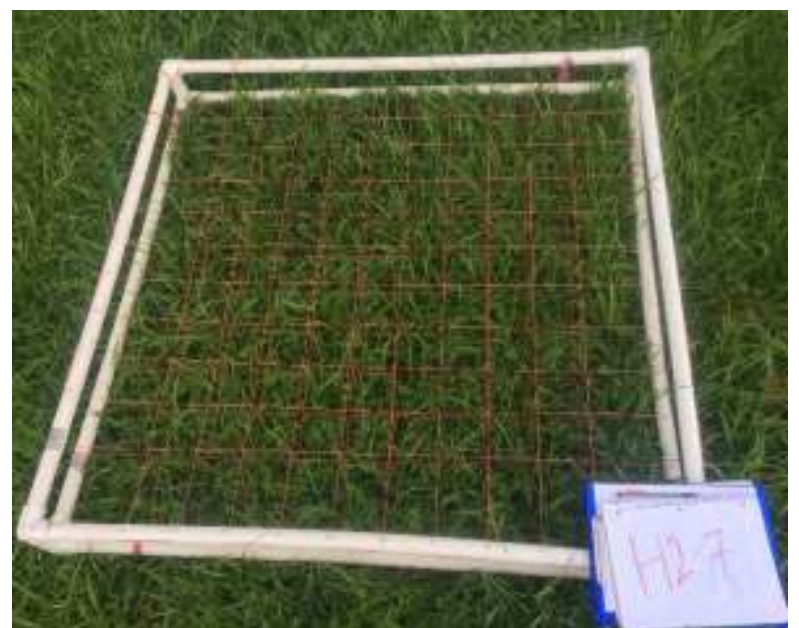

(g)

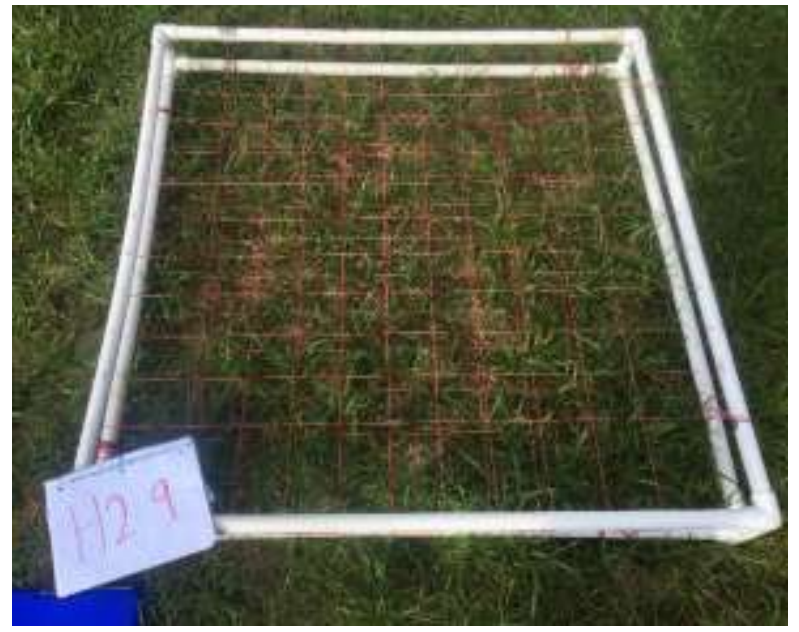

(i)

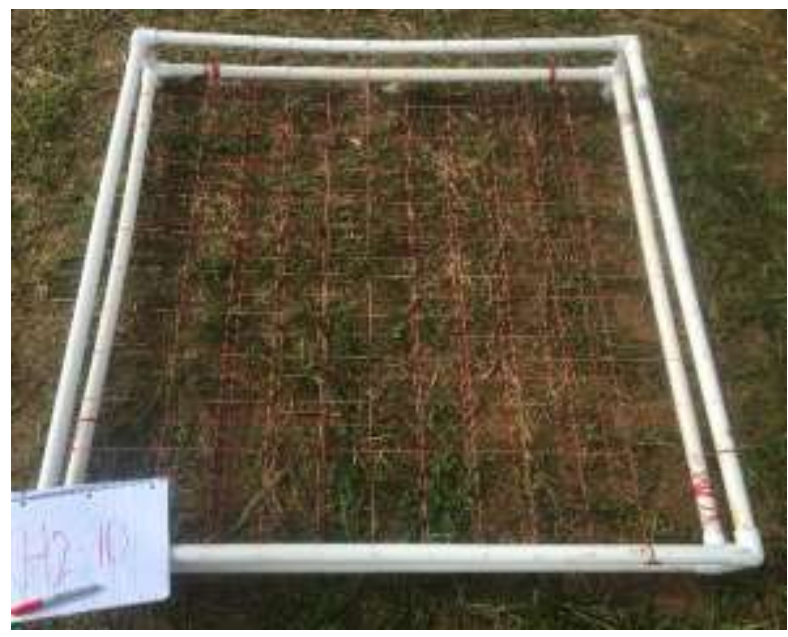

(j)

Figure 28. Hillslope 2 Portable Point Frames at the five sampling locations $(f, g, h, i$, and $j$ ). 


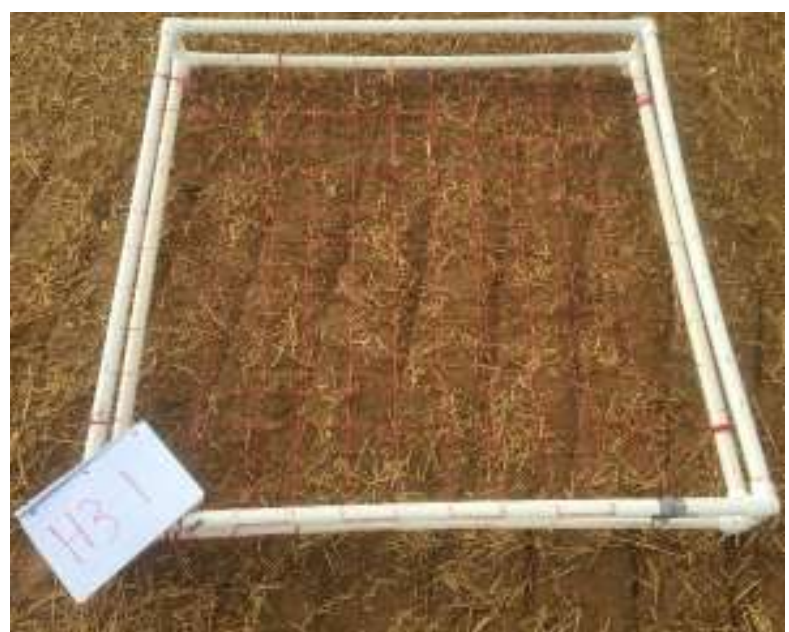

(a)

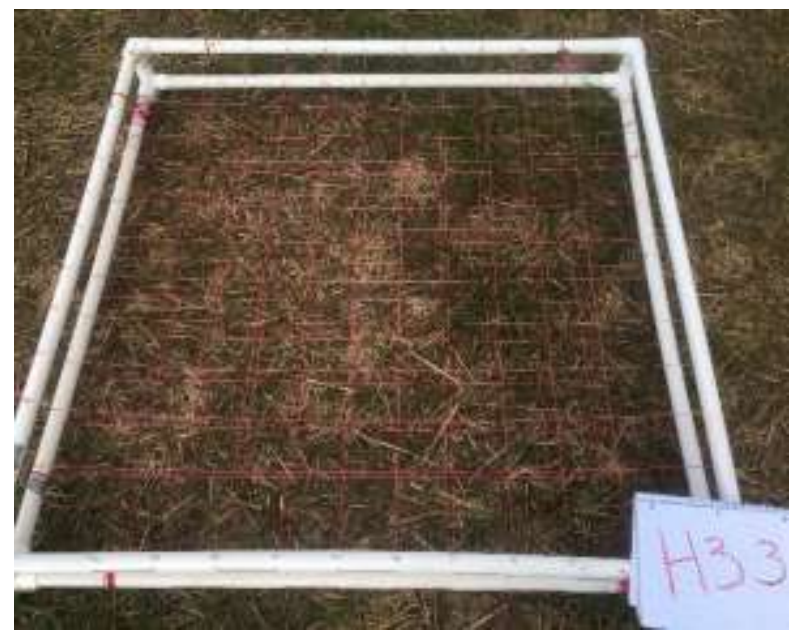

(c)

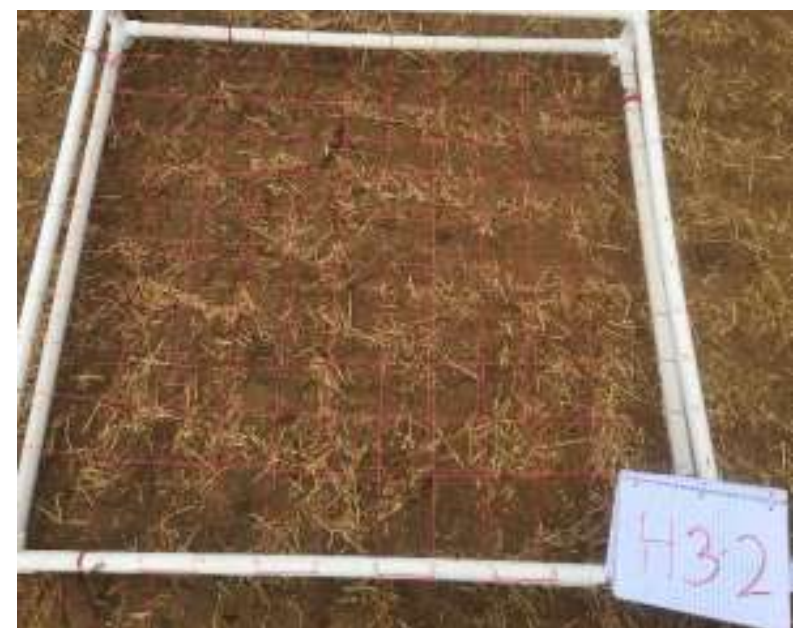

(b)

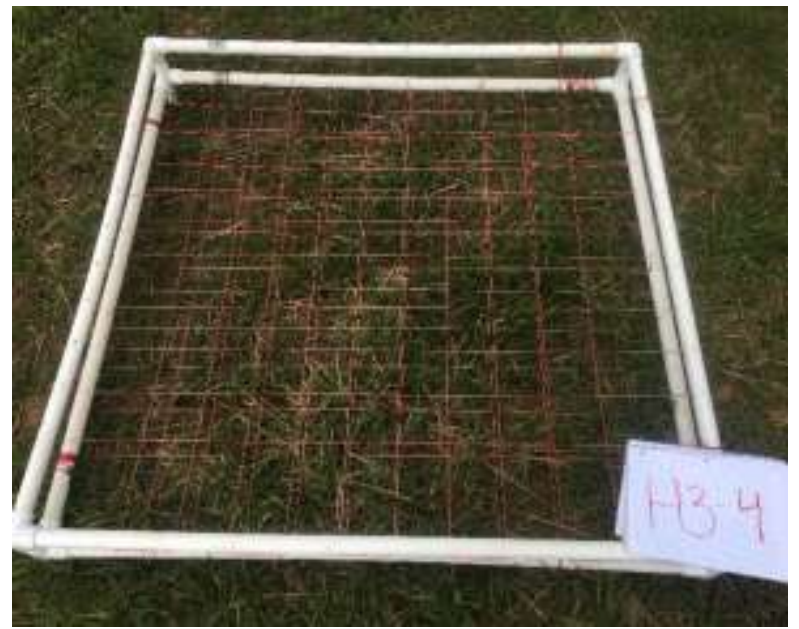

(d)

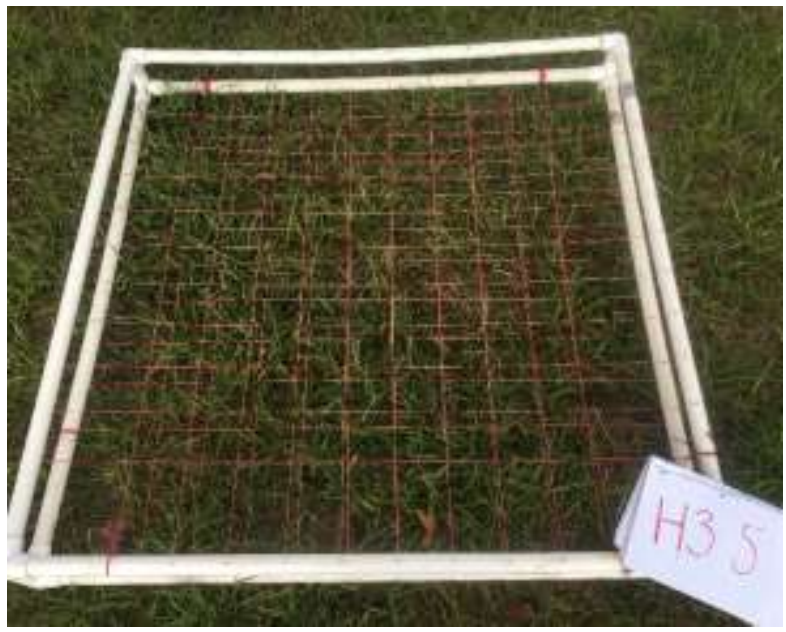

(e)

Figure 29. Hillslope 3 Portable Point Frames at the five sampling locations ( $a, b, c, d$, and e). 


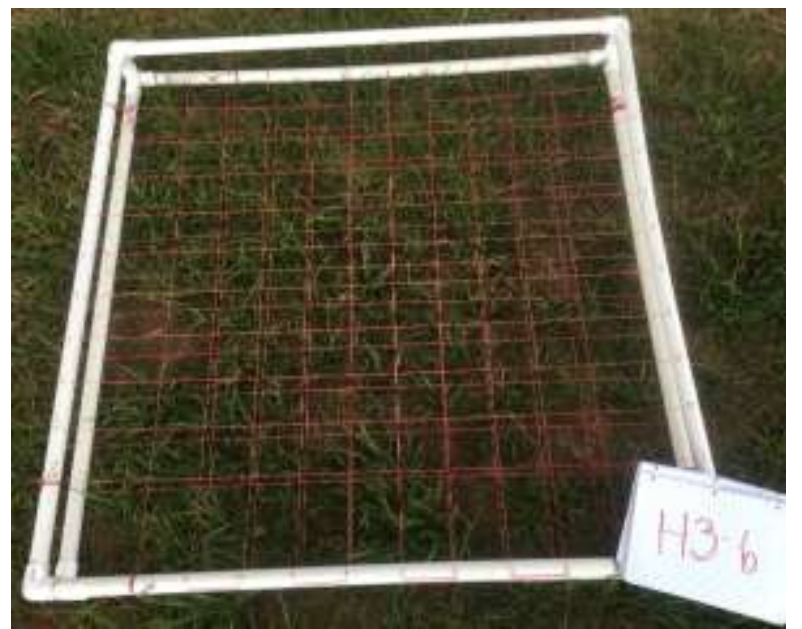

(f)

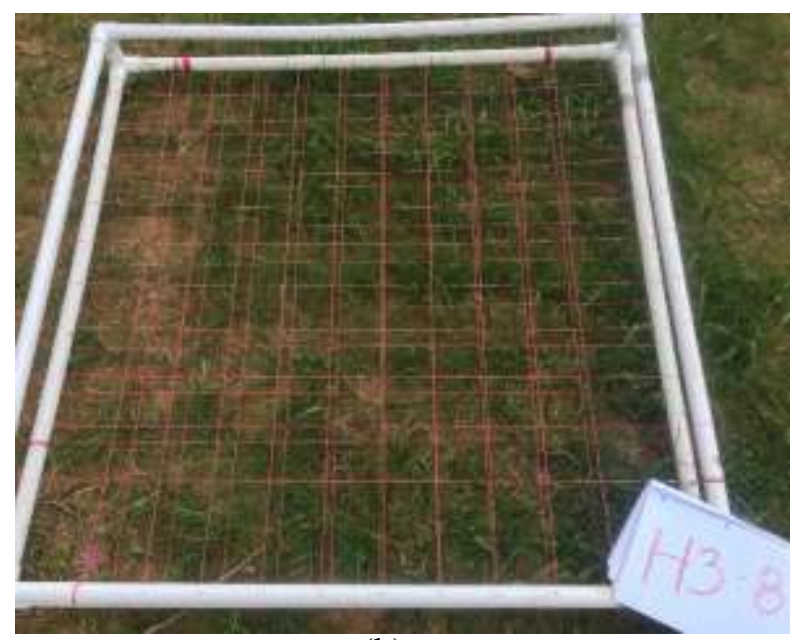

(h)

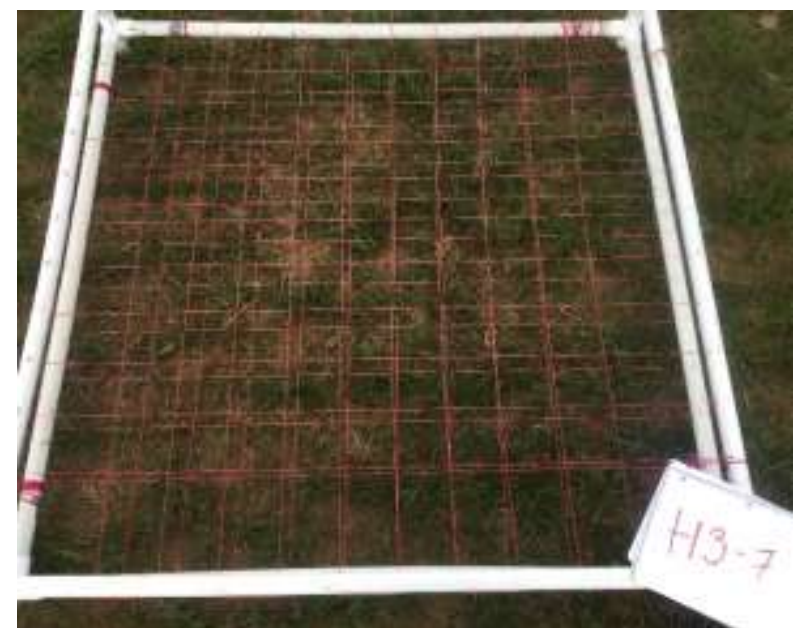

(g)

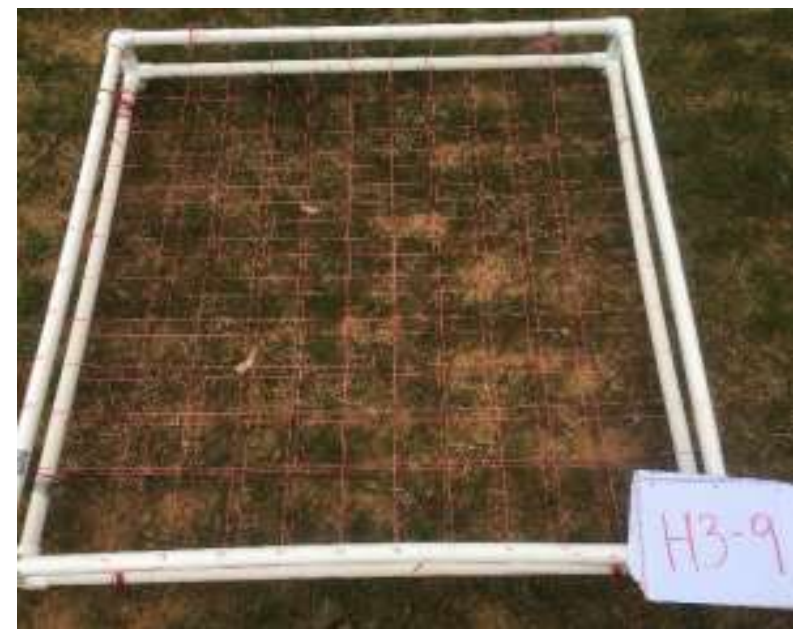

(i)

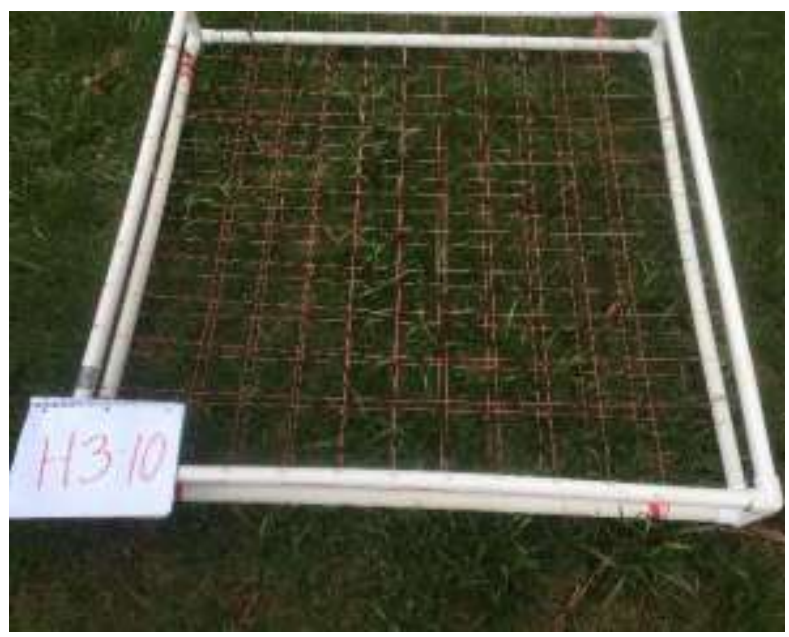

(j)

Figure 30. Hillslope 3 Portable Point Frames at the five sampling locations $(f, g, h, i$, and $j)$. 